\title{
MINIMUM WAGES AND TEENAGE CHILDBEARING: NEW ESTIMATES USING A DYNAMIC DIFFERENCE-IN-DIFFERENCES APPROACH
}

\author{
Daniel I. Rees \\ Joseph J. Sabia \\ Rebecca Margolit \\ Working Paper 29334 \\ http://www.nber.org/papers/w29334 \\ NATIONAL BUREAU OF ECONOMIC RESEARCH \\ 1050 Massachusetts Avenue \\ Cambridge, MA 02138 \\ October 2021
}

Dr. Sabia acknowledges support from the Center for Health Economics and Policy Studies (CHEPS), which has received grant funding from the Troesh Family Foundation and the Charles Koch Foundation. We are grateful to Alicia Marquez and Samuel Safford for outstanding research assistance. The views expressed herein are those of the authors and do not necessarily reflect the views of the National Bureau of Economic Research.

NBER working papers are circulated for discussion and comment purposes. They have not been peer-reviewed or been subject to the review by the NBER Board of Directors that accompanies official NBER publications.

(C) 2021 by Daniel I. Rees, Joseph J. Sabia, and Rebecca Margolit. All rights reserved. Short sections of text, not to exceed two paragraphs, may be quoted without explicit permission provided that full credit, including $(\odot$ notice, is given to the source. 
Minimum Wages and Teenage Childbearing: New Estimates Using a Dynamic Difference-in-Differences Approach

Daniel I. Rees, Joseph J. Sabia, and Rebecca Margolit

NBER Working Paper No. 29334

October 2021

JEL No. J13,J18

\section{ABSTRACT}

The minimum wage is increasingly viewed as an important tool for improving public health outcomes, including reducing childbearing among teenagers. Taken at face value, recently reported estimates suggest that raising the federal minimum wage to $\$ 15$ per hour could reduce the number of teenage births by 35,000 per year. Using an event study framework that accounts for dynamic and heterogeneous treatment effects, we find little evidence that minimum wages are causally related to teenage childbearing. Moreover, the estimated effects of minimum wages on teenage sexual behaviors, including contraception use, abstinence, and number of partners are consistently small and statistically insignificant.

Daniel I. Rees

Department of Economics

University of Colorado at Denver

Campus Box 181

Denver, CO 80217

and NBER

Daniel.Rees@ucdenver.edu

Joseph J. Sabia

San Diego State University

Department of Economics

Center for Health Economics

$\&$ Policy Studies

5500 Campanile Drive

San Diego, CA 92182

and IZA \& ESSPRI

jsabia@sdsu.edu
Rebecca Margolit

Center for Health Economics \& Policy Studies

San Diego State University

San Diego, CA 92182

United States

rebecca.margolit@gmail.com 


\section{INTRODUCTION}

The labor market consequences of raising the minimum wage have been studied intensely for nearly a century (Stigler 1946; Welch 1974; Card and Krueger 1995; Neumark and Shirley 2021). Recently, however, minimum wage researchers have turned their attention to public health outcomes (Leigh 2016; Leigh, Leigh and Due 2021). One of the highest-profile findings to emerge from this fast-moving literature is that raising the minimum wage reduces teenage childbearing (Bullinger 2017; Lenhart 2021).

If minimum wages and teenage childbearing are negatively and causally related, then there could be substantial societal benefits to raising the minimum wage. The Raise the Wage Act of 2021, which is now being debated in Congress, establishes a new federal minimum wage of $\$ 15$ per hour (U.S. Senate Bill S.53). Recently reported estimates suggest that a $\$ 15$ minimum wage could result in 35,000 fewer teenage births per year, substantially reducing public expenditures. According to Power to Decide, a nonprofit, nonpartisan organization, the U.S. government spends nearly $\$ 2$ billion per year on teenage mothers and their babies (Power to Decide 2018).

Popular media outlets, including the Los Angeles Times and the New York Times Magazine, have highlighted the negative association between minimum wages and teenage births, arguing that minimum wages are an important, but generally neglected, tool for improving public health (Healy 2017; Desmond 2019). This argument is bolstered by the results of several academic studies showing negative associations between minimum wages and binge drinking, depressive symptomology, "deaths of despair," obesity, reports of child maltreatment, smoking, and unmet medical needs (McCarrier et al. 2011; Conklin et al. 2016; Lenhart 2017; Raissian and Bullinger 2017; Reeves et al. 2017; Sabia, Pitts and Argys 2019; Wehby, Dave and Kaestner 2019; Dow et al. 2020). ${ }^{1}$

\footnotetext{
${ }^{1}$ Leigh (2016) and Leigh, Leigh and Due (2021) review these and other studies, concluding that there may be important public health benefits from increases in the minimum wage.
} 
The current study revisits the relationship between minimum wages and teenage fertility, making several important contributions. First, we use novel econometric techniques designed to better identity the causal impact of minimum wages on teen fertility, including event study analyses that account for staggered, continuous treatment (Dube 2019; Schmidheiny and Siegloch 2020) and difference-in-differences (DD) estimation techniques that expunge bias due to heterogeneous dynamic treatment effects (Goodman-Bacon 2021; Callaway and Sant'Anna 2021). Second, we exploit more policy variation than was available to previous researchers by including data from 20152019, a period during which there were 86 separate state-by-quarter changes in the effective minimum wage. Third, we carefully explore mechanisms through which minimum wages could affect teenage fertility, including teenage sexual behavior, contraceptive use, marriage, and abortion. Peering inside the "black-box" linking minimum wages and teenage childbearing is critical because previous studies have asserted causality without examining potential pathways.

Using data for the period 2003-2019 and employing several recently developed econometric techniques, we find no evidence that raising the minimum wage reduces teenage childbearing. Standard DD regression estimates suggest that a one-dollar increase in the minimum wage is associated with a (statistically insignificant) 0.04 to 0.09 increase in the birth rate of 15- through 19year-olds. Dynamic event study estimates (Dube 2019; Schmidheiny and Siegloch 2020) support the parallel trends assumption and continue to show a positive and statistically insignificant relationship between minimum wages and the teenage birth rate over the 2003-2019 period. Moreover, event study estimates based on prominent minimum wage increases (i.e., minimum wage increases of $\$ 1$ or more) using the Callaway and Sant'Anna (2021) estimator confirm this same basic pattern of results. Our results stand in contrast to earlier findings reported in the literature and suggest that newly developed dynamic difference-in-differences techniques can help future researchers accurately gauge the public health effects of minimum wage increases. 
The remainder of our paper is devoted to exploring potential mechanisms through which the minimum wage could have affected teenage birthrates. Using Current Population (CPS) data for the period 2003-2019, we estimate the relationship between minimum wages and teenage marriage rates. This analysis suggests that teenagers are no more (or less) likely to marry after an increase in the minimum wage, although we do find a positive and significant association between the minimum wage and fertility among married teenagers. Then, using state and national Youth Risk Behavior Survey (YRBS) data for the period 2003-2019, we explore the relationship between the minimum wage and self-reported teenage sexual behavior. DD regression estimates are uniformly small and statistically insignificant at conventional levels, providing no evidence that increasing the minimum wage affects the number of lifetime sexual partners, having had sex in the past month, having had unprotected sex in the past month, the use of birth control, or the use of condoms. We conclude that raising the minimum wage is not an effective policy tool for curbing teenage childbearing.

\section{BACKGROUND}

Four to 5 decades ago, most economists were convinced that raising the minimum wage came at the cost of reducing employment (Brown, Gilroy and Kohen 1982). Today, however, this issue is vigorously debated. Estimates from Dube, Lester and Reich (2010), Allegretto, Dube and Reich (2011), and Cengiz et al. (2019) suggest that the employment effect of raising the minimum wage is either zero or trivially small. By contrast, Neumark and Shirly (2021) argue that the "preponderance" of estimates from high-quality studies in this literature are negative, statistically distinguishable from zero, and often substantial. ${ }^{2}$

\footnotetext{
2 See also Clemens and Wither (2019), Sabia, Burkhauser and Hansen (2012; 2016), Neumark and Wascher (2008), and Sabia (2008). It should be noted that the empirical strategies used by Dube, Lester and Reich (2010), Allegretto, Dube and Reich (2011), and Cengiz et al. (2019) have been criticized by, among others, Neumark, Salas and Wascher (2014), Sabia (2014), Meer and West (2016), and Neumark and Shirley (2021).
} 
In theory, the relationship between minimum wages and teenage childbearing depends upon the magnitudes of the wage and employment effects. Teenagers who are laid off (or work fewer hours) after an increase in the minimum wage may find that condoms and other forms of contraception have become unaffordable; those who retain their minimum-wage job and experience an increase in earnings may be more likely to use contraception, purposely postponing becoming a parent. Moreover, teenagers who retain their jobs may, according to Fone et al. (2020), be “incapacitated": i.e., left with less leisure time to engage in various delinquent behaviors, which could include unprotected sex.

Two studies provide evidence of a negative relationship between minimum wages and teenage fertility in the United States. Using data at the state-quarter level for the period 2003-2014, Bullinger (2017) found that a 10 percent increase in the minimum wage was associated with a 1.5 to 3.4 percent reduction in the birth rate of 15-through 19-year-olds. Bullinger (2017) speculated that teenagers respond to better labor market opportunities by working harder and delaying childbearing (p. 447). Using a longer panel (1995-2017), Lenhart (2021) confirmed the negative relationship between minimum wages and teenage fertility in the Unites States, finding that a 10 percent increase in the minimum wage was associated with a 1 to 2 percent reduction in the birth rate of 15 - through 19-year-olds.

If minimum wages and teenage childbearing are in fact related in a causal sense, then there could be substantial societal benefits to raising the federal minimum wage from, for instance, $\$ 7.25$ to $\$ 15$ per hour as proposed in the Raise the Wage Act of 2021 (U.S. Senate Bill S.53). Giving birth as a teenager is associated with increases in the risk of dropping out of high school and living in poverty; children born to teenage mothers clearly struggle cognitively and economically as compared 
to children born to older mothers (Hoffman and Maynard 2008; Kearney and Levine 2012). ${ }^{3}$ The nonpartisan National Campaign to Prevent Teen and Unplanned Pregnancy (2013) estimated that children of single mothers generate $\$ 2.1$ billion per year in additional public sector health costs, $\$ 3.1$ billion in additional child welfare costs, and $\$ 2$ billion in future incarceration costs. Although the U.S. adolescent fertility rate has declined substantially since 2007 , it is still higher than in any other developed country (Sedgh et al. 2015), and several federal programs are exclusively focused on preventing teenage pregnancies and reducing their attendant costs (Fernandes-Alcantara 2018). Among these programs are the Teen Pregnancy Prevention (TPP) program, the Personal Responsibility Education Program (PREP), and the Sexual Risk Avoidance Education program. ${ }^{4}$ Power to Decide, a nonprofit, nonpartisan organization dedicated to reducing unplanned pregnancies, explicitly argues that reducing the outlays of these programs is an important benefit of empowering young people to make their own reproductive health choices (Power to Decide 2021). ${ }^{5}$

Figure 1 shows the evolution of teenage childbearing in the United States during the period 2003-2019. There is no obvious trend in teenage childbearing through mid-2000s, but the number of births per 1,000 female 15-through 19-year-olds begins to trend downwards after 2007. By 2019, there were only 16 births per 1,000 female 15-through 19-year-olds, the lowest level recorded (Hamilton, Martin and Osterman 2021).

\footnotetext{
${ }^{3}$ These associations, of course, do not necessarily reflect underlying causal relationships. As noted by SmithBattle (2018, p. 80), poverty can affect "child and family health and development in insidious ways that predispose disadvantaged youth to engage in unprotected sex. See, for example, Hotz et al. (2005).

${ }^{4}$ According to Power to Decide (2021), recent reductions in teenage childbearing have reduced public health costs by almost $\$ 4.4$ billion per year.

${ }^{5}$ For example, according to Power to Decide (2021):

Providing a system of support that enables young people to have the power to decide if, when, and under what circumstances to get pregnant and have a child not only benefits the young people themselves, but also leads to significant savings in publicly funded programs.
} 
Figure 1 also shows the effective minimum wage for the United States during the period 2003-2019, defined as the higher of the real (2014\$s) federal and state minimum wage for each stateyear-quarter. ${ }^{6}$ Interestingly, the effective minimum wage climbed sharply between 2006 and 2010, largely due to the $2007-2009$ federal minimum wage hike from $\$ 5.15$ per hour to $\$ 7.25$ per hour (in nominal dollars). If we only had access to data through 2010, it would be easy to make the case that teenage childbearing and minimum wages were somehow negatively linked. However, the effective minimum wage fell by 5.1 percent from 2010 to 2013, while births per 1,000 female 15-through 19year-olds continued to trend downwards, suggesting that, at a minimum, other "third" factors could be at play.

\section{BENCHMARK ESTIMATES FOR THE PERIOD 2003-2014}

We begin by benchmarking our estimates against those reported in the literature on minimum wages and teenage fertility. Specifically, we use state-by-quarter birth data from the $4^{\text {th }}$ quarter of 2003 through the $4^{\text {th }}$ quarter of 2014 . This is the same period as was examined by Bullinger (2017), arguably the most influential study in this literature. We estimate the following DD regression using ordinary least squares (OLS):

(1) BirthRate $_{s, t}=\beta_{0}+v_{s}+\lambda_{t}+\beta_{1} M W_{s, t-3}+\boldsymbol{\beta}_{2}^{\prime} \boldsymbol{X}_{s, t-3}+\varepsilon_{s, t}$,

where Birth Rate is equal to the number of births in state $s$ and quarter $t$ per 1,000 female 15- through 19-year-olds. The coefficient of interest is $\beta_{1}$, equal to the change in the teenage birth rate resulting from a one-dollar increase in the effective minimum wage, $M W . \quad M W$ is measured in 2014 dollars.

\footnotetext{
${ }^{6}$ We use the consumer price index to convert from nominal to real (2014) dollars to adjust for inflation (Bureau of Labor Statistics 2021).
} 
It is equal to the state or federal minimum wage in state $s$ and quarter $t-3$, whichever is higher. ${ }^{7}$ The vector $\boldsymbol{X}$ is composed of the same set of "baseline control variables" employed by Bullinger (2017): demographic controls, the unemployment rate, and a series of policy dummies. ${ }^{8}$ State fixed effects $\left(v_{s}\right)$ account for state-specific determinants of the teenage birth rate that are constant over time; yearby-quarter fixed effects $\left(\lambda_{t}\right)$ account for common (i.e., nationwide) shocks to the teenage birth rate. Regressions are weighted by the population of female 15- through 19-year-olds in state $s$ and quarter t. Standard errors are corrected for clustering at the state level (Bertrand et al. 2004).

We report OLS estimates of $\beta_{1}$ from equation (1) in Table 1. Including only state and yearby-quarter fixed effects on the right-hand side, a one-dollar increase in the effective minimum wage is associated with a 0.339 reduction in births per 1,000 female 15-through 19-year-olds. When we add the full vector of controls described above, a one-dollar minimum wage increase is associated with a 0.402 reduction in the teenage birth rate, or about 4 percent relative to the sample mean (8.97). This is precisely the estimate found by Bullinger (2017, Table 1). In 2014, there were 249,078 babies born to 15- through 19-year-olds in the United States (Hamilton et al. 2015). Taken at face value, our estimate of $\beta_{1}$ suggests that raising the minimum wage by one dollar, or about 12.9

\footnotetext{
${ }^{7}$ Bullinger (2017, p. 448) lagged the effective minimum wage (and the controls) to better capture "conditions at the time of conception".

${ }^{8}$ Baseline demographic controls include the proportion of adolescents (ages 16-19 years) who were nonHispanic White, non-Hispanic Black, and Hispanic, the proportion who graduated from high school, the proportion who were 17 years of age, 18 years of age, and 19 years of age, the proportion who were married, the proportion who were cohabitating, and the proportion living in a metropolitan area. These data come from the Current Population Survey Outgoing Rotation Groups and are measured annually. Macroeconomic and policy controls include the maximum combined Temporary Assistance for Needy Families and Supplemental Nutrition Assistance Program payment for a family of three, the unemployment rate, the state Earned Income Tax Credit (EITC) rate, an indicator for whether the EITC was refundable, and separate indicators for whether the state had a Medicaid family planning expansion waiver, a parental notification abortion restriction, or a contraceptive insurance coverage mandate. Descriptive statistics for these and the outcome variables are reported in Appendix Table 1.
} 
percent, would have led to approximately 10,000 fewer babies being born to 15- through 19-year-

olds in 2014.

Several of the baseline controls in $\boldsymbol{X}$ are arguably endogenous, including marriage rate among teenagers, which could have been affected by changes in the minimum wage (Sen and Ariizumi 2013). The vector $\boldsymbol{X}$ also includes the high school graduation rate and the overall unemployment rate, which includes teenage unemployment. ${ }^{9}$ In the third column of Table 1, we report estimates of equation (1) using only those controls that can plausibly be characterized as exogenous. ${ }^{10}$ Using this (i.e., our preferred) set of controls, the estimate of $\beta_{1}$ very similar to the estimate reported in column (1): a one-dollar increase in the minimum wage is associated with a 0.049 reduction in the adolescent fertility rate. This estimate is statistically significant at the 1 percent level and confirms the negative association between the minimum wage and teenage childbearing reported in the existing literature (Bullinger 2017; Lenhart 2021).

\section{DYNAMIC ESTIMATES FOR THE PERIOD 2003-2014}

Following Schmidheiny and Siegloch (2019), we explore the dynamic effects of raising the minimum wage by estimating an event study regression for the period 2003-2014:

\footnotetext{
${ }^{9}$ Raising the minimum wage could, in theory, encourage teenagers to finish high school by reducing the number of low-skilled jobs available (Sutch 2010). Evidence on the relationship minimum wages and education attainment comes from, for instance, Crofton, Anderson and Rawe (2009) and Sutch (2010).

${ }^{10}$ Following Burkhauser et al. (2000) and Sabia et al. (2012; 2016), we controlled for the prime-age unemployment rate and the prime-age wage rate rather than the overall unemployment rate so as not to capture an important mechanism through which the minimum wage could impact teen fertility (teen employment). Our preferred set of controls includes all of Bullinger's controls except those that might capture mechanisms through which the minimum wage might affect teen fertility (the proportion who graduated from high school, the proportion who were married, the proportion who were cohabitating, and the unemployment rate). We instead included additional controls for the prime-age (ages 25-54) unemployment rate, the prime-age wage rate $(2014 \$ s)$, the house price index, and an indicator variable for whether the state had required sex education.
} 
(2) BirthRate $_{s, t}=\beta_{0}+v_{s}+\lambda_{t}+\sum_{j=-19}^{-5} \pi_{j} D_{s, t+j}+\sum_{j=-3}^{13} \pi_{j} D_{s, t+j}+\boldsymbol{\beta}_{1}^{\prime} \boldsymbol{X}_{s, t-3}+\varepsilon_{s, t}$,

where $t$ represents quarters, $j$ represents event time, the $\pi$ s show the effect of raising the minimum wage on teenage birth rates, and the $D s$ are state-by-quarter variables equal to the difference between current- and past-quarter minimum wages $j$ quarters from $t^{11}$ Note that $j=-4$ is omitted, which normalizes the estimates of $\pi$ to zero in that quarter. The pre-treatment estimates of $\pi$ can be thought of as falsification tests — their pattern and statistical significance allow us to test the parallel trends assumption. Small and statistically insignificant pre-treatment estimates of $\pi$ would provide evidence that the parallel trends assumption is not being violated.

Weighted OLS estimates of the $\pi$ s from equation (2) are shown in Panel A of Figure 2. While the post-treatment estimates of $\pi$ are generally negative, the pre-treatment estimates, which are positive and clearly trending downwards, cast doubt on whether the post-treatment estimates should be given a causal interpretation. Substituting our preferred set of controls for the baseline controls produces the same basic pattern of results (Panel B, Figure 2).

\section{ESTIMATES FOR THE PERIOD 2003-2019}

Next, we explore the effects of raising the minimum wage on adolescent fertility using 5 additional years of data (2015-2019). During these 5 years, there were 86 separate increases in state minimum wages; the average minimum wage increase was $\$ 0.62 .{ }^{12}$ By comparison, there were 255 increases in state minimum wages during the period 2004-2014 and the average increase was $\$ 0.40$.

${ }^{11}$ Following Bullinger (2017), event-quarter 0 corresponds to $t-3$. Following Schmidheiny and Siegloch (2019), the values of the Ds for binned "endpoints" of the event studies are the sum of the cumulated events that occurred in the periods before and after the last lead and lag in event time

12 These increases were due to legislative action, but do include changes in the nominal minimum wage resulting from inflation (i.e., state indexing). The identifying variation in our regression comes from real 
DD estimates based on equation (1) are reported in Table 2. These estimates provide no evidence that raising the minimum wage discourages female 15-through 19-year-olds from becoming pregnant and having babies. Controlling for only state and year-by-quarter fixed effects (column 1), a one-dollar increase in the minimum wage is associated with a (statistically insignificant) increase in the adolescent fertility rate of $0.044(p$-value $=.733)$. Including the baseline controls or our preferred set of controls, a one-dollar increase in the minimum wage is associated with a (statistically insignificant) increase in the adolescent fertility rate of 0.039 ( $\mathrm{p}$-value $=.786$ ) to 0.085 $(\mathrm{p}$-value $=.618)$.

Next, we estimate a slightly modified version of equation (2) using birth rate data from the $4^{\text {th }}$ quarter of 2003 through the $4^{\text {th }}$ quarter of 2019 :

(3) BirthRate $_{s, t}=\beta_{0}+v_{s}+\lambda_{t}+\sum_{j=-23}^{-5} \pi_{j} D_{s, t+j}+\sum_{j=-3}^{17} \pi_{j} D_{s, t+j}+\boldsymbol{\beta}_{1}^{\prime} \boldsymbol{X}_{s, t-3}+\varepsilon_{s, t}$,

The results are shown in Figure 3, Panels A and B. The pre-treatment estimates of the $\pi$ s are generally statistically insignificant and the pre-treatment birthrate trend is essentially flat. However, the post-treatment estimates of the $\pi$ s provide no evidence of reductions in adolescent fertility. When we control for state-specific linear and quadratic time trends, there is evidence of a posttreatment decline in teenage fertility, but there is also evidence that the parallel trends assumption does not hold: the estimates of the $\pi \mathrm{s}$ are positive, statistically significant, and trending downwards one through 16 quarters before treatment (Appendix Table 3). ${ }^{13}$ Together, these findings provide strong evidence that minimum wage increases have little effect on teenage childbearing.

changes in the effective state minimum wage, which includes changes due to legislated state increases as well as inflation-related changes that are not fully captured by year dummies in our regression models.

${ }^{13}$ Neumark et al. (2014) and Meer and West (2016) provide evidence that including state-specific linear (or quadratic) time trends on the right-hand side of the standard "two-way fixed effects" (TWFE) regression may obscure dynamic (and negative) employment effects of raising the minimum wage. 


\subsection{Estimates by race and ethnicity, 2003-2019}

DD estimates based on equation (1) by race and ethnicity are reported in Table $3 .{ }^{14}$

Restricting our focus to non-Hispanic Black 15-through 19-year-olds produces little evidence that minimum wages reduce fertility (Panel A). Regardless of which controls are used, the estimates of $\beta_{1}$ are small and statistically insignificant.

When we restrict our attention to Hispanic 15- through 19-year-olds, the estimates of $\beta_{1}$ become consistently negative, but are still small and statistically indistinguishable from zero. For instance, using our preferred set of controls, a one-dollar increase in the minimum age is associated with a (statistically insignificant) 0.094 reduction in the Hispanic adolescent fertility rate, or approximately .76 percent relative to the mean (Panel B, Table 3).${ }^{15}$ Event study analyses by race and ethnicity using data from the $4^{\text {th }}$ quarter of 2003 through the $4^{\text {th }}$ quarter of 2019 provide no support for the hypothesis that raising the minimum wage discourages teenage childbearing (Appendix Figure 1).

Finally, restricting our sample to Non-Hispanic White 15- through 19-year-olds produces some evidence, albeit tentative, that raising the minimum wage actually increases teenage fertility. Only controlling for state and year-by-quarter fixed effects, a one-dollar increase in the minimum wage is associated with 0.148 additional babies per 1,000 Non-Hispanic White female 15- through 19-year-olds. This represents an increase of 2.9 percent relative to the mean (5.176). The estimates

\footnotetext{
${ }^{14}$ The estimates in Table 3 are weighted by population and are based on data from the $4^{\text {th }}$ quarter of 2003 through the $4^{\text {th }}$ quarter of 2019.

15 By contrast, using data for the period 2003-2014, Bullinger (2017, Table 1) found that a one-dollar increase in the minimum wage was associated with a 0.49 to 1.75 reduction in the Hispanic fertility rate. Bullinger (2017, p. 449) found less consistent evidence that minimum wage increases reduced fertility among Black adolescents and noted that Hispanic teenagers were more likely to be employed than their Black counterparts.
} 
of $\beta_{1}$, however, shrink and become statistically insignificant when controls are included on the righthand side of the estimating equation. ${ }^{16}$

\subsection{Estimates by marital status of the mother, 2003-2019}

Sen and Ariizumi (2013) examined the relationship between minimum wages and teenage fertility in Canada during the period 1990-2005. Using a DD regression model and data at the province-year level, these authors found that minimum wages were unrelated to the fertility decisions of unmarried Canadian teenagers, but it encouraged married Canadian teenagers to have more children. ${ }^{17}$

Following Sen and Ariizumi (2013), we report DD regression estimates of the effects of minimum wages on fertility rates by the marital status of the mother in Table 4. Regardless of which controls are used, there is no evidence of reductions in fertility. In fact, using our preferred set of controls, a one-dollar increase in the minimum wage is associated with a 0.088 increase in the fertility rate of married teenagers, although this estimate is only marginally significant. ${ }^{18}$

\footnotetext{
16 In columns (2) through (4) of Appendix Table 3, we examine the effect of raising the minimum wage on the fertility of female 15- through 19-year-olds by race and ethnicity controlling for state-specific linear and quadratic time trends. The results provide little support for the hypothesis that minimum wage increases reduce teen fertility. The estimated coefficients on the policy leads are often significant, positive, and declining over the pre-treatment period (Panel B).

${ }_{17}$ Pooling married and unmarried 15- through 19-year-olds, a 10 percent increase in the minimum wage was associated with a 3 to 5 percent increase in the birth rate (Sen and Ariizumi 2013, pp. 346-349). By comparison, Bullinger (2017) found that a 10 percent increase in the minimum wage was associated with a 3 percent reduction in the birth rate of U.S. 15- through 19-year-olds, while Lenhart (2021) found that a 10 percent increase in the minimum wage was associated with a 1 to 2 percent reduction in the birth rate of U.S. 15- through 19-year-olds.

18 Below, we examine the effect of minimum wages on marriage rates among female 15- through 19-year-olds (Table 6). Marriage rates at the state-year level are from Current Population Surveys, 2003-2019. We find no evidence that raising the minimum wage encourages (or discourages) female teenagers to marry. In Appendix Table 4, we examine the effects of minimum wages on the fertility and marriage rates of female 30- through 54-year-olds. Again, there is no evidence that minimum wages are related to these outcomes.
} 


\subsection{Focusing on prominent increases in the minimum wage}

Next, following Cengiz et al. (2019), we focus on estimating the effects of prominent minimum wages increases — i.e., minimum wage increases of at least one dollar. ${ }^{19}$ Specifically, we estimate a standard DD regression model of the form:

\section{(4) BirthRate $_{s, t}=\beta_{0}+v_{s}+\lambda_{t}+\beta_{1}(\text { Increase } \geq \$ 1)_{s, t-3}+\boldsymbol{\beta}_{2}^{\prime} \boldsymbol{X}_{s, t-3}+\varepsilon_{s, t}$,}

where Increase $\geq \$ 1$ is an indicator for increases in the state minimum wage of at least one dollar. If the indicator Increase $\geq \$ 1$ "turns on" (i.e., goes from 0 to 1 ) in quarter $t$ - 3, it "stays on" (i.e., is equal to 1) through quarters $t-2, t-1, t$, and so forth. States that did not increase their minimum wage during the period under study (or increased their minimum wage by less than one dollar) comprise the never-treated group. ${ }^{20}$

Estimates of $\beta_{1}$ based on equation (4) are reported in Table 5, columns (1) and (2). They suggest that even prominent minimum wage increases have little or no effect on teenage fertility: with or without controlling for our preferred set of $\boldsymbol{X}_{\mathbf{s}}$, the estimates of $\beta_{1}$ are small and statistically insignificant at conventional levels. In column (3) of Table 5, we control for less prominent changes in the minimum wage by including an indicator for "small" minimum wage increases, defined as

\footnotetext{
${ }^{19}$ To be considered prominent, the increase in the minimum wage must have been through legislative action and equal to (or more than) one 2014 dollar. Cengiz et al. (2019), examined employment changes resulting from 138 "prominent" state-level minimum wage increases, defined as an increase in the minimum wage of at least $\$ 0.25$ that directly affected at least 2 percent of the workforce.

${ }^{20}$ States often increased their minimum wage in annual increments. The indicator Increase $\geq \$ 1$ "turns on" in period $t-3$ if the state minimum wage went up by at least one dollar over the course of periods $t-3, t-2, t-1$, and t.
} 
increases between $\$ 0.50$ and $\$ 0.99$. Again, the resulting estimate of $\beta_{1}$ is small and statistically insignificant.

Event study estimates of the effects of prominent increases in the minimum wage are shown in Figure $4 .^{21}$ Both the pre- and post-treatment estimates are small and statistically indistinguishable from zero, but these estimates are potentially biased if the effects of prominent minimum wage increases are heterogeneous across cohorts (Sun and Abraham 2020). To address this issue, we produce alternative event study estimates restricting the counterfactuals to "never-treated" states (Callaway and Sant'Anna 2021). These alternative event study estimates provide little evidence that prominent minimum wage increases reduce teenage fertility (Figure 5). The overall average treatment effect on the treated (ATT), which is the average of the estimated post-treatment ATTs, shown in columns (4) through (6) of Table 5, are positive and statistically indistinguishable from zero. $^{22}$ The post-treatment estimates in the event study in Figure 5 are generally positive (44 out of 54 of the post-treatments estimates are greater than zero) and never statistically significant at conventional levels (Figure 5). ${ }^{23}$

21 These estimates were obtained by replacing Increase $\geq \$ 1$ in equation (4) with a series of its leads and lags. Following Bullinger (2017), event-quarter 0 corresponds to $t-3$. Our preferred set of controls are included on the right-hand side of (4).

22 An introduction to the R package used to estimate the treatment effects in Callaway and Sant'Anna (2021) is available at: https://bcallaway11.github.io/did/articles/index.html. In this event study, we also include time-invariant macroeconomic controls for the state's mean house price index and the prime-age (ages 25-54) unemployment rate.

${ }^{23}$ In Appendix Figure 2, we show alternate Callaway and Sant'Anna (2021) event studies that exclude macroeconomic controls (Panels A and B), and include controls for smaller minimum wage increases (Panels $\mathrm{C}$ and $\mathrm{D}$ ) defined as an indicator variable for whenever the state experienced a minimum wage increase greater than $\$ 0.50$ and less than $\$ 0.99$ over the course of periods $t-3, t-2, t-1$, and $t$ for the periods 2003Q42014Q4 and 2003Q4-2019Q4, respectively. The findings are qualitatively similar to those reported in Figures 4 and 5 . 


\section{MINIMUM WAGES, MARITAL STATUS, AND SEXUAL BEHAVIOR}

We turn now to the exploration of potential mechanisms. First, using data from the Current Population (CPS), we estimate the relationship between minimum wages and teenage marriage rates, defined as the percentage of 16-to-19-year-olds who were married. ${ }^{24}$ The CPS data, which cover the period 2003-2019, are aggregated to the state-year level.

Standard DD regression estimates are reported in Table 6. They provide little evidence that raising the minimum wage encourages (or discourages) teenagers from marrying. ${ }^{25}$ For instance, including Bullinger's controls on the right-hand side of estimating equation, a one-dollar increase in the minimum wage is associated with a (statistically insignificant) 1.23 increase in the teenage marriage rate, or 7.6 percent of the mean; using our preferred set of controls, a one-dollar increase is associated with a (statistically insignificant) 0.97 increase in the teenage marriage rate.

Next, we explore the effects of minimum wages on the sexual behavior of female 15through 19-year-olds. The data come from state and national Youth Risk Behavior Surveys (YRBS), which measure the health and health behaviors of U.S. high school students. The national YRBS is conducted by the Centers for Disease Control and Prevention (CDC), and, when weighted, is designed to be nationally representative of students attending $9^{\text {th }}$ through $12^{\text {th }}$ grades. State YRBS surveys are typically administered by state health or education agencies.

DD regression estimates of the relationship between minimum wages and teenage sexual behavior based on YRBS data for period 2003-2019 are reported in Table $7 .^{26}$ Seven outcomes are

\footnotetext{
${ }^{24}$ The CPS does not collect information on marital status of 15 -year-olds.

25 Using Canadian data at the province-year level for the period 1990-2005, Sen and Ariizumi (2013), found that increasing the minimum wage encouraged teenagers to marry. Specifically, they found that a 10 percent increase in the minimum wage was associated with a (statistically significant) 1.3 to 1.6 percent increase the teenage marriage rate (Sen and Ariizumi 2013, pp. 352-353).

26 These are weighted OLS estimates from the following equation:
} 
considered, all of which could, in theory, affect the fertility of teenagers. They include whether respondent $i$ was sexually active at the time of the interview, and, if sexually active, whether she used birth control. ${ }^{27}$

The results are unequivocal. There is no evidence that minimum wages are related to sexual behavior. In both the state and the national YRBS, the estimated coefficients of $M W_{i, s, t}$ are, without exception, small and statistically insignificant. For instance, using the state YRBS data, a one-dollar increase in the minimum wage is associated with a (statistically insignificant) 0.004 increase in the probability of being sexually active, which is 1.2 percent of the sample mean; a onedollar increase in the minimum wage is also associated with a (statistically insignificant) 0.001 increase in the probability of having unprotected sex, which is 1.1 percent of the sample mean. This basic pattern of results does not change when we include YRBS respondents ages $12-13$ in the analysis (available upon request) or when we control for state-specific linear time trends. ${ }^{28}$

In Table 8, we report DD regression estimates of the effect of minimum wages on the sexual behavior of U.S. teenagers by race and ethnicity. State YRBS data are used, but results based on the

$$
\text { Behavior }_{i, s, t}=\beta_{0}+v_{s}+\lambda_{t}+\beta_{1} M W_{s, t}+\boldsymbol{\beta}_{2}^{\prime} \boldsymbol{X}_{s, t}+\varepsilon_{i, s, t}
$$

where $i$ indexes YRBS respondents, $s$ indexes states, and $t$ indexes years (the YRBS is conducted on a biennial basis). They are weighted using age-by-gender-by-race population weights generated using the Surveillance Epidemiology and the End Results Program.

27 The variable for current sexual activity is defined as a response of at least one person to the question "During the past 3 months, with how many people did you have sexual intercourse?" The variable for unprotected sex is an indicator for whether the respondent has engaged in sexual intercourse in the last three months and did not use any form of contraception defined as birth control pills, condoms, IUDs, implants, shots, or rings, during the last time they engaged in sexual intercourse.

${ }^{28}$ Results controlling for state-specific linear time trends are reported in Appendix Table 5. In Appendix Figures 3 and 4, we report estimates from a distributed lag model using the state and national YRBS data, respectively. In Appendix Figure 5, we focus on prominent minimum wage increases ( $\$ 1$ or more in 2014 dollars) and report estimates based on the Callaway-Sant'Anna estimator. There is no evidence that increasing the minimum wage leads to important changes in sexual activity or contraceptive use conditional on sexual behavior. 
national YRBS data are similar. Among non-Hispanic White respondents, there is no evidence that minimum wages affect any of the outcomes considered. The estimated coefficients are consistently small and statistically insignificant. A one-dollar increase in the minimum wage is associated with a 0.012 increase in the probability that Black respondents reported being sexually active, but this estimate is only significant at the 10 percent level. None of the other estimated coefficients are statistically significant for Black respondents. Among Hispanic respondents, the results are mixed and, in fact, difficult to interpret. A one-dollar increase in the minimum wage is associated with a 0.006 increase in the probability that Hispanic teenagers reported having unprotected sex, which is 5.6 percent of the mean. Conditional on having had sex, a one-dollar increase in the minimum wage is associated with a 0.036 decrease in the probability of using a condom (8.6 percent of the mean), but a 0.028 increase in the probability of being on the pill (21.4 percent of the mean) ${ }^{29}$

Finally, in Appendix Table 7, we explore the effects of minimum wage increase on sexual behavior of males, whose behavior could also influence teenage fertility. The results provide little support for the hypothesis that minimum wage increases were an important driver of male teenage sexual behavior.

\section{MINIMUM WAGES, PREGANCIES AND ABORTIONS}

In this section, we turn our attention to investigating the effects of minimum wages on pregnancies and abortions among U.S. teenagers, ages 15-19. The data are at the state-year level and come from the Centers for Disease Control and Prevention (CDC) and the Guttmacher Institute.

\footnotetext{
${ }^{29}$ In Appendix Table 6, we report race- and ethnicity-specific estimates of the effect of minimum wage increases on the sexual behavior of female adolescents controlling for state-specific linear time trends. The results are qualitatively similar to those reported in Table 8.
} 
The Guttmacher Institute collects their data on abortions by conducting a nationwide census of all known providers. ${ }^{30}$

OLS estimates of equation (1) in which the teenage fertility rate is replaced with the teenage pregnancy rate are shown in the top panel (Panel A) of Table 9. These estimates are weighted by the state population and standard errors are corrected for clustering at the state level (Bertrand et al. 2004). Teenage pregnancy rates by state and year are from the Guttmacher Institute and cover the period $2005-2017 .^{31}$

Consistent with the results reported above, there is no evidence that minimum wages are related to pregnancies among U.S. teenagers. For instance, using our preferred set of controls and specification (i.e., without state-specific linear trends), a one-dollar increase in the minimum wage is associated with a 0.29 decrease in the number of pregnancies per 100,000 population, which is only 0.55 percent of the mean. ${ }^{32}$

OLS estimates of equation (1) in which the teenage fertility rate is replaced with one of two abortion rates are shown in the remaining panels of Table 9. The first abortion rate is from the Guttmacher Institute, covers the period 2005-2017, and is calculated as the number of abortions per 1,000 women ages $15-19$ by state of residence; the second is from the Centers for Disease Control, covers the period 2003-2018, and is calculated as the number of abortions per 1,000 women ages 15-

\footnotetext{
30 The methodology for estimating the number of pregnancies requires data collection from numerous sources, including births from the National Vital Statistics System and abortion distributions from the CDC.

31 The Guttmacher Institute defines pregnancies as the sum of births, abortions, and fetal losses (i.e., miscarriages, ectopic pregnancies, and still births). Pregnancies are calculated by state of residence.

32 If we control for state-specific linear trends, this estimate becomes -.366 with a standard error of 0.284.
} 
19 by state of occurrence. ${ }^{33}$ Again, the estimates are weighted by state population and standard errors are corrected for clustering at the state level.

The results, reported in Panels B and C of Table 9, provide no evidence that abortions to teenage mothers are responsive to changes in the minimum wage. Using either definition of the abortion rate, the estimated effects are small (0.1 to 3.8 percent) and statistically insignificant. Using our preferred specification, a one-dollar increase in the minimum wage is associated with a (statistically insignificant) 0.11 reduction in the abortion rate as measured by abortions among resident females per 1,000 population (Panel B). If the alternative abortion rate is used (measured as abortions performed in the state, independent of resident status), a one-dollar increase in the minimum wage is associated with a (statistically insignificant) 0.42 reduction (Panel C).

To explore whether the effects of minimum wages on pregnancies and abortions take time to manifest, we estimate dynamic regression models similar to those discussed above. The results are shown in Figure 6. The pre-treatment estimates are never statistically significant and exhibit no distinct trends. The post-treatment estimates for the abortion outcomes appear to trend upwards but these estimates are trivially small even three full years after an increase in the minimum wage.

Finally, we explore the effect of prominent increases in the minimum wage, defined as a onedollar increase in the effective state minimum wage over a calendar year. To avoid any bias from heterogenous treatment effects, we restrict the counterfactuals to "never-treated" states (Callaway and Sant'Anna 2021). The results are shown in Figure 7. With the abortion rate is on the left-hand

\footnotetext{
33 The CDC calculates abortion incidence rates for 2003-2018 and are derived from actual counts of every abortion reported to state health departments, however, reporting to the CDC is not mandatory. The Guttmacher Institute provides abortion rate estimates for all states annually for 2005-2017. US Census Bureau estimates of the resident female population were used as the denominator in both abortion rate calculations.
} 
side, the pre- and post-treatment estimates are small and statistically indistinguishable from zero. ${ }^{34}$

There is no evidence of a post-treatment trend either upwards or downwards. With the pregnancy rate is on the left-hand side, the pre- estimates are flat, but the post-treatment estimates, although insignificant, are clearly trending upwards.

\section{CONCLUSION}

Minimum wage increases have proven to be very popular. All 7 of the most recent ballot initiatives to raise the state minimum wage have been approved by voters. Recent initiatives in the "red" states of Missouri, Florida, and Arkansas have passed with 60 to 68 percent of the popular vote (Ballotpedia 2021). While a long literature in labor economics has studied the impact of minimum wages on teenage labor market outcomes, recent high-profile research suggests that there may be important public health benefits from increases in the minimum wage (Leigh 2016).

If enacted, the Raise the Wage Act of 2021 would raise the effective minimum wage for teenagers in the United States by $\$ 5.28$ per hour (in 2021 dollars) and more than double the nominal minimum wage in approximately 20 states. Taken at face value, recent estimates in the literature suggest that, if passed, the Raise the Wage Act of 2021 would reduce the teen birth rate by 21.5 percent, generating short-run cost savings (for direct medical care and economic support) of as much as $\$ 665$ million per year. ${ }^{35}$

\footnotetext{
${ }^{34}$ For computational purposes, the sample is restricted to a balanced panel of states and, consequently, is slightly smaller $(N=585$ as opposed to $N=679)$. Control variables used include the house price index and the prime-age (ages 25-54) unemployment rate.

35 The number of births to 15-to-19-year-olds was 171,674 in 2019 (CDC 2021). Taken at face value, the estimate reported by Bullinger (2017) suggests that raising the federal minimum wage by $\$ 5.28$ (in 2021 dollars) for the average U.S. resident would reduce the teenage fertility rate by 21.5 percent (or about 36,909) births. At a cost of $\$ 18,028$ (in 2021 dollars) per teenage birth through the first year of infancy (Power to Decide 2018), this implies short-run cost savings from the Raise the Wage Act of 2021 of $\$ 665$ million per year.
} 
This study reassesses a growing consensus in the public health literature that minimum wages are an effective policy tool to combat teenage pregnancies. We do this by (i) exploiting new econometric tools to more fully assess the parallel trends assumption and expunge bias caused by heterogeneous dynamic treatment effects, (ii) using recent, large increases in minimum wages to identify policy impacts, and (iii) empirically exploring the potential mechanisms through which minimum wages could have impacted teenage fertility.

Our findings provide no support for the hypothesis that raising the minimum wage is an effective policy tool for reducing teenage childbearing. Dynamic models show that teenage birth rates were already declining prior to the enactment of minimum wage increases, which strongly suggests that the common trends assumption is violated. Using data for the period 2003 through 2019, difference-in-differences regression and dynamic models provide no evidence that minimum wages are, in a causal sense, related to teenage childbearing. An exploration of prominent minimum wage increases (of $\$ 1$ or more) using the approach pioneered by Callaway and Sant'Anna (2021) confirms that teenage births do not respond to minimum wage hikes. Finally, we find little evidence that minimum wages are related to the hypothesized mechanisms: difference-in-difference analyses using data from the Youth Risk Behavior Survey, the Current Population Survey, and the Guttmacher Institute show no evidence that minimum wage increases result in economically important or statistically significant changes in teenage sexual behavior, contraceptive use, marriage rates, abortion rates, or pregnancy rates.

The redistribution of income from raising the minimum wage could, in principle, improve public health. However, the results of this study suggest that raising the minimum wage is not an effective strategy for discouraging teenagers from having babies. Future researchers could fruitfully explore the relationship between minimum wages and other public health outcomes using recently developed econometric tools. 


\section{REFERENCES}

Allegretto, Sylvia, Arindrajit Dube, and Michael Reich. 2011. "Do Minimum Wages Really Reduce Teen Employment? Accounting for Heterogeneity and Selectivity in State Panel Data," Industrial Relations, 50(2): 945-964.

Ballotpedia. 2021. Minimum wage on the ballot. August 10. Available at: https://ballotpedia.org/Minimum wage on the ballot

Bertrand, Marianne, Esther Duflo, and Sendhil Mullainathan. 2004. "How Much Should We Trust Differences-In-Differences Estimates?” Quarterly Journal of Economics, 119(1): 249-275.

Bullinger, Lindsey Rose. 2017. "The Effect of Minimum Wages on Adolescent Fertility: A Nationwide Analysis.” American Journal of Public Health, 107(3): 447-452.

Burkhauser, Richard V., Couch, Kenneth A., and Wittenburg, David C. 2000. "A reassessment of the new economics of the minimum wage literature with monthly data from the Current Population Survey." Journal of Labor Economics, 18(4): 653-680.

Bureau of Labor Statistics. (n.d.). CPI for all urban consumers (CPI-U). 2003-2019. [Data set]. Retrieved October 2020, from https://beta.bls.gov/dataViewer/view/timeseries/CUUR0000SA0

Brown, Charles, Curtis Gilroy, and Andrew Kohen. 1982. “The Effect of the Minimum Wage on Employment and Unemployment.” Journal of Economic Literature, 20(2): 487-528.

Callaway, Brantly, and Pedro H.C. Sant'Anna. 2021. "Difference-in-Differences with Multiple Time Periods." Forthcoming, Journal of Econometrics.

Card, David and Alan B. Krueger. 1995. Myth and Measurement: The New Economics of the Minimum Wage. Princeton NJ: Princeton University Press.

Cengiz, Doruk, Arindrajit Dube, Attila Lindner, and Ben Zipperer. 2019. "The Effect of Minimum Wages on Low-Wage Jobs.” Quarterly Journal of Economics, 134(3): 1405-1454.

Centers for Disease Control and Prevention. 2021. Teen Births. Available at: https://www.cdc.gov/nchs/fastats/teen-births.htm

Clemens, Jeffrey and Michael Wither. 2019. "The Minimum Wage and the Great Recession: Evidence of Effects on the Employment and Income Trajectories of Low-Skilled Workers." Journal of Public Economics, 170: 53-67.

Conklin, Annalijn I, Ninez A Ponce, John Frank, Arijit Nandi, and Jody Heymann. 2016. "Minimum Wage and Overweight and Obesity in Adult Women: A Multilevel Analysis of Low and Middle Income Countries. PLoS One, 11 (3), Article e0150736.

Crofton, Stephanie O. William L. Anderson, and Emily C. Rawe. 2009. "Do Higher Real Minimum Wages Lead to More High School Dropouts? Evidence from Maryland Across Races, 1993-2004." American Journal of Economics and Sociology, 68 (2): 445-464 
Desmond, Matthew, 2019. "Dollars on the Margins." The New York Times Magazine, February 21. Available at: https://www.nytimes.com/interactive/2019/02/21/magazine/minimum-wage-savinglives.html

Dow, William H., Anna Godøy, Christopher A. Lowenstein, and Michael Reich. 2020. "Can Economic Policies Reduce Deaths of Despair?” NBER WP No. 25787.

Dube, Arindrajit, T. William Lester, and Michael Reich. 2010. "Minimum Wage Effects Across State Borders: Estimates Using Contiguous Counties.” The Review of Economics and Statistics, 92 (4): 945-964.

Dube, Arindrajit. 2019. "Minimum Wages and the Distribution of Family Incomes." American Economic Journal: Applied Economics, 11(4)-268-304.

Fone, Zachary S., Joseph J. Sabia, and Resul Cesur. 2020. “Do Minimum Wage Increases Reduce Crime?”. NBER WP No. 25647.

Goodman-Bacon, Andrew. 2021. "Difference-in-differences with Variation in Treatment Timing." Forthcoming, Journal of Econometrics.

Hamilton, Brady E., Joyce A. Martin, and Michelle J.K. Osterman. 2021. "Births: Provisional Data for 2020." Vital Statistics Rapid Release, no. 12.

Hamilton, Brady E., Joyce A. Martin, Michelle J.K. Osterman, Sally C. Curtin, and T.J. Mathews. 2015. "Births: Final Data for 2014." 2015. National Vital Statistics Reports, 64(12): 1-63.

Healy, Melissa. 2017. "For Teens, a Higher Minimum Wage could be an Effective form of Birth Control.” The Lost Angeles Times, January 19. Available at:

https:/ /www.latimes.com/science/sciencenow/la-sci-sn-minimum-wage-birth-rate-20170119story.html

Hotz, V. Joseph, McElroy, Susan W., \& Sanders, Seth G. 2005. "Teenage childbearing and its life cycle consequences exploiting a natural experiment." Journal of Human Resources, 40 (3): 683-715.

Hoffman, S.D. and Maynard, R.A. eds., 2008. Kids having kids: Economic costs \& social consequences of teen pregnancy. The Urban Institute.

Fernandes-Alcantara, Adrienne L. 2018. Teen Pregnancy: Federal Prevention Programs. Congressional Research Service (CRS) Report No. R45183.

Kearney, M.S. and Levine, P.B. 2012. "Why is the teen birth rate in the United States so high and why does it matter?” Journal of Economic Perspectives, 26(2): 141-63.

Lenhart, Otto. 2017. "Do Higher Minimum Wages Benefit Health? Evidence from the UK." Journal of Policy Analysis and Management, 36(4): 828-852.

Lenhart, Otto. 2021. “The Effects of Minimum Wages on Teenage Birth Rates.” Economics Letters, 198: Article 109670.

Leigh, J.P., 2016. “Could Raising the Minimum Wage Improve the Public's Health?” American Journal of Public Health, 106(8): 1355. 
Leigh, J. Paul, Wesley A. Leigh, and Juan Due. 2021. "Minimum Wages and Public Health: A Literature Review.” Preventive Medicine, 118: 122-134

McCarrier, Kelly P., Frederick J. Zimmerman, James D. Ralston, and Diane P. Martin. 2011. "Associations between Minimum Wage Policy and Access to Health Care: Evidence from the Behavioral Risk Factor Surveillance System, 1996-2007.” American Journal of Public Health, 101 (2): 359-367.

Meer, Jonathan and Jeremy West. 2016. "Effects of the minimum wage on employment dynamics." Journal of Human Resources 51(2): 500-522.

National Campaign to Prevent Teen and Unplanned Pregnancy. 2013. Counting It Up_-The Public Cost of Teen Childbearing: Key Data, December. Available at: https://powertodecide.org/what-wedo/information/resource-library/counting-it-key-data

Neumark, David and William L. Wascher. 2008. Minimum Wages. Cambridge, MA: MIT Press.

Neumark, David, J. M. Ian Salas, and William L. Wascher. 2014. "Revisiting the Minimum WageEmployment Debate: Throwing Out the Baby with the Bathwater?” Industrial and Labor Relations Review, 67 (3_suppl): 608-648.

Neumark, David and Peter Shirley. 2021. "Myth or Measurement: What Does the New Minimum Wage Research Say about Minimum Wages and Job Loss in the United States?" National Bureau of Economics (NBER) Working Paper No. 28388.

Power to Decide. 2018. Progress Pays Off. Accessed August 23. Available at: https://powertodecide.org/sites/default/files/media/savings-fact-sheet-national.pdf

Power to Decide. 2021. Why It Matters. July 11. Available at: https://powertodecide.org/what-wedo/information/why-it-matters. Washington: Author.

Raissian, Kerri M. and Lindsey Rose Bullinger. 2017 “Money Matters: Does the Minimum Wage affect Child Maltreatment Rates?" Children and Youth Services Review, 72 (C): 60-70.

Reeves, Aaron, Martin McKee, Johan Mackenbach, Margaret Whitehead, and David Stuckler. 2017. "Introduction of a National Minimum Wage Reduced Depressive Symptoms in Low-Wage Workers: A Quasi-Natural Experiment in the UK." Health Economics, 26(5):639-655.

Sabia, Joseph J. 2008. "Minimum wages and the economic well-being of single mothers." Journal of Policy Analysis and Management, 27 (4): 848-866.

Sabia, Joseph J. 2014. "Minimum wages: an ineffective and antiquated anti-poverty tool," Journal of Policy Analysis and Management, 33 (4): 1028-1036.

Sabia, Joseph J., Burkhauser, Richard V., and Hansen, Benjamin. 2012. "Are the effects of minimum wage increases always small? New evidence from a case study of New York state." Industrial and Labor Relations Review, 65 (2): 350-376.

Sabia, Joseph J., Richard V. Burkhauser, and Benjamin Hansen. 2016. "When good measurement goes wrong: New evidence that New York State's minimum wage reduced employment." Industrial and Labor Relations Review, 69 (2): 312-319. 
Sabia, Joseph J., M. Melinda Pitts, and Laura M. Argys. 2019. “Are Minimum Wages a Silent Killer? New Evidence on Drunk Driving Fatalities." Review of Economics and Statistics, 101 (1): 192-199.

Schmidheiny, Kurt and Sebastian Siegloch. 2020. "On Event Study Designs and Distributed Lag Models: Equivalence, Generalization and Practical Implications.” IZA DP No. 12079.

Sedgh, Gilda, Lawrence B. Finer, Akinrinola Bankole, Michelle A. Eilers, and Susheela Singh S. 2015. "Adolescent Pregnancy, Birth, and Abortion Rates Across Countries: Levels and Recent Trends." Journal of Adolescent Health, 56 (2): 223-230.

Sen, Anindya and Hideki Ariizumi. 2013. "Teen Families, Welfare Transfers, and the Minimum Wage: Evidence from Canada." Canadian Journal of Economics, 46 (1): 338-360.

SmithBattle, Lee. 2018. "Teen Mothering in the United States: Fertile Ground for Shifting the Paradigm." In A. Kampand and M. McSharry (eds.), Re/ Assembling the Pregnant and Parenting Teenager: Narratives from the Field(s). New York: Peter Lang Ltd., pp. 75-103

Stigler, George J. 1946. "The Economics of Minimum Wage Legislation.” American Economic Review, 36 (3): 358-365.

Sutch, Richard. 2010. “The Unexpected Long-Run Impact of the Minimum Wage: An Educational Cascade.” NBER Working Paper No. 16355.

Sun, L. and Abraham, S. 2020. "Estimating dynamic treatment effects in event studies with heterogeneous treatment effects." Journal of Econometrics.

U.S. Senate Bill S.53. Raise the Wage Act of 2021. $117^{\text {th }}$ Congress, $1^{\text {st }}$ session. Introduced in Senate January 26, 2021. https://www.congress.gov/bill/117th-congress/senate-bill/53

Vaghul, Kavya and Ben Zipperer. 2019. "Historical State and Sub-state Minimum Wages." Version 1.2.0, https://github.com/benzipperer/historicalminwage/releases/tag/v1.2.0.

Wehby, George L., Dhaval M. Dave, and Robert Kaestner. 2019. "Effects of the Minimum Wage on Infant Health.” Journal of Policy Analysis and Management, 39(2): 411-443.

Welch, Finis. 1974. "Minimum Wage Legislation in the United States.” Economic Inquiry, 12 (3): 285 318. 


\section{Figure 1. Trends in the Teenage Fertility Rate and the Effective Minimum Wage, 2003-2019}

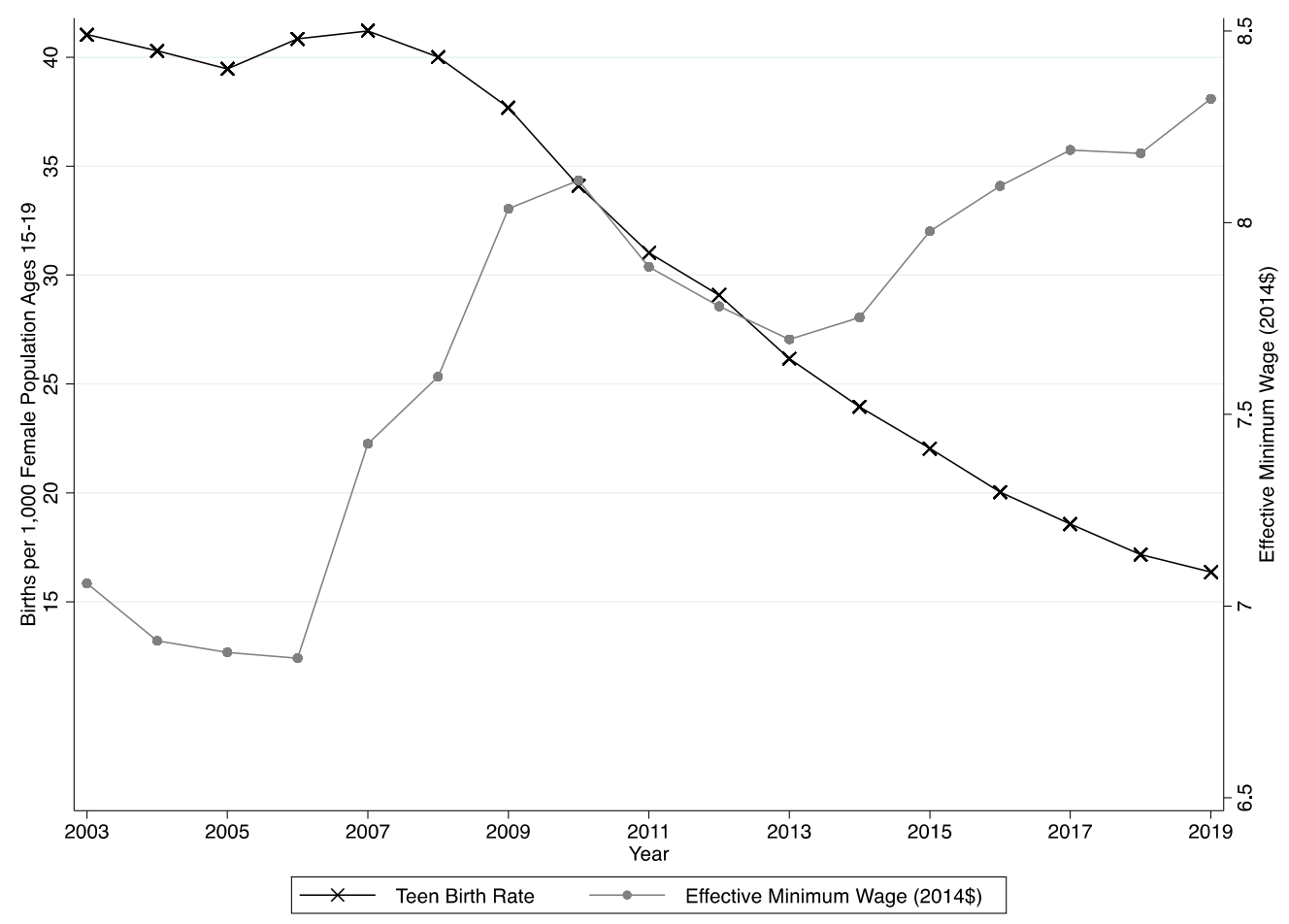

Notes: Data on annual number of births to teenage (ages 15-to-19) mothers and the annual population of 15-to-19-year-olds are obtained from the National Vital Statistics System. Data on the annual effective minimum wage are obtained from Vaghul and Zipperer (2019) and adjusted for inflation (2014\$s) using the Consumer Price Index (CPI) obtained from the Bureau of Labor Statistics. 
Figure 2. Dynamic Effects of Minimum Wages on Teenage Fertility, 2003-2014

Panel A. Using Baseline Controls

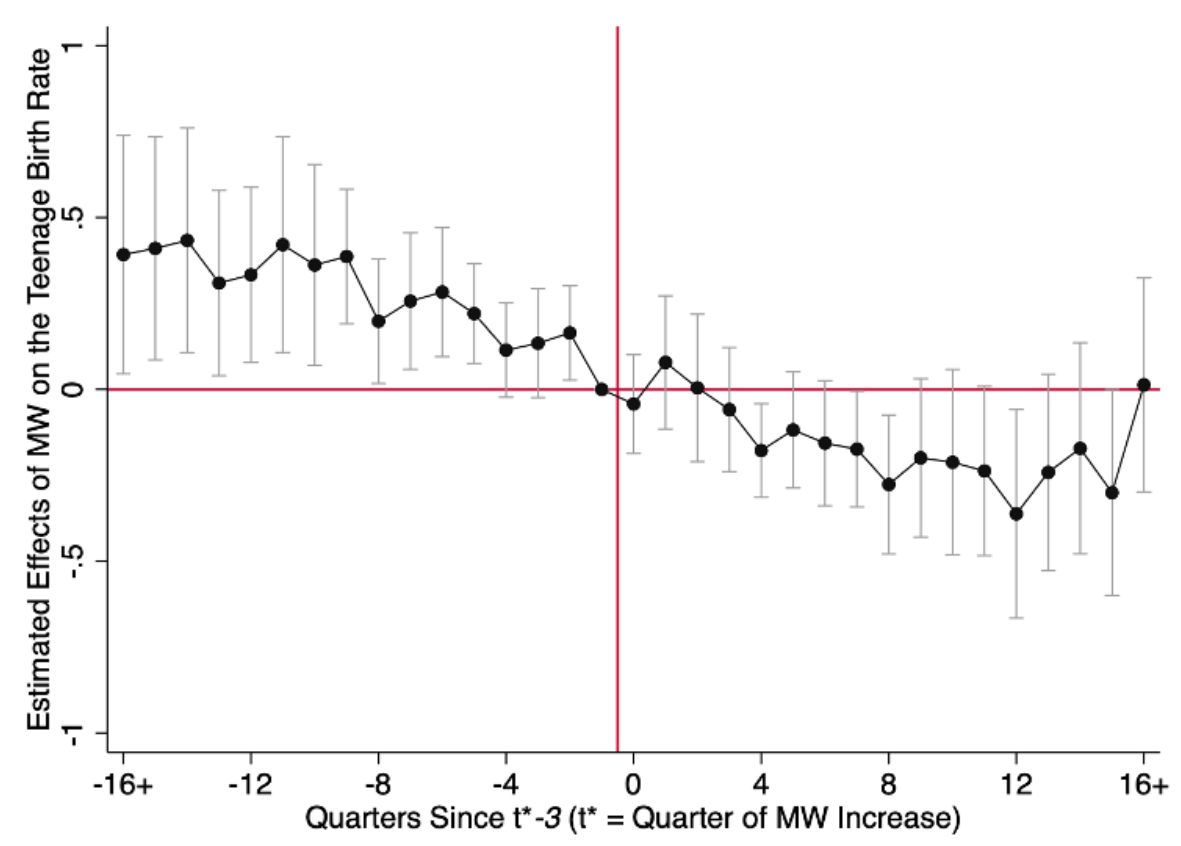

Panel B. Using Our Preferred Controls

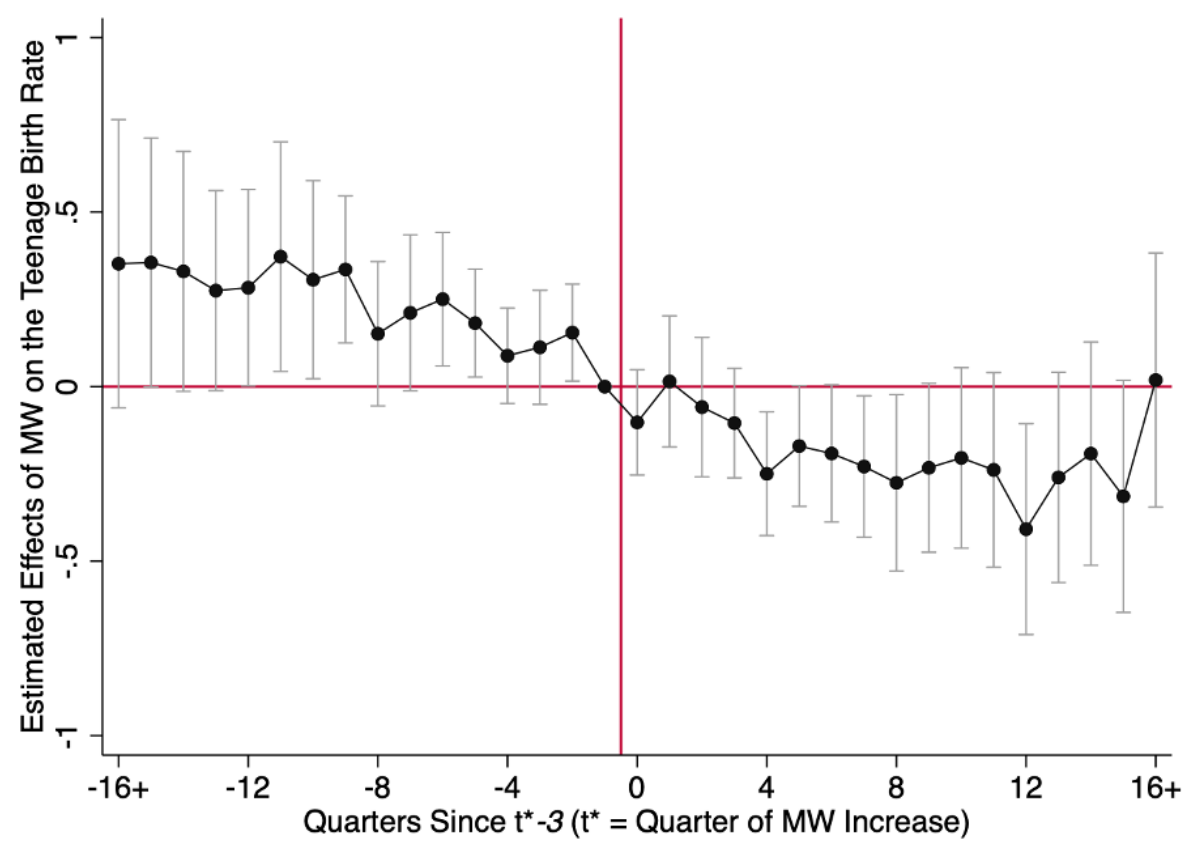

Notes: Population weighted OLS estimates (and their 95\% CIs) from the event study regression model described in equation (2) are shown. Data are at the state-year-quarter level and cover the period 2003Q42014Q4. Following Bullinger (2017), event-quarter 0 corresponds to $t-3$. Regressions used to generate the OLS estimates include controls for state fixed effects, year-by-quarter fixed effects, and either baseline controls (Panel A) or our preferred controls (Panel B), each of which are listed in Appendix Table 1. 


\section{Figure 3. Dynamic Effects of Minimum Wages on Teenage Fertility, 2003-2019}

Panel A. Using Baseline Controls

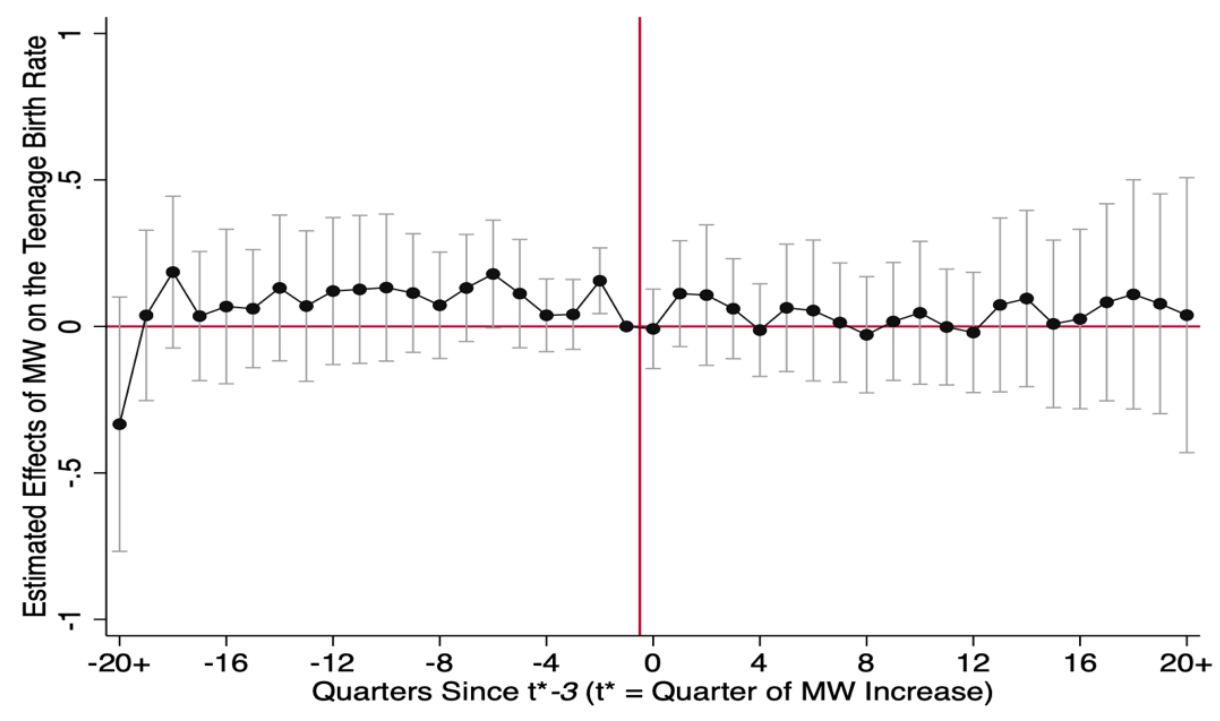

Panel B. Using Our Preferred Controls

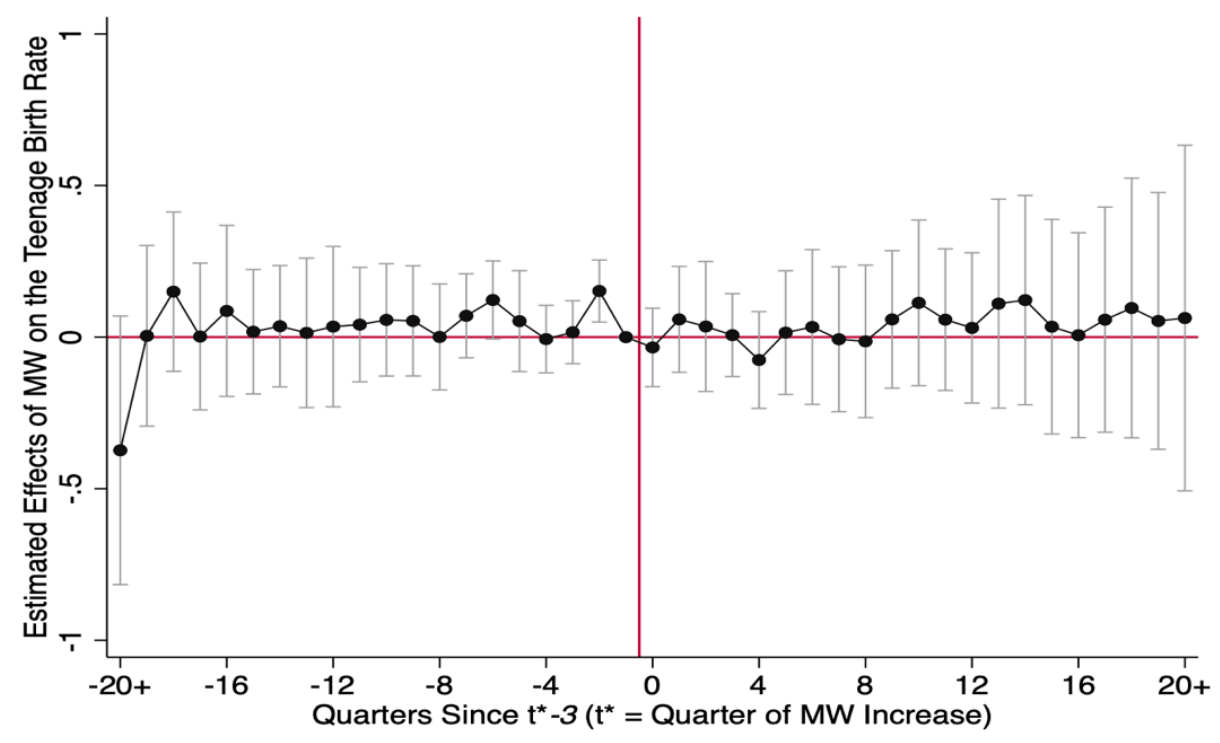

Notes: Population weighted OLS estimates (and their 95\% CIs) from the event study regression model described in equation (3) are shown. Data are at the state-year-quarter level and cover the period 2003Q42019Q4. Following Bullinger (2017), event-quarter 0 corresponds to $t$-3. Regressions used to generate the OLS estimates include controls for state fixed effects, year-by-quarter fixed effects, and either baseline controls (Panel A) or our preferred controls (Panel B), each of which are listed in Appendix Table 1. 
Figure 4. Prominent Minimum Wage Increases and the Teenage Fertility Rate: Event Study Estimates

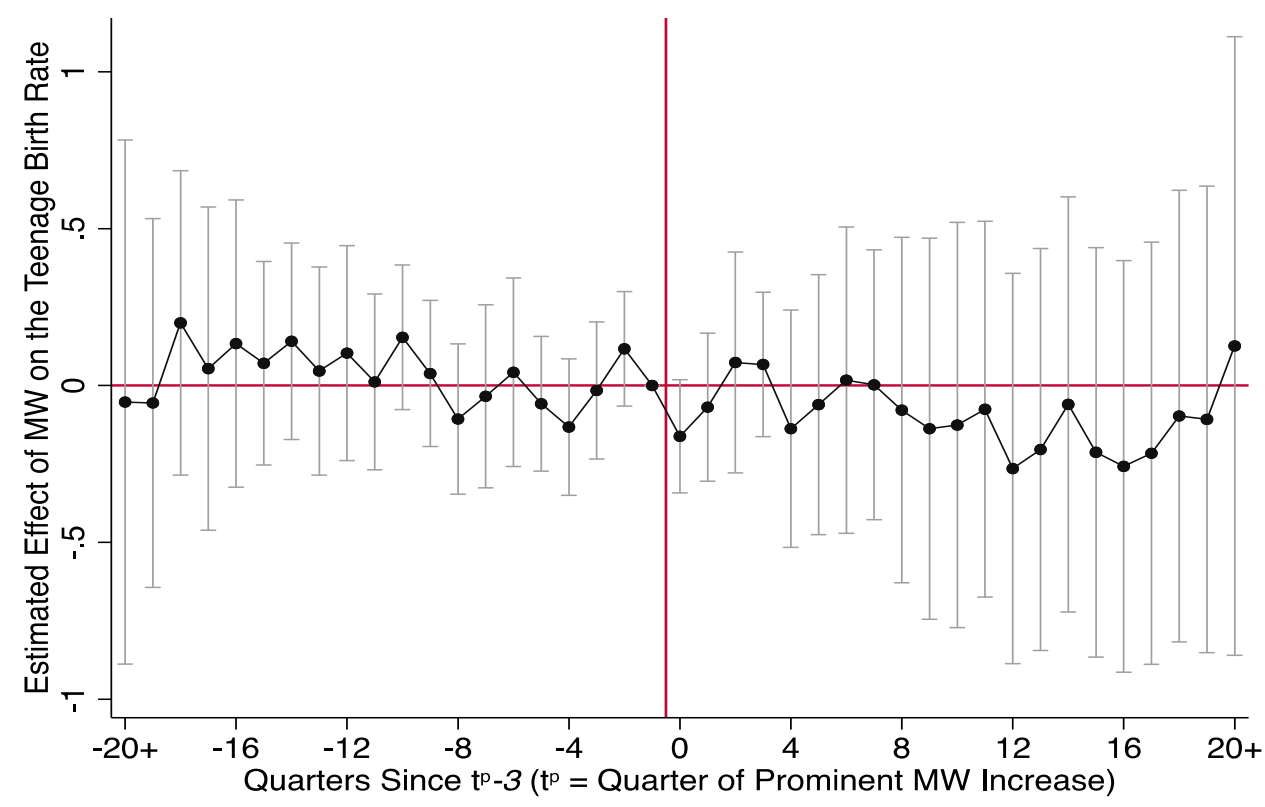

Notes: Population weighted OLS estimates (and their 95\% CIs) are shown above. A prominent minimum wage increase occurs when the state minimum wage rises by at least $\$ 1$ (in 2014\$s) over any four-quarter (one year) period. Data are at the state-year-quarter level and cover the period 2003Q4-2019Q4. Following Bullinger (2017), event-quarter 0 corresponds to $t-3$. Controls used to generate the estimates are our preferred controls, which are listed in Appendix Table 1. 


\section{Figure 5. Prominent Minimum Wage Increases and the Teenage Fertility Rate: Using Callaway-Sant'Anna Estimates, 2003-2019}

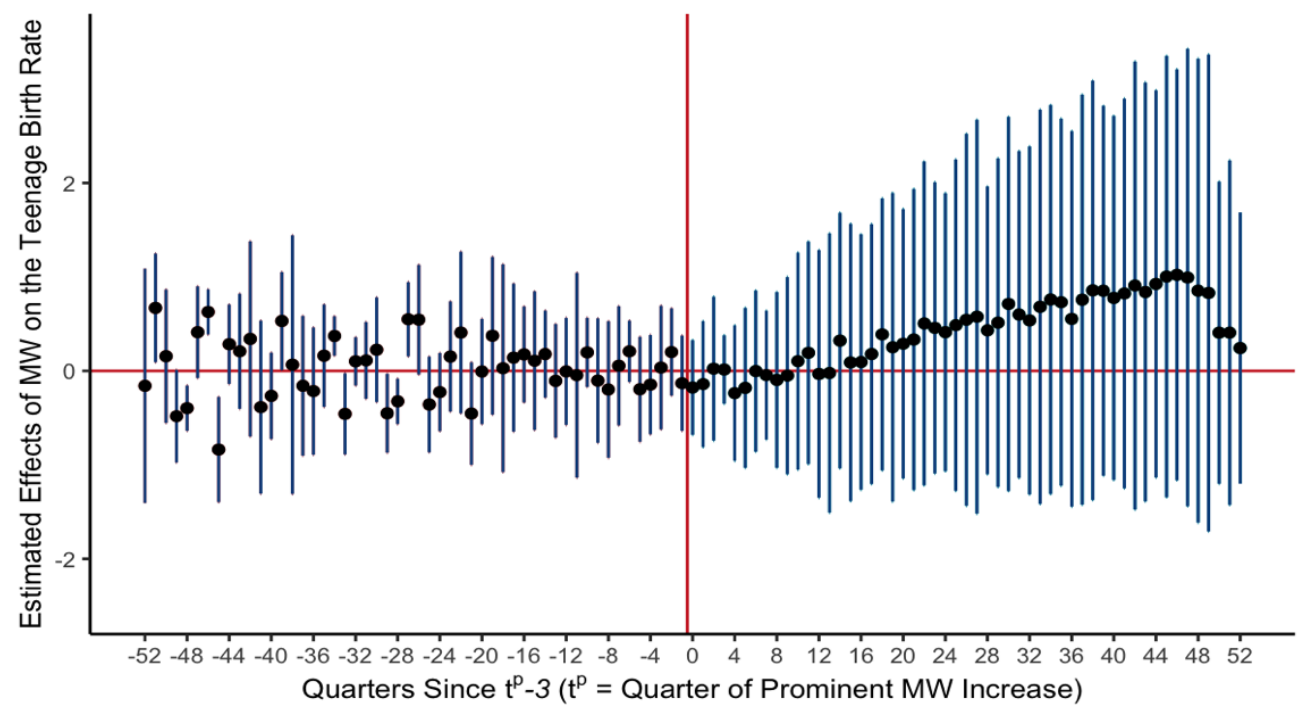

Notes: Callaway-Sant'Anna (2021) estimates (and their 95\% CIs) are shown above. A prominent minimum wage increase occurs when the state minimum wage rises by at least $\$ 1$ (in 2014\$s) over any four-quarter (one year) period. Data are at the state-year-quarter level and cover the period 2003Q4-2019Q4. Following Bullinger (2017), event-quarter 0 corresponds to $t-3$. The counterfactuals used for the Callaway-Sant'Anna estimates consist of those states that did not experience a $\$ 1$ minimum wage increase (in 2014\$s) over a four-quarter period (never adopters). Controls used to generate the Callaway-Sant'Anna estimates include the house price index and the prime-age (ages 25-54) unemployment rate. 


\section{Figure 6. Dynamic Effects of Minimum Wages on Teenage Pregnancy and Abortion Rates: Event Study Estimates}

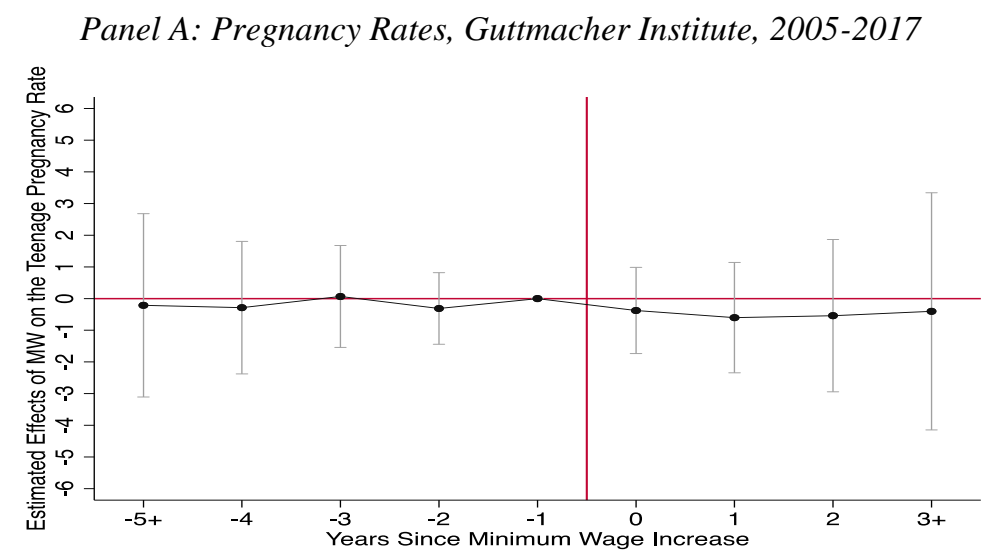

Panel B: Abortion Rates, Guttmacher Institute, 2005-2017

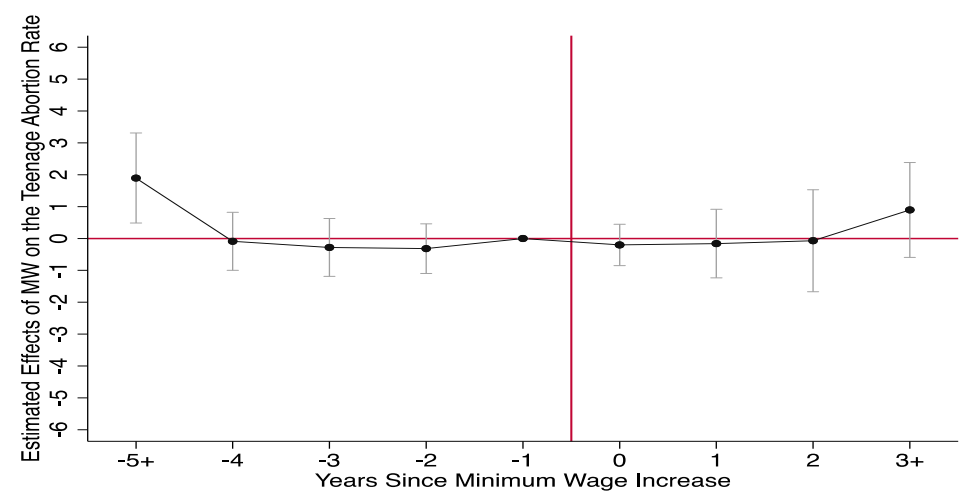

Panel C: Abortion Rates, CDC, 2003-2018

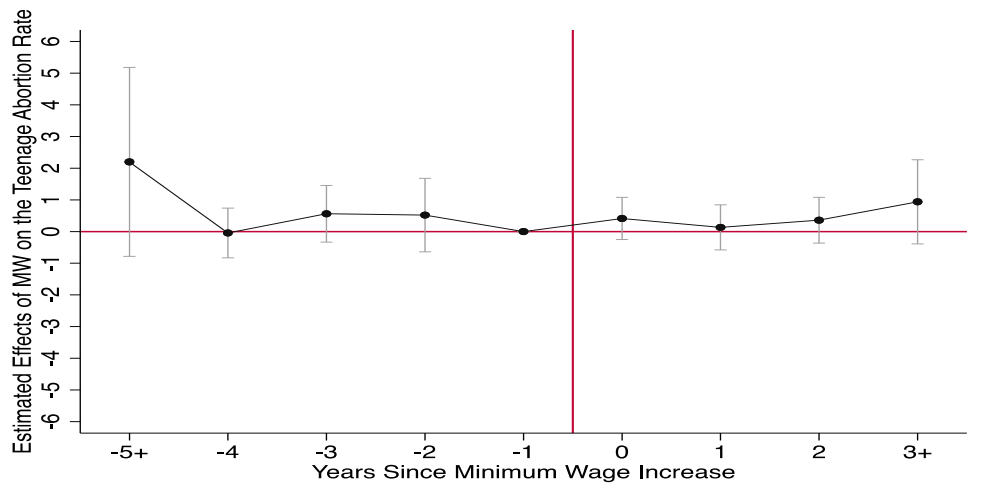

Notes: Population weighted OLS estimates (and their 95\% CIs) from an event study regression model are shown. Data are at the annual year level and cover the period 2005-2017 (Panels A and B) and 2003-2018 (Panel C). Regressions used to generate the OLS estimates include controls for state fixed effects, year fixed effects, and our preferred controls, each of which are listed in Appendix Table 1. 

Figure 7. Prominent Minimum Wage Increases, the Teenage Pregnancy Rate,
and the Teenage Abortion Rate: Using Callaway-Sant'Anna Estimates

Panel A: Pregnancy Rates, Guttmacher Institute, 2005-2017

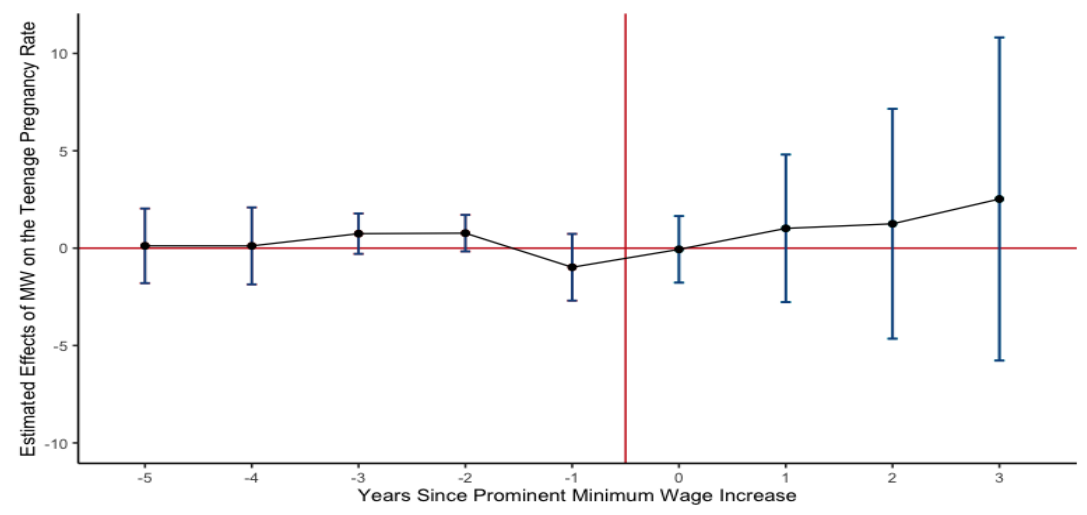

Panel B: Abortion Rates, Guttmacher Institute, 2005-2017

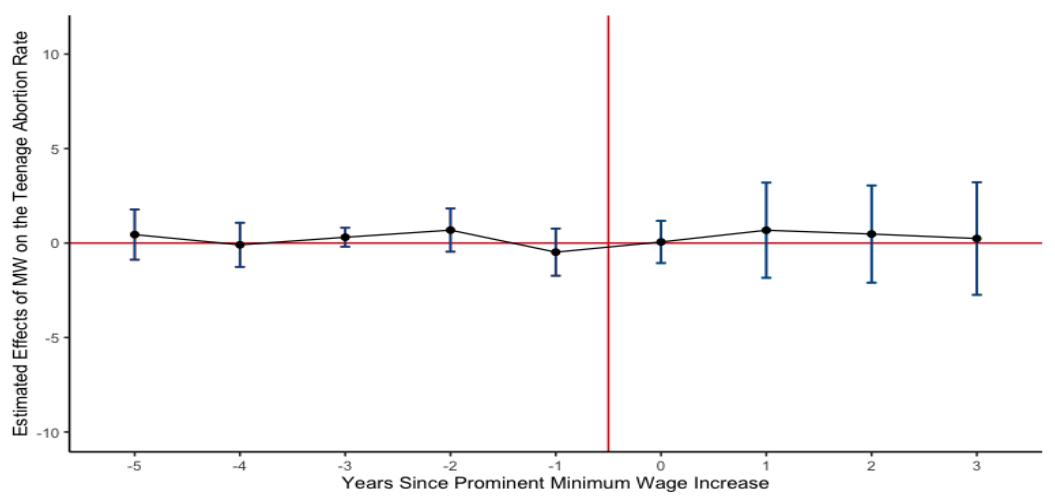

Panel C: Abortion Rates, CDC, 2003-2018

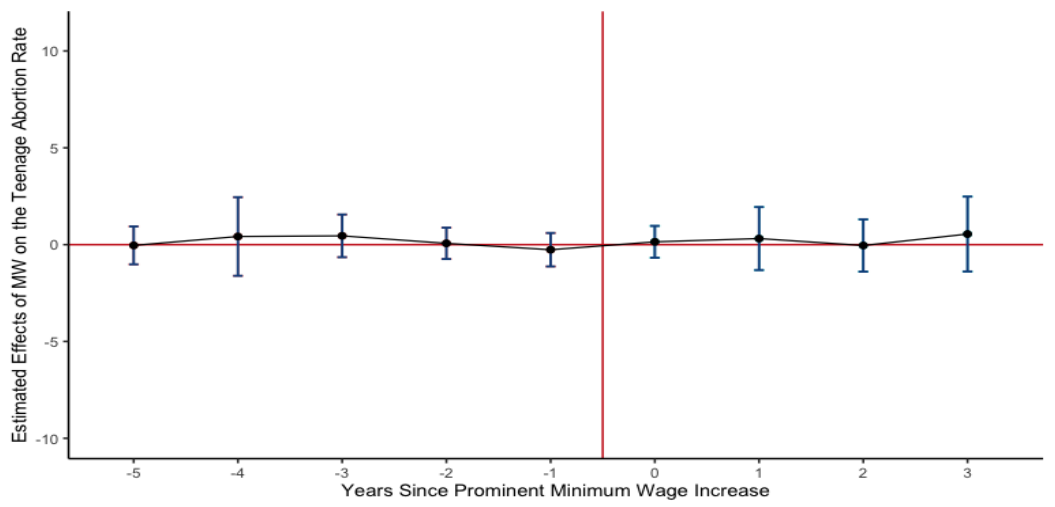

Notes: Callaway-Sant'Anna (2021) estimates (and their 95\% CIs) are shown above. A prominent minimum wage increase occurs when the state minimum wage rises by at least $\$ 1$ (in $2014 \$$ s) over a calendar year. Data are at the annual level. Panels A and B cover the period 2005-2017, and panel C covers the period 2003-2018. The counterfactuals used for the Callaway-Sant'Anna estimates consist of those states that did not experience a $\$ 1$ minimum wage increase (in $2014 \$$ s) over a calendar year (never adopters). Control variables used for the models include the house price index and the prime-age (ages 25-54) unemployment rate. 


\section{Table 1. Minimum Wages and the Teenage Fertility Rate, 2003Q4-2014Q4}

\begin{tabular}{lccc}
\hline & $\mathbf{( 1 )}$ & $\mathbf{( 2 )}$ & $\mathbf{( 3 )}$ \\
\hline Minimum Wage $(2014 \$ \mathrm{~s})$ & $-0.339^{* *}$ & $-0.402^{* * *}$ & $-0.409^{* * *}$ \\
& $(0.148)$ & $(0.106)$ & $(0.128)$ \\
\hline State and year-by-quarter FEs & Yes & Yes & Yes \\
\hline Baseline controls & No & Yes & No \\
\hline Preferred controls & No & No & Yes \\
\hline Mean of dependent variable & 8.967 & 8.967 & 8.967 \\
\hline $\mathrm{N}$ & 2,142 & 2,142 & 2,142 \\
\hline
\end{tabular}

*** Statistically significant at the $1 \%$ level; **at the $5 \%$ level; *at the $10 \%$ level.

Notes: Population weighted OLS estimates of the association between minimum wages and the fertility of female 15through 19-year-olds are reported. The data are at the state-quarter level and cover the period 2003Q4-2014Q4. Standard errors, reported in parentheses, are corrected for clustering at the state level. Baseline controls are identical to those used by Bullinger (2017): demographic controls are the proportion of adolescents (ages 16-19 years) who were non-Hispanic White, non-Hispanic Black, and Hispanic, the proportion who graduated from high school, the proportion who were 17 years of age, 18 years of age, and 19 years of age, the proportion who were married, the proportion who were cohabitating, and the proportion living in a metropolitan area. Her other controls are the maximum combined Temporary Assistance for Needy Families and Supplemental Nutrition Assistance Program payment for a family of three, the state Earned Income Tax Credit (EITC) rate, an indicator for whether the EITC was refundable, the unemployment rate, and separate indicators for whether the state had a Medicaid family planning expansion waiver, a parental notification abortion restriction, or a contraceptive insurance coverage mandate. Our preferred controls include those listed above except those that might capture mechanisms through which the minimum wage might affect teen fertility (the proportion who graduated from high school, the proportion who were married, the proportion who were cohabitating, and the unemployment rate). We also included additional controls for the prime-age (ages 25-54) unemployment rate, the prime-age wage rate $(2014 \$ s)$, the house price index, and an indicator variable for whether the state had comprehensive sex education. 


\section{Table 2. Minimum Wages and the Teenage Fertility Rate, 2003Q4-2019Q4}

\begin{tabular}{lccc}
\hline & $\mathbf{( 1 )}$ & $\mathbf{( 2 )}$ & $\mathbf{( 3 )}$ \\
\hline & 0.044 & 0.039 & 0.085 \\
Minimum Wage $(2014 \$ \mathbf{s})$ & $(0.129)$ & $(0.143)$ & $(0.175)$ \\
& & Yes & Yes \\
\hline State and year-by-quarter FEs & Yes & Yes & No \\
\hline Baseline controls & No & No & Yes \\
\hline Preferred controls & No & 7.539 & 7.539 \\
\hline Mean of dependent variable & 7.539 & 3,315 & 3,315 \\
\hline $\mathrm{N}$ & 3,315 & & \\
\hline
\end{tabular}

$* * *$ Statistically significant at the $1 \%$ level; **at the $5 \%$ level; *at the $10 \%$ level.

Notes: Population weighted OLS estimates of the association between minimum wages and the fertility of female 15through 19-year-olds are reported. The data are at the state-quarter level and cover the period 2003Q4-2019Q4. Standard errors, reported in parentheses, are corrected for clustering at the state level. Baseline controls are identical to those of Bullinger (2017): demographic controls are the proportion of adolescents (ages 16-19 years) who were non-Hispanic White, non-Hispanic Black, and Hispanic, the proportion who graduated from high school, the proportion who were 17 years of age, 18 years of age, and 19 years of age, the proportion who were married, the proportion who were cohabitating, and the proportion living in a metropolitan area. Her other controls are the maximum combined Temporary Assistance for Needy Families and Supplemental Nutrition Assistance Program payment for a family of three, the state Earned Income Tax Credit (EITC) rate, an indicator for whether the EITC was refundable, the unemployment rate, and separate indicators for whether the state had a Medicaid family planning expansion waiver, a parental notification abortion restriction, or a contraceptive insurance coverage mandate. Our preferred controls include those listed above except those that might capture mechanisms through which the minimum wage might affect teen fertility (the proportion who graduated from high school, the proportion who were married, the proportion who were cohabitating, and the unemployment rate). We also included additional controls for the prime-age (ages 25-54) unemployment rate, the prime-age wage rate $(2014 \$ s)$, the house price index, and an indicator variable for whether the state had comprehensive sex education. 


\section{Table 3. Minimum Wages and the Teenage Fertility Rate by Race and Ethnicity, 2003Q4-2019Q4}

(1)
(2)

(3)

Panel A. Black TFR

\begin{tabular}{lccc}
\hline Minimum Wage $(2014 \$ \mathrm{~s})$ & 0.085 & -0.015 & 0.032 \\
& $(0.094)$ & $(0.140)$ & $(0.134)$ \\
\hline Mean of dependent variable & 11.329 & 11.329 & 11.329 \\
\hline
\end{tabular}

Panel B. Hispanic TFR

\begin{tabular}{lccc} 
Minimum Wage $(2014 \$ \mathrm{~s})$ & -0.038 & -0.254 & -0.094 \\
& $(0.296)$ & $(0.332)$ & $(0.347)$ \\
\hline Mean of dependent variable & 12.309 & 12.309 & 12.309 \\
\hline
\end{tabular}

Panel C. Non-Hispanic White TFR

\begin{tabular}{lccc}
\hline Minimum Wage (2014\$s) & $0.148^{* *}$ & 0.099 & 0.128 \\
& $(0.071)$ & $(0.083)$ & $(0.089)$ \\
\hline Mean of dependent variable & 5.176 & 5.176 & 5.176 \\
\hline & & & Yes \\
\hline State and year-by-quarter FEs & Yes & Yes & No \\
\hline Baseline controls & No & No & Yes \\
\hline Preferred controls & No & 3,315 & 3,315 \\
\hline $\mathrm{N}$ & 3,315 & & \\
\hline
\end{tabular}

***Statistically significant at the $1 \%$ level; **at the $5 \%$ level; *at the $10 \%$ level.

Notes: Population weighted OLS estimates of the association between minimum wages and the fertility of female 15through 19-year-olds are reported. The data are at the state-quarter level and cover the period 2003Q4-2019Q4. Standard errors, reported in parentheses, are corrected for clustering at the state level. Baseline demographic controls are the proportion of adolescents (ages 16-19 years) who were non-Hispanic White, non-Hispanic Black, and Hispanic, the proportion who graduated from high school, the proportion who were 17 years of age, 18 years of age, and 19 years of age, the proportion who were married, the proportion who were cohabitating, and the proportion living in a metropolitan area. Her other controls are the maximum combined Temporary Assistance for Needy Families and Supplemental Nutrition Assistance Program payment for a family of three, the state Earned Income Tax Credit (EITC) rate, an indicator for whether the EITC was refundable, the unemployment rate, and separate indicators for whether the state had a Medicaid family planning expansion waiver, a parental notification abortion restriction, or a contraceptive insurance coverage mandate. Our preferred controls include those listed above except those that might capture mechanisms through which the minimum wage might affect teen fertility (the proportion who graduated from high school, the proportion who were married, the proportion who were cohabitating, and the unemployment rate). We also included additional controls for the prime-age (ages $25-54)$ unemployment rate, the prime-age wage rate (2014\$s), the house price index, and an indicator variable for whether the state had comprehensive sex education. 


\section{Table 4. Minimum Wages and Teenage Fertility by the Marital Status of Mother, 2003Q4-2019Q4}

(1)

(2)

(3)

Panel A. Married 15- through 19-Year-Olds

\begin{tabular}{lccc}
\hline Minimum Wage (2014\$s) & 0.071 & 0.056 & $0.088^{*}$ \\
& $(0.043)$ & $(0.039)$ & $(0.048)$ \\
\hline Mean of dependent variable & 1.019 & 1.019 & 1.019 \\
\hline
\end{tabular}

Panel B. Unmarried 15- through 19-Year-Olds

\begin{tabular}{lccc}
\hline Minimum Wage (2014\$s) & 0.022 & 0.004 & 0.013 \\
& $(0.105)$ & $(0.113)$ & $(0.133)$ \\
\hline Mean of dependent variable & 6.677 & 6.677 & 6.677 \\
\hline & & Yes & Yes \\
\hline State and year-by-quarter FEs & Yes & Yes & No \\
\hline Baseline controls & No & No & Yes \\
\hline Preferred controls & 3,303 & 3,303 & 3,303 \\
\hline N & &
\end{tabular}

Notes: Population weighted OLS estimates of the association between minimum wages and the marital status-specific fertility of female 15- through 19-year-olds are reported. The data are at the state-quarter level and cover the period 2003Q4-2019Q4. Standard errors, reported in parentheses, are corrected for clustering at the state level. Baseline demographic controls are the proportion of adolescents (ages 16-19 years) who were non-Hispanic White, non-Hispanic Black, and Hispanic, the proportion who graduated from high school, the proportion who were 17 years of age, 18 years of age, and 19 years of age, the proportion who were married, the proportion who were cohabitating, and the proportion living in a metropolitan area. Her other controls are the maximum combined Temporary Assistance for Needy Families and Supplemental Nutrition Assistance Program payment for a family of three, the state Earned Income Tax Credit (EITC) rate, an indicator for whether the EITC was refundable, the unemployment rate, and separate indicators for whether the state had a Medicaid family planning expansion waiver, a parental notification abortion restriction, or a contraceptive insurance coverage mandate. Our preferred controls include those listed above except those that might capture mechanisms through which the minimum wage might affect teen fertility (the proportion who graduated from high school, the proportion who were married, the proportion who were cohabitating, and the unemployment rate). We also included additional controls for the prime-age (ages 25-54) unemployment rate, the prime-age wage rate (2014\$s), the house price index, and an indicator variable for whether the state had comprehensive sex education. 
Table 5. Prominent Minimum Wage Increases and Fertility Rates among 15- through 19-Year-Olds, 2003-2019

\begin{tabular}{|c|c|c|c|c|c|c|}
\hline & \multicolumn{3}{|c|}{ DD Estimates } & \multicolumn{3}{|c|}{ Callaway-Sant'Anna Estimates } \\
\hline & (1) & (2) & (3) & (4) & (5) & (6) \\
\hline \$1 Minimum Wage $(2014 \$ s)$ & $\begin{array}{l}-0.002 \\
(0.351)\end{array}$ & $\begin{array}{l}-0.036 \\
(0.298) \\
\end{array}$ & $\begin{array}{c}-0.108 \\
(0.350)\end{array}$ & $\begin{array}{c}0.307 \\
(0.514)\end{array}$ & $\begin{array}{c}0.392 \\
(0.374)\end{array}$ & $\begin{array}{c}0.164 \\
(0.318)\end{array}$ \\
\hline State and year-by-quarter FEs & Yes & Yes & Yes & Yes & Yes & Yes \\
\hline Preferred Controls & No & Yes & No & No & No & No \\
\hline Limited Macroeconomic Controls & No & Yes & No & No & Yes & No \\
\hline “Small” MW Increase Controls & No & No & Yes & No & No & Yes \\
\hline Mean of dependent variable & 7.539 & 7.539 & 7.539 & 7.539 & 7.539 & 7.539 \\
\hline $\mathrm{N}$ & 3,315 & 3,315 & 3,315 & 3,315 & 3,315 & 3,315 \\
\hline
\end{tabular}

Notes: Population weighted OLS estimates of the association between minimum wages and the fertility of female 15- through 19-year-olds are reported. The data are at the state-year-quarter level and cover the period 2003Q4-2019Q4. Standard errors, reported in parentheses, are corrected for clustering at the state level. Our preferred controls include the proportion of adolescents (ages 16-19) who were non-Hispanic White, non-Hispanic Black, and Hispanic, the proportion who graduated from high school, the proportion who were 17 years of age, 18 years of age, and 19 years of age, the proportion living in a metropolitan area, the maximum combined Temporary Assistance for Needy Families and Supplemental Nutrition Assistance Program payment for a family of three, the state Earned Income Tax Credit (EITC) rate, an indicator for whether the EITC was refundable, the prime-age (ages 25-54) unemployment rate, the prime-age real wage rate, the house price index, and separate indicators for whether the state had a Medicaid family planning expansion waiver, a parental notification abortion restriction, or a contraceptive insurance coverage mandate. Limited macroeconomic controls include the prime-age unemployment rate and the house price index. "Small" MW Increase controls include an indicator for whether a minimum wage increase between $\$ 0.50$ and $\$ 0.99$ occurred. 


\section{Table 6. Minimum Wages and Marriage Rates among Female 15- through 19- Year-Olds: Based on Data from the Current Population Survey, 2003-2019}

\begin{tabular}{lccc}
\hline & $\mathbf{( 1 )}$ & $\mathbf{( 2 )}$ & $\mathbf{( 3 )}$ \\
\hline Minimum Wage (2014\$s) & 0.555 & 1.229 & 0.970 \\
& $(0.924)$ & $(0.924)$ & $(0.803)$ \\
\hline State and Year FE? & & & Yes \\
\hline Baseline Controls? & Yes & Yes & No \\
\hline Preferred Controls? & No & No & Yes \\
\hline Mean of dependent variable & No & 16.162 & 16.162 \\
\hline $\mathrm{N}$ & 16.162 & 867 & 867 \\
\hline
\end{tabular}

$* * *$ Significant at $1 \%$ level **at $5 \%$ level *at $10 \%$ level

Notes: Population weighted OLS estimates of the association between minimum wages and the marriage rates of females 15- through 19-year-olds are reported. The data are at the state-quarter level and cover the period 2003Q4-2019Q4. Standard errors, reported in parentheses, are corrected for clustering at the state level. Baseline demographic controls are the proportion of adolescents (ages 16-19 years) who were non-Hispanic White, non-Hispanic Black, and Hispanic, the proportion who graduated from high school, the proportion who were 17 years of age, 18 years of age, and 19 years of age, the proportion who were cohabitating, and the proportion living in a metropolitan area. Her other controls are the maximum combined Temporary Assistance for Needy Families and Supplemental Nutrition Assistance Program payment for a family of three, the state Earned Income Tax Credit (EITC) rate, an indicator for whether the EITC was refundable, and separate indicators for whether the state had a Medicaid family planning expansion waiver, a parental notification abortion restriction, or a contraceptive insurance coverage mandate. Our preferred controls include those listed above except those that might capture mechanisms through which the minimum wage might affect teen fertility (the proportion who graduated from high school, the proportion who were married, the proportion who were cohabitating, and the unemployment rate). We also included additional controls for the prime-age (ages 25-54) unemployment rate, the primeage wage rate $(2014 \$ s)$, and additional state-level controls. 
Table 7. Minimum Wages and the Sexual Behavior of Female 15- through 19-Year-Olds, 2003-2019

(1)

Ever Sex Active

\section{(2)}

Current Sex

Active

\section{(3)}

Number of

Partners $\mid$ Sex

\section{(4)}

Unprotected Sex
(5)

Birth Control

Current Sex

\section{(6)}

Condom

Current Sex
(7)

Pill | Current

Sex

\section{Panel A. State YRBS}

\begin{tabular}{lccccccc}
\hline Minimum Wage (2014\$s) & -0.014 & 0.004 & 0.003 & 0.001 & -0.004 & -0.007 & 0.006 \\
& $(0.018)$ & $(0.003)$ & $(0.014)$ & $(0.002)$ & $(0.007)$ & $(0.006)$ & $(0.004)$ \\
\hline Mean of dependent variable & 0.539 & 0.344 & 2.459 & 0.088 & 0.721 & 0.412 & 0.228 \\
\hline $\mathrm{N}$ & 524,168 & 446,399 & 186,892 & 441,559 & 142,284 & 145,100 & 138,914 \\
\hline
\end{tabular}

Panel B. National YRBS

\begin{tabular}{|c|c|c|c|c|c|c|c|}
\hline Minimum Wage (2014\$s) & $\begin{array}{l}-0.009 \\
(0.011)\end{array}$ & $\begin{array}{l}-0.001 \\
(0.009)\end{array}$ & $\begin{array}{c}0.027 \\
(0.032)\end{array}$ & $\begin{array}{c}0.001 \\
(0.005)\end{array}$ & $\begin{array}{l}-0.003 \\
(0.011)\end{array}$ & $\begin{array}{c}0.001 \\
(0.0159)\end{array}$ & $\begin{array}{l}-0.003 \\
(0.011)\end{array}$ \\
\hline Mean of dependent variable & 0.504 & 0.359 & 2.515 & 0.101 & 0.716 & 0.420 & 0.225 \\
\hline $\mathrm{N}$ & 57,177 & 52,682 & 25,450 & 52,005 & 19,258 & 19,366 & 18,953 \\
\hline
\end{tabular}

$* * *$ Significant at $1 \%$ level $* *$ at $5 \%$ level $*$ at $10 \%$ level

Notes: Population weighted OLS estimates of the association between minimum wages and sexual behaviors of females 15 - through $18+$-year-olds are reported. The data are biannual and are obtained from the State and National Youth Risk Behavior Surveys from 2003-2019. Standard errors, reported in parentheses, are corrected for clustering at the state level. Ever Sex Active is an indicator for whether the respondent has ever engaged in sexual intercourse, Current Sex Active is an indicator for whether the respondent has engaged in sexual intercourse in the last three months, Number of Partners | Sex measures the lifetime number of sexual partners for sexually active respondents, Unprotected Sex is an indicator for whether the respondent has engaged in sexual intercourse in the last three months and did not use any form of contraception, defined as birth control pills, condoms, IUDs, implants, shots, or rings, during the last time they engaged in sexual intercourse, Birth Control | Current Sex is an indicator for if a respondent used any aforementioned contraception method during the last time they engaged in sexual intercourse, conditionally on being sexually active, Condom | Current Sex is an indicator for whether the respondent condoms during the last time they engaged in sexual intercourse, conditional on being sexually active, Pill $\mid$ Current Sex is an indicator for whether the used birth control pills during the last time they engaged in sexual intercourse, conditional on being sexually active. All models include controls for state fixed effects, wave fixed effects, and individual indicators for race/ethnicity, gender, grade, and age. All models also include our preferred state-specific time-varying policy controls, including the maximum combined Temporary Assistance for Needy Families and Supplemental Nutrition Assistance Program payment for a family of three, the state Earned Income Tax Credit (EITC) rate, an indicator for whether the EITC was refundable, the prime-age (ages 25-54) unemployment rate, the prime-age real wage rate, the house price index, and separate indicators for whether the state had a Medicaid family planning expansion waiver, a parental notification abortion restriction, required sexual education, or a contraceptive insurance coverage mandate. 
Table 8. Minimum Wages and the Sexual Behavior of Female 15- through 19-Year-Olds by Race and Ethnicity

(1)

Ever Sex Active
(2)

Current Sex Active
(3)

Number of

Partners | Sex

\section{(4)}

\section{(5)}

Unprotected Sex

Birth Control

Current Sex

\section{(6)}

Condom

Current Sex
(7)

Pill $\mid$ Current

Sex

Panel A. Black Students

\begin{tabular}{lccccccc}
\hline Minimum Wage (2014\$s) & -0.028 & $0.012^{*}$ & -0.030 & 0.0019 & -0.008 & -0.003 & -0.001 \\
& $(0.024)$ & $(0.0064)$ & $(0.036)$ & $(0.003)$ & $(0.009)$ & $(0.015)$ & $(0.017)$ \\
\hline Mean of dependent variable & 0.650 & 0.378 & 2.692 & 0.105 & 0.681 & 0.467 & 0.111 \\
\hline $\mathrm{N}$ & 71,951 & 54,721 & 25,319 & 53,760 & 17,481 & 17,897 \\
\hline
\end{tabular}

Panel B. Hispanic Students

\begin{tabular}{|c|c|c|c|c|c|c|c|}
\hline Minimum Wage (2014\$s) & $\begin{array}{c}0.0049 \\
(0.0129)\end{array}$ & $\begin{array}{c}0.006 \\
(0.005)\end{array}$ & $\begin{array}{c}0.001 \\
(0.028)\end{array}$ & $\begin{array}{c}0.006 * * \\
(0.003)\end{array}$ & $\begin{array}{l}-0.008 \\
(0.010)\end{array}$ & $\begin{array}{c}-0.036 * * * \\
(0.010)\end{array}$ & $\begin{array}{c}0.028^{* *} \\
(0.011)\end{array}$ \\
\hline Mean of dependent variable & 0.520 & 0.328 & 2.222 & 0.111 & 0.625 & 0.417 & 0.131 \\
\hline $\mathrm{N}$ & 79,562 & 66,903 & 29,695 & 65,855 & 21,481 & 21,937 & 21,109 \\
\hline
\end{tabular}

Panel C. Non-Hispanic White Students

\begin{tabular}{|c|c|c|c|c|c|c|c|}
\hline Minimum Wage (2014\$s) & -0.022 & -0.002 & 0.002 & $1.05 \mathrm{e}-05$ & -0.008 & -0.005 & 0.001 \\
\hline & $(0.019)$ & $(0.003)$ & $(0.016)$ & $(0.003)$ & $(0.007)$ & $(0.009)$ & $(0.005)$ \\
\hline Mean of dependent variable & 0.520 & 0.348 & 2.455 & 0.073 & 0.771 & 0.399 & 0.297 \\
\hline $\mathrm{N}$ & 291,128 & 260,271 & 106,975 & 257,298 & 85,392 & 87,019 & 83,306 \\
\hline
\end{tabular}

***Significant at $1 \%$ level **at $5 \%$ level *at $10 \%$ level

Notes: Population weighted OLS estimates of the association between minimum wages and sexual behaviors of females 15 - through $18+$-year-olds are reported. The data are biannual and are obtained from the State and National Youth Risk Behavior Surveys from 2003-2019. Standard errors, reported in parentheses, are corrected for clustering at the state level. Ever Sex Active is an indicator for whether the respondent has ever engaged in sexual intercourse, Current Sex Active is an indicator for whether the respondent has engaged in sexual intercourse in the last three months, Number of Partners $\mid$ Sex measures the lifetime number of sexual partners for sexually active respondents, Unprotected Sex is an indicator for whether the respondent has engaged in sexual intercourse in the last three months and did not use any form of contraception, defined as birth control pills, condoms, IUDs, implants, shots, or rings, during the last time they engaged in sexual intercourse, Birth Control | Current Sex is an indicator for if a respondent used any aforementioned contraception method during the last time they engaged in sexual intercourse, conditionally on being sexually active, Condom | Current Sex is an indicator for whether the respondent condoms during the last time they engaged in sexual intercourse, conditional on being sexually active, Pill $\mid$ Current Sex is an indicator for whether the used birth control pills during the last time they engaged in sexual intercourse, conditional on being sexually active. All models include controls for state fixed effects, wave fixed effects, and individual indicators for race/ethnicity, gender, grade, and age. All models also include our preferred state-specific time-varying policy controls, listed in the notes to Table 7. 


\section{Table 9. Minimum Wages, Teenage Abortion Rates and Teenage Pregnancy Rates, 2003-2018}

Panel A. Teenage Pregnancy Rate, 2005-2017

\begin{tabular}{lccc}
\hline Minimum Wage (2014\$s) & -0.307 & 0.111 & -0.290 \\
& $(0.569)$ & $(0.701)$ & $(0.833)$ \\
\hline Mean of dependent variable & 52.796 & 52.796 & 52.796 \\
\hline $\mathrm{N}$ & 663 & 663 & 663 \\
\hline
\end{tabular}

Panel B. Teenage Abortion Rate, by State of Residence, 2005-2017

\begin{tabular}{lccc}
\hline Minimum Wage (2014\$s) & -0.093 & 0.240 & -0.113 \\
& $(0.232)$ & $(0.398)$ & $(0.412)$ \\
\hline Mean of dependent variable & 13.661 & 13.661 & 13.661 \\
\hline $\mathrm{N}$ & 663 & 663 & 663 \\
\hline
\end{tabular}

Panel C. Teenage Abortion Rate, by State of Occurrence, 2003-2018

\begin{tabular}{lccc}
\hline Minimum Wage (2014\$s) & -0.356 & -0.307 & -0.422 \\
& $(0.423)$ & $(0.399)$ & $(0.472)$ \\
\hline Mean of dependent variable & 11.029 & 11.029 & 11.029 \\
\hline $\mathrm{N}$ & 679 & 679 & 679 \\
\hline$* * *$ Statistically significant at the $1 \%$ level; $* *$ at the $5 \%$ level; $*$ at the $10 \%$ level. &
\end{tabular}

Notes: Population weighted OLS estimates of the association between minimum wages and the abortion or pregnancy rate of female 15- through 19-year-olds are reported. The data are at the state-year level. Teenage pregnancy and abortion data (Panels A and B) are provided by the Guttmacher Institute from 2005-2017. Teen abortion data by state of occurrence (Panel C) are provided by the Centers for Disease Control and Prevention from 2003-2018. Standard errors, reported in parentheses, are corrected for clustering at the state level. Our preferred controls include the proportion of adolescents (ages 16-19) who were non-Hispanic White, non-Hispanic Black, and Hispanic, the proportion who were 17 years of age, 18 years of age, and 19 years of age, and the proportion living in a metropolitan area. Other preferred controls are the maximum combined Temporary Assistance for Needy Families and Supplemental Nutrition Assistance Program payment for a family of three, the state Earned Income Tax Credit (EITC) rate, an indicator for whether the EITC rate was refundable, the prime-age (ages 25-54) unemployment rate, the prime-age wage rate (2014\$s), the house price index, and separate indicators for whether the state had a Medicaid family planning expansion waiver, a parental notification abortion restriction, a contraceptive insurance coverage mandate, and if a state had required comprehensive sex education. 


\section{Appendix Figure 1A. Dynamic Effects of Minimum Wages on Teenage Fertility, 2003-2019, by Race/Ethnicity}

Panel A. Overall Teen Fertility Rate

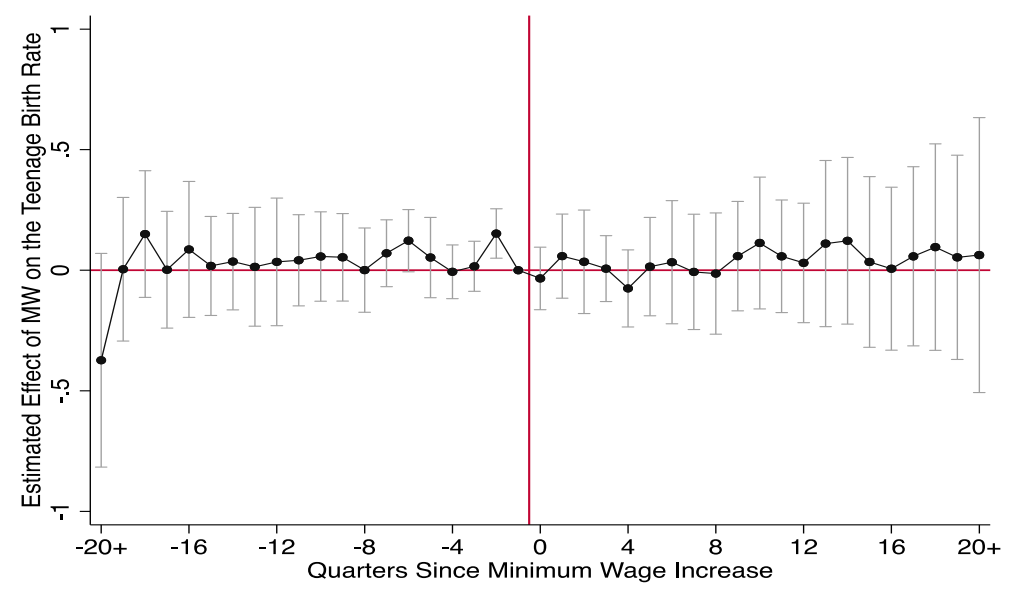

Panel C. Hispanic Teen Fertility Rate

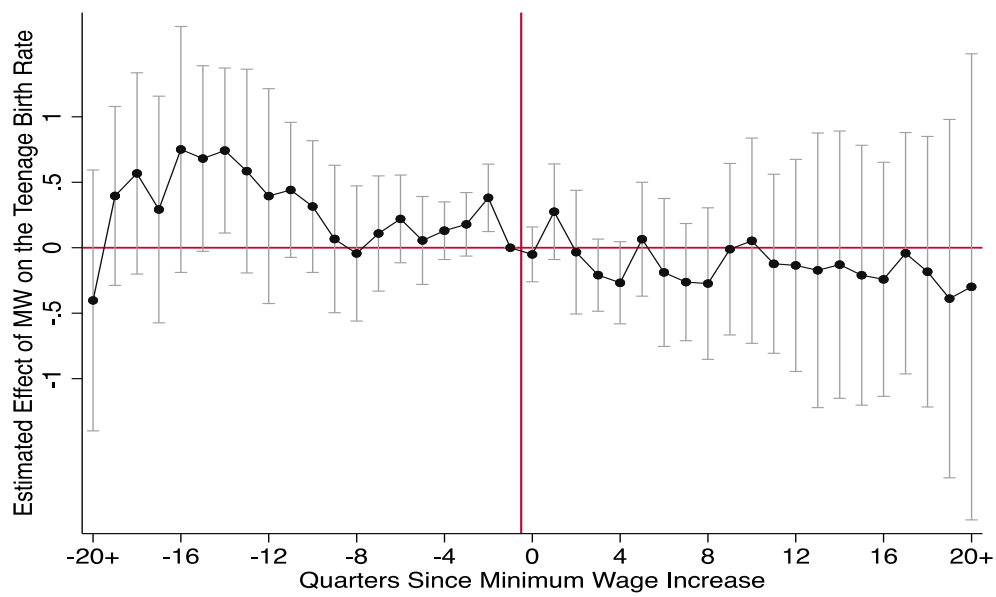

Panel B. Black Teen Fertility Rate

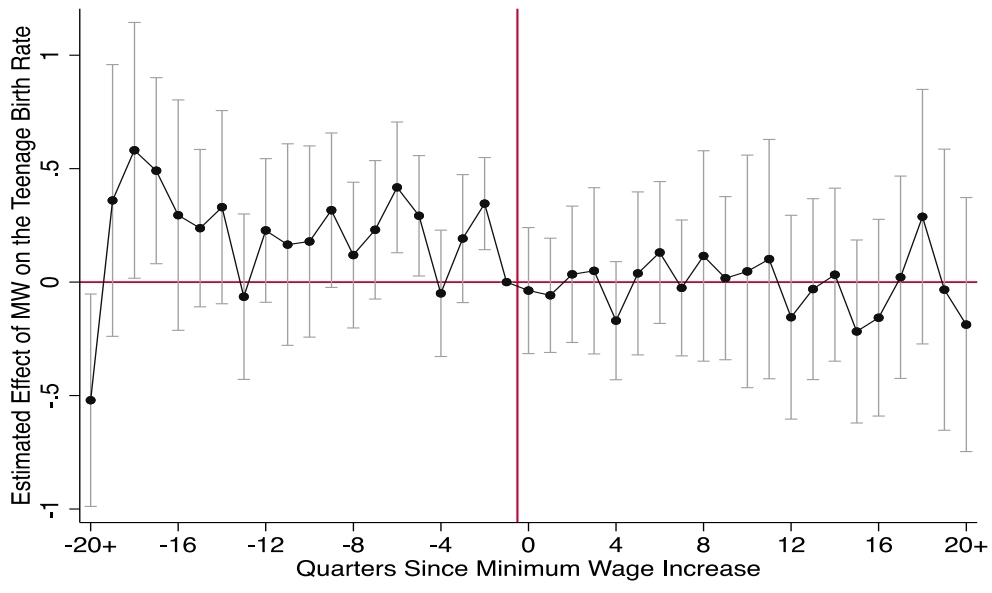

Panel D. Non-Hispanic White Teen Fertility Rate

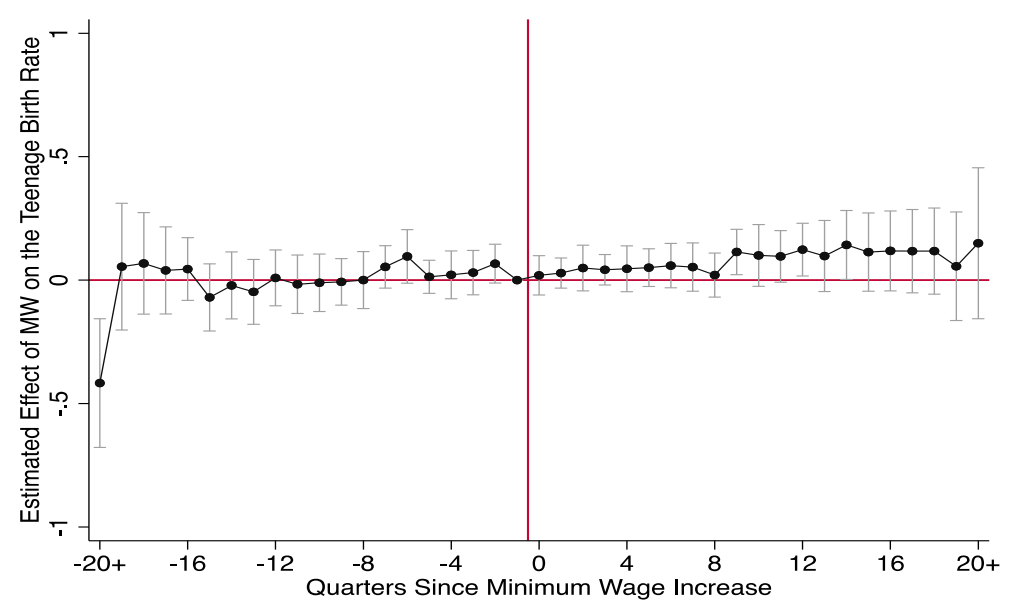

Notes: Population weighted OLS estimates (and their 95\% CIs) from the event study regression model described in equation (3) are shown. Data are at the state-year-quarter level and cover the period 2003Q4-2019Q4. Following Bullinger (2017), event-quarter 0 corresponds to $t-3$. Regressions used to generate the OLS estimates include controls for state fixed effects, year-by-quarter fixed effects, and our preferred controls, each of which are listed in Appendix Table 1. 
Appendix Figure 1B. Sensitivity of Event Study Analyses in Appendix Figure 1A to Controls for State-Specific Linear Time Trends

Panel A. Overall Teen Fertility Rate

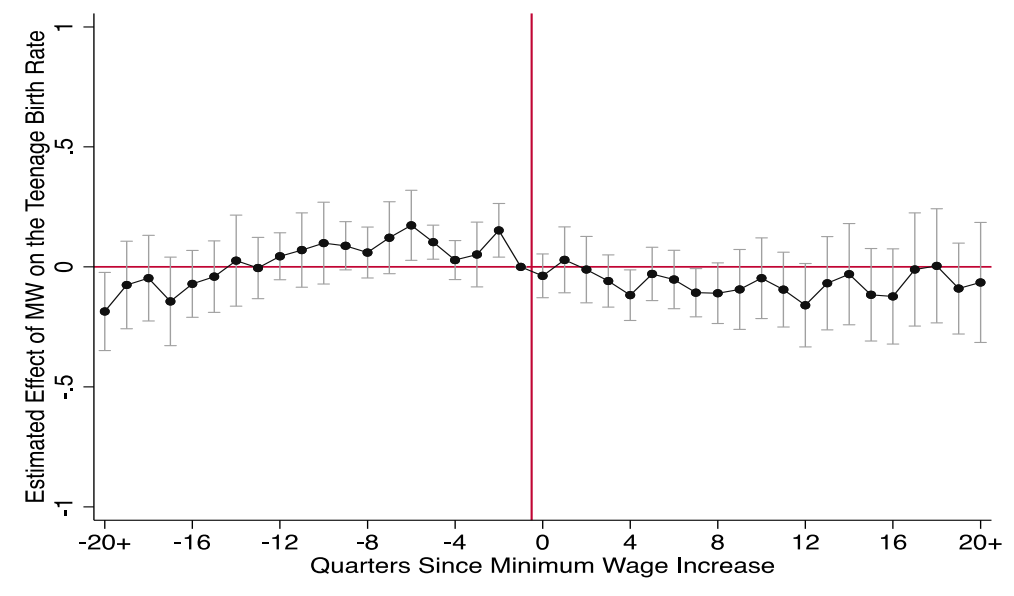

Panel C. Hispanic Teen Fertility Rate

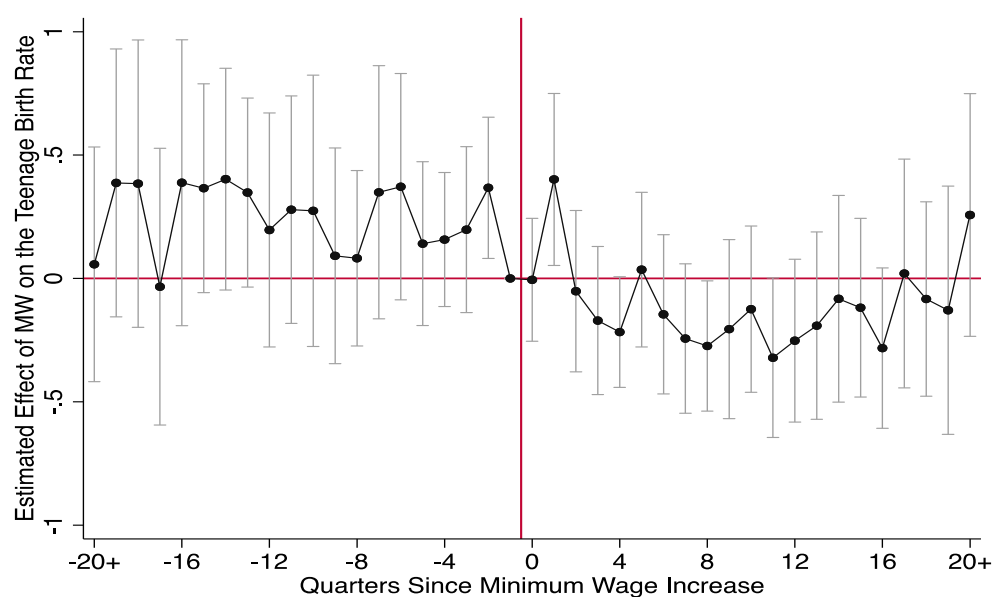

Panel B. Black Teen Fertility Rate

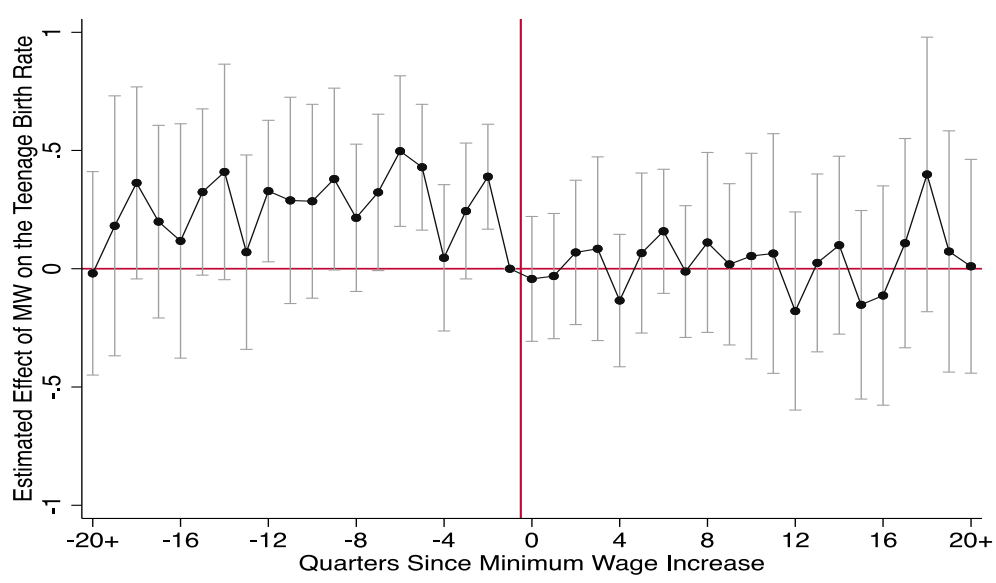

Panel D. Non-Hispanic White Teen Fertility Rate

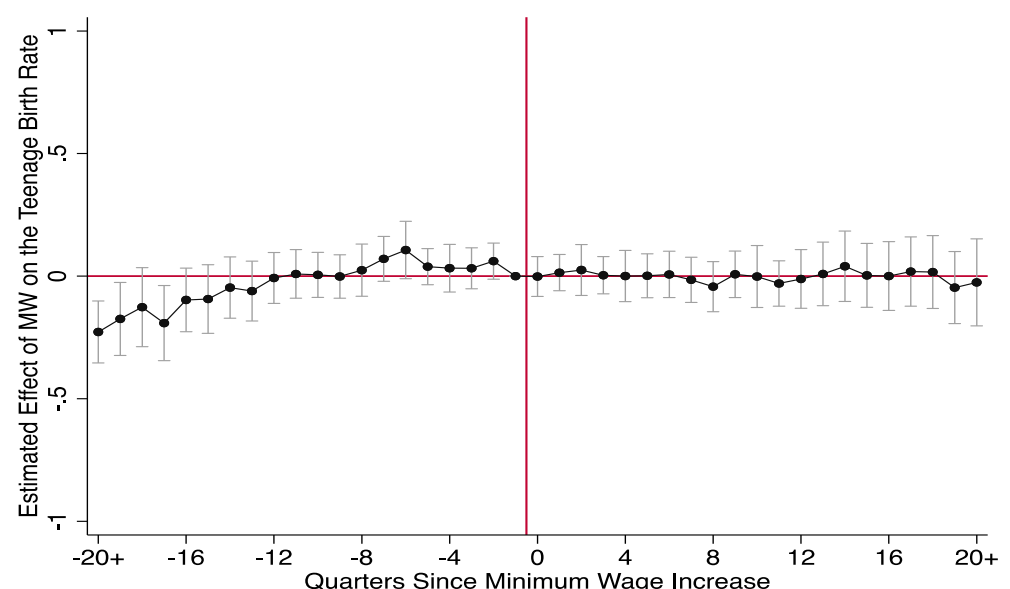

Notes: Population weighted OLS estimates (and their 95\% CIs) from the event study regression model described in equation (3) are shown. Data are at the state-year-quarter level and cover the period 2003Q4-2019Q4. Following Bullinger (2017), event-quarter 0 corresponds to $t-3$. Regressions used to generate the OLS estimates include controls for state fixed effects, year-by-quarter fixed effects, and our preferred controls, each of which are listed in Appendix Table 1. 
Appendix Figure 2. Sensitivity of Callaway-Sant'Anna Event Study Analysis of Prominent Minimum Wages to Exclusion of Macroeconomic Controls and Inclusion of Control for Less Prominent Minimum Wage Increases

Panel A. No Controls, 2003-2014

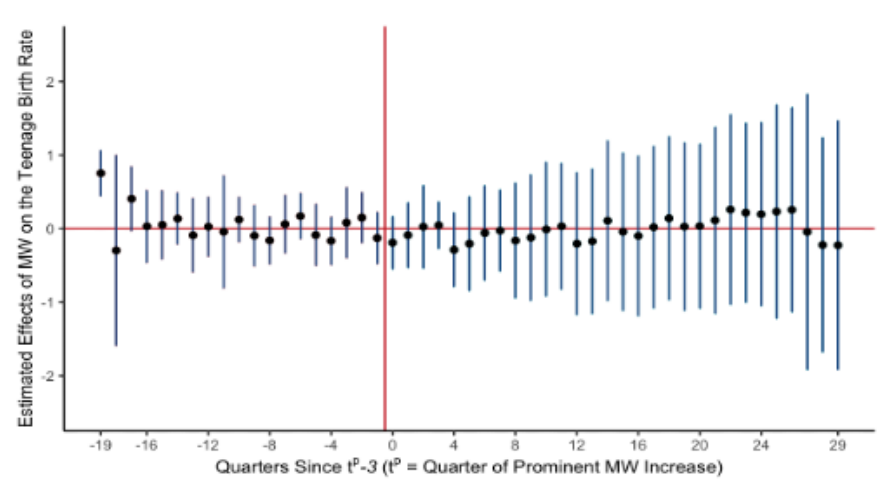

Panel C. Controls for Smaller MW Increases 2003-2014

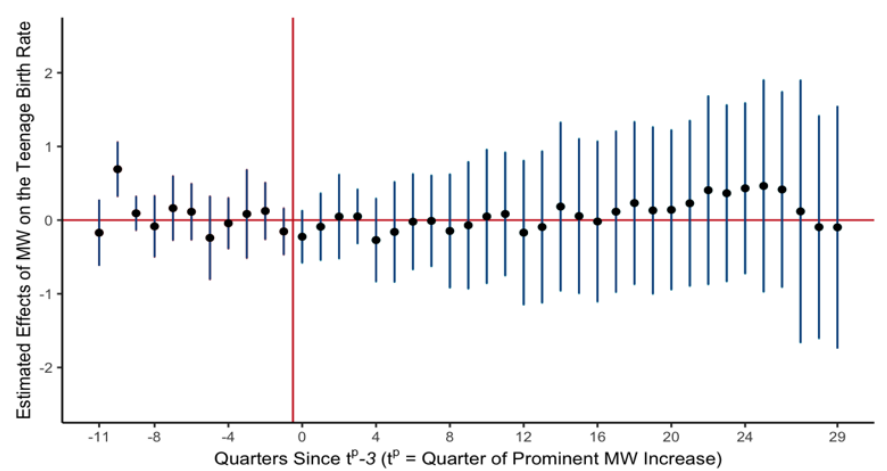

Panel B. No Controls, 2003-2019

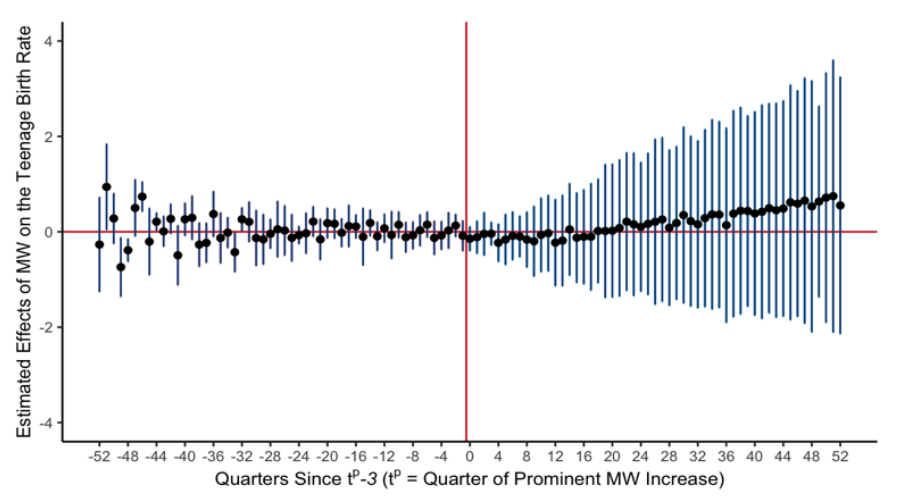

Panel D. Control for Smaller MW Increases, 2003-2019

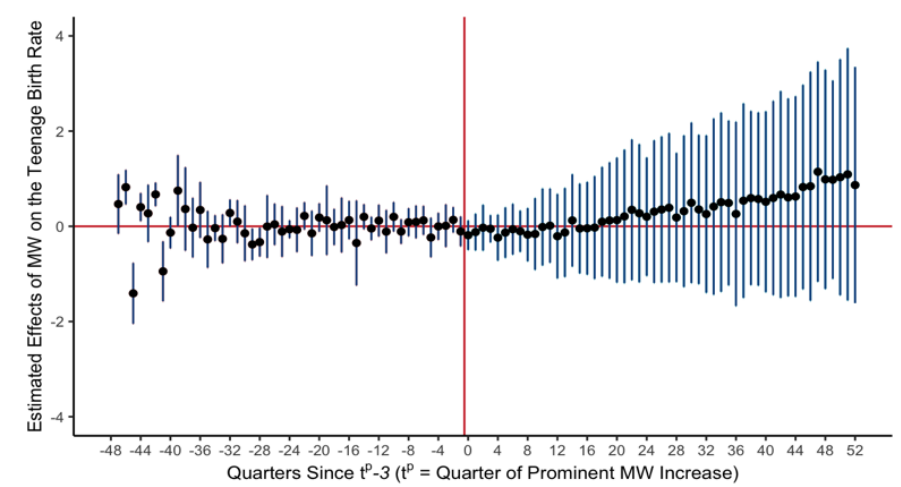

Notes: Callaway-Sant'Anna (2021) estimates (and their 95\% CIs) are shown above. A prominent minimum wage increase occurs when the state minimum wage rises by at least \$1 (in 2014\$s) over any four-quarter (one year) period. Data are at the state-year-quarter level and cover the period 2003Q4-2019Q4. Following Bullinger (2017), event-quarter 0 corresponds to $t-3$. The counterfactuals used for the Callaway-Sant'Anna estimates consist of those states that did not experience a $\$ 1$ minimum wage increase (in 2014\$s) over a four-quarter period (never adopters). In panels A and B, no controls are included. The control used for panels $\mathrm{C}$ and $\mathrm{D}$ is an indicator for a smaller minimum wage increase, defined as when the state's minimum wage rises by between $\$ 0.50$ and $\$ 0.99$ (in $2014 \$$ s) over any four-quarter (one year) period. 
Appendix Figure 3. Dynamic Effects of Minimum Wages on Sexual Behaviors of Female 15 -through 19-Year-Olds Based on State YRBS Data, 2003-2019

Panel A. Ever Sex Active

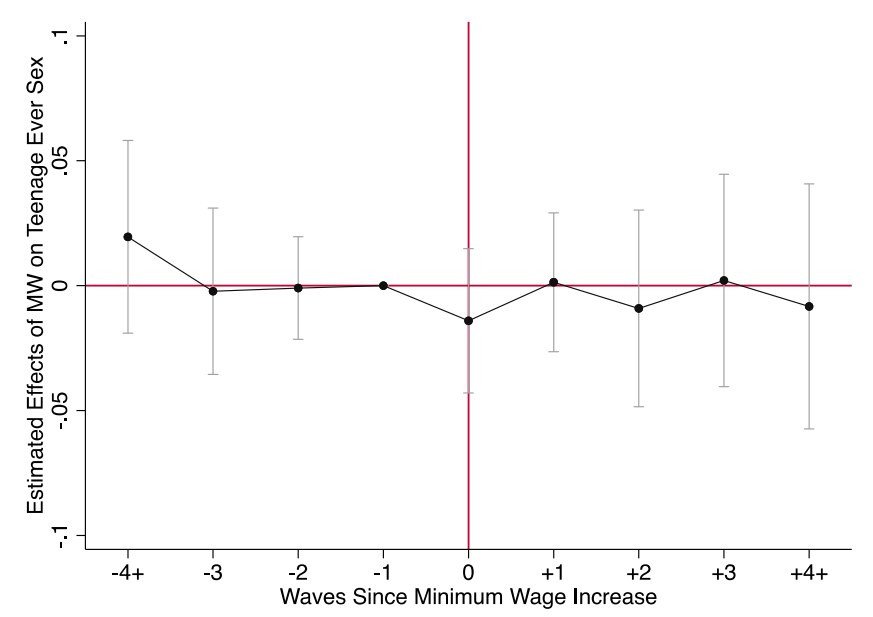

Panel C. Number of Sex Partners | Sex

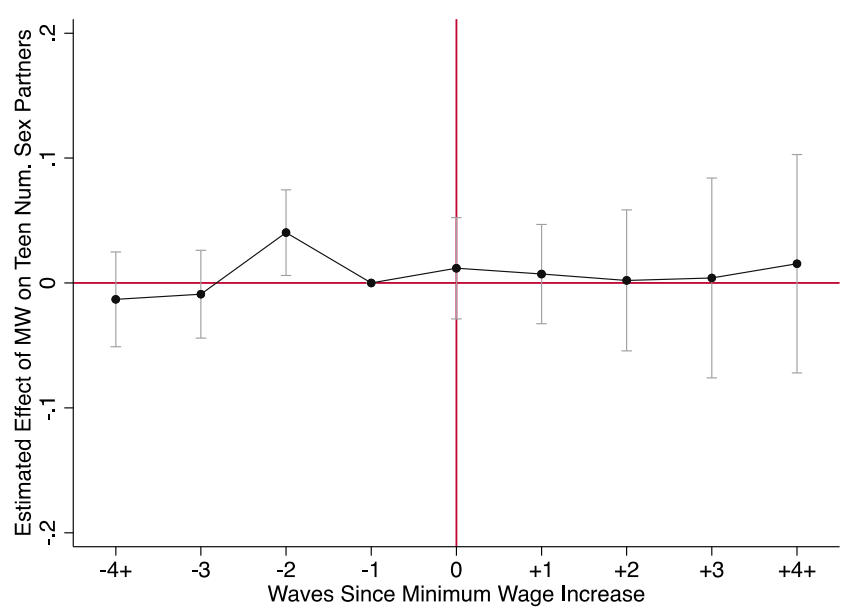

Panel B. Current Sex Active

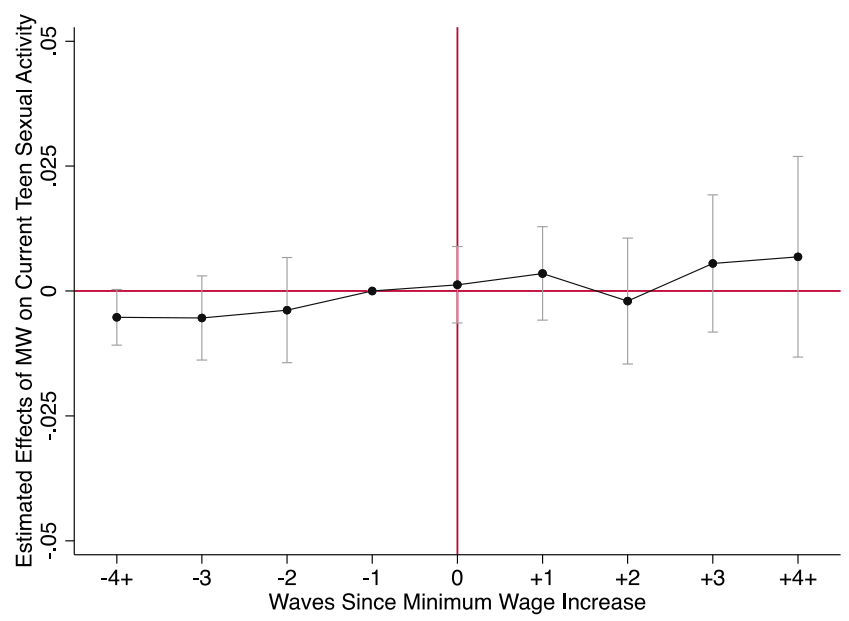

Panel D. Current Unprotected Sex

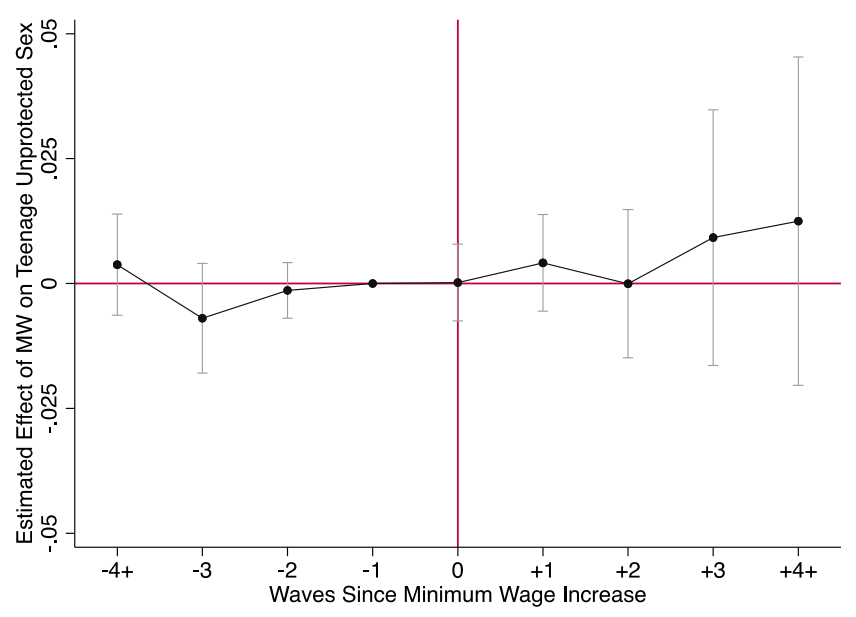




\section{Appendix Figure 3, Continued}

Panel E. Birth Control | Current Sex

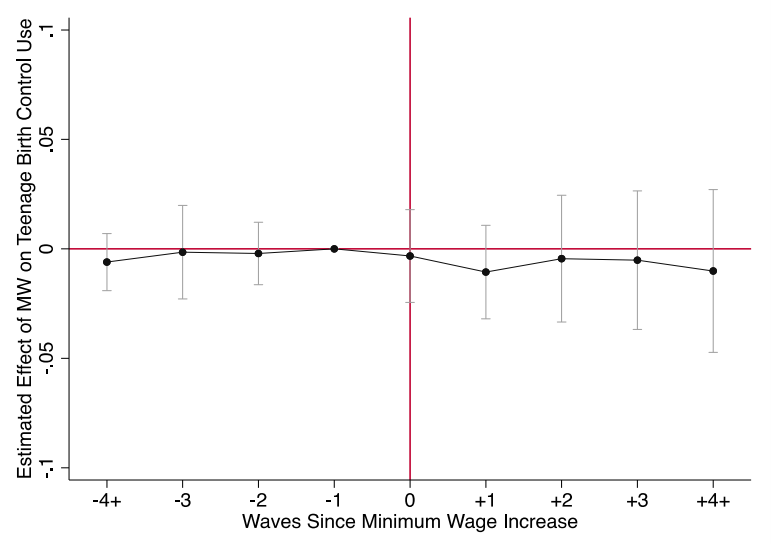

Panel G. Pill | Current Sex

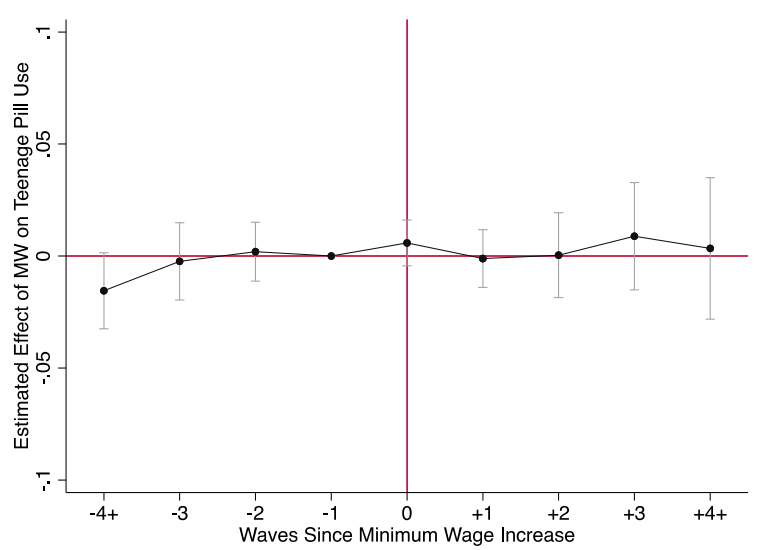

Panel F. Condom | Current Sex

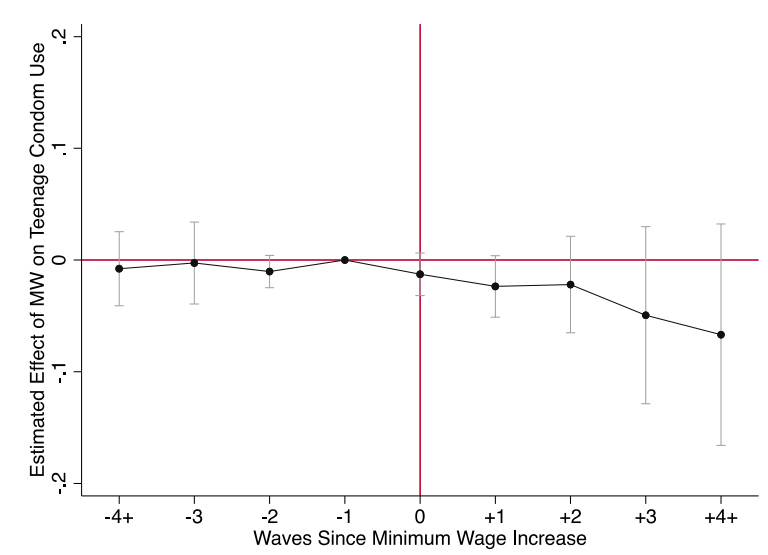

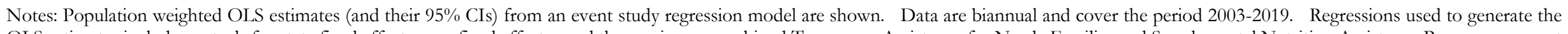

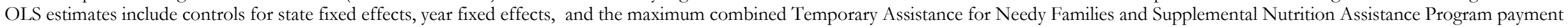

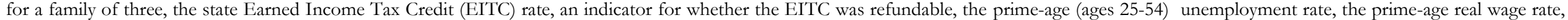

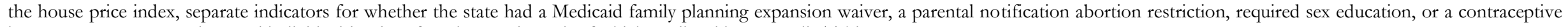
insurance coverage mandate, and individual-level preferred controls, each of which are listed in Appendix Table 2. 
Appendix Figure 4. Dynamic Effects of Minimum Wages on Sexual Behaviors of Female 15 -through 19-Year-Olds Based on the National YRBS Data, 2003-2019

Panel A. Ever Sex Active

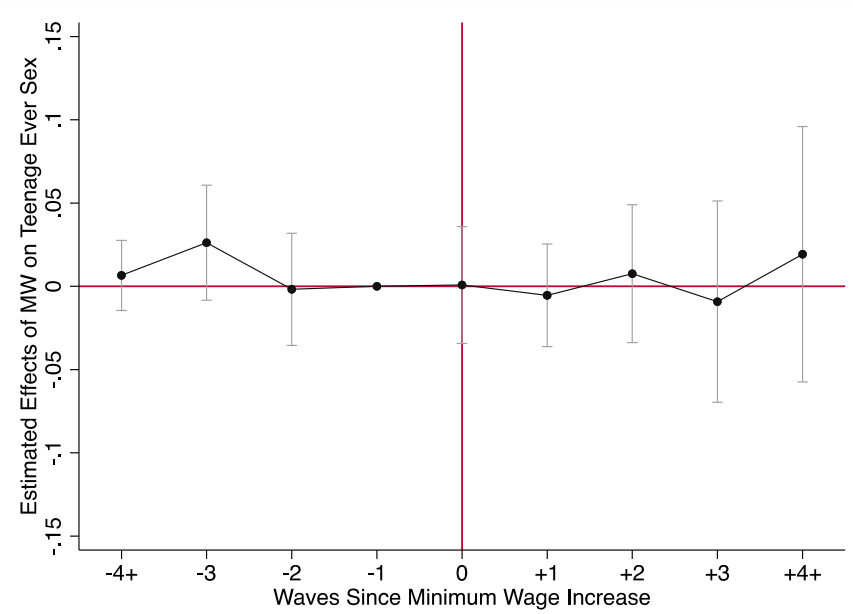

Panel C. No. Partners | Sex

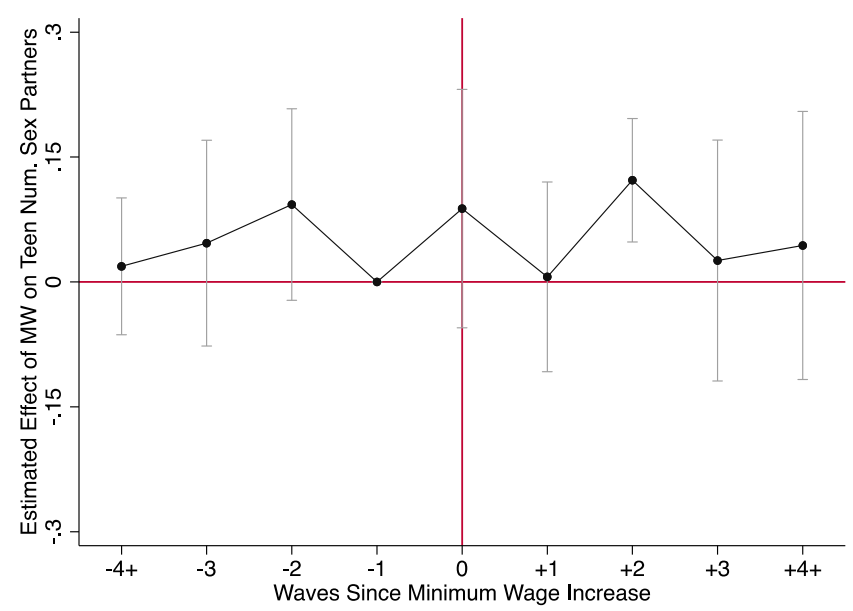

Panel B. Current Sex Active

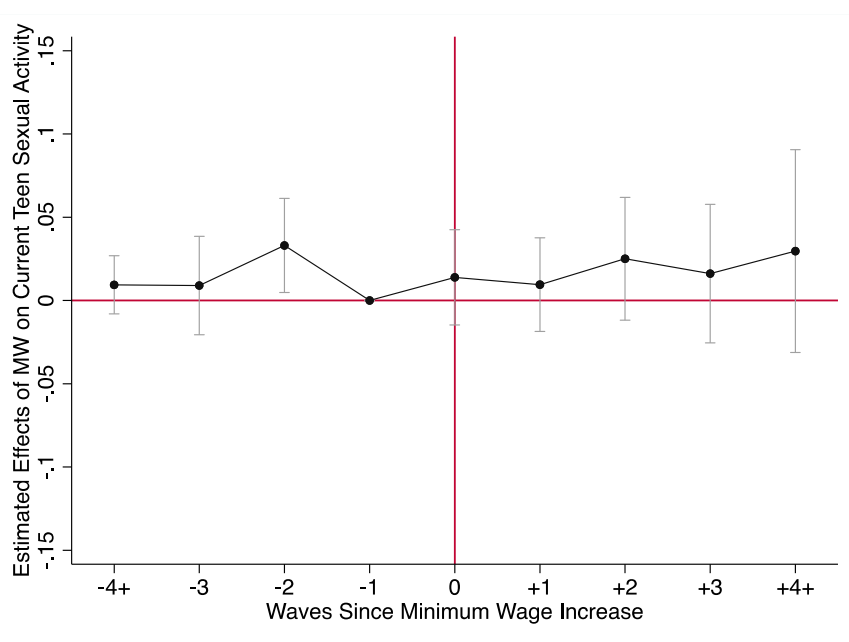

Panel D. Current Unprotected Sex

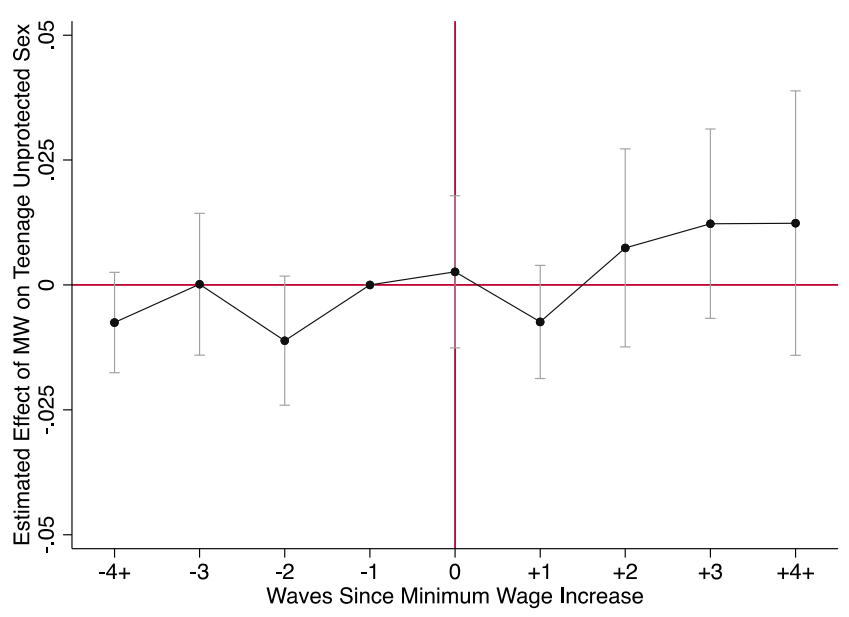




\section{Appendix Figure 4, Continued}

Panel E. Birth Control | Current Sex

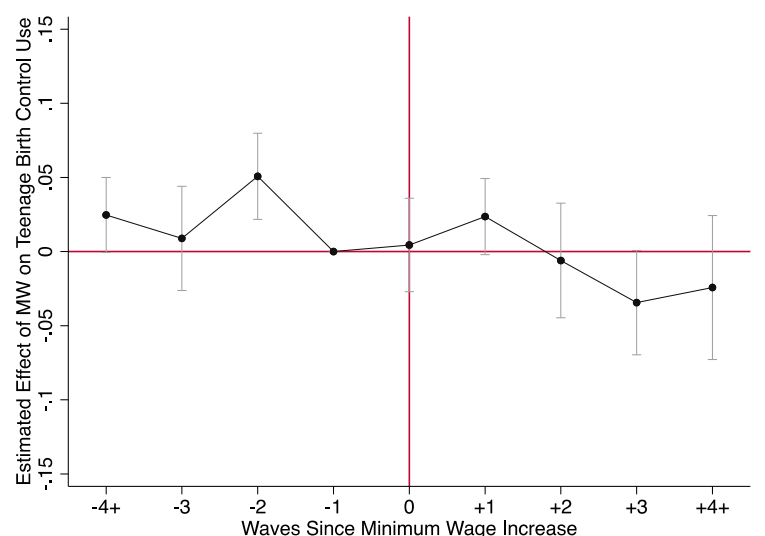

Panel G. Pill | Current Sex

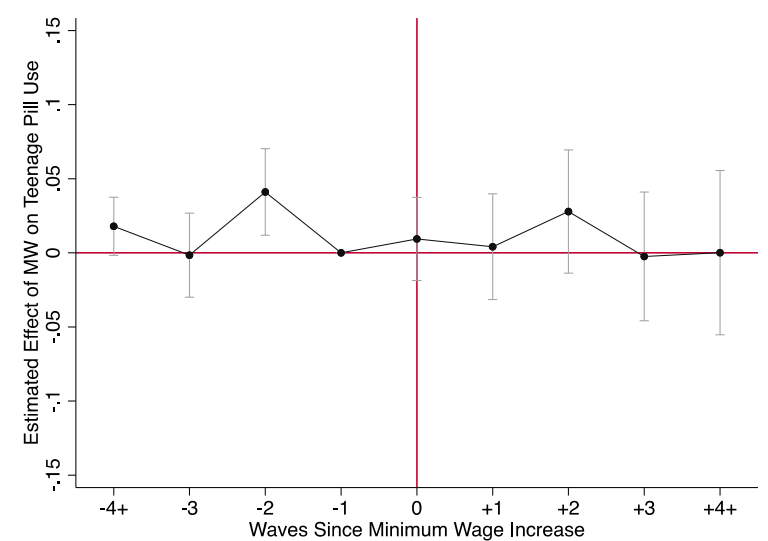

Panel F. Condom | Current Sex

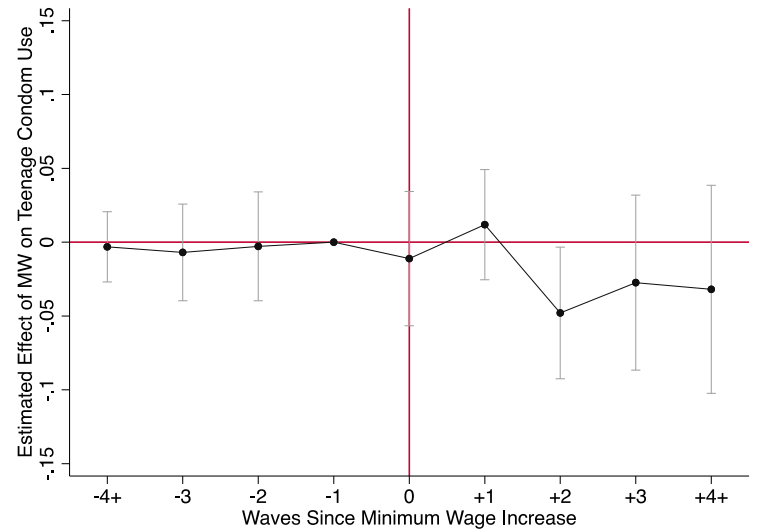

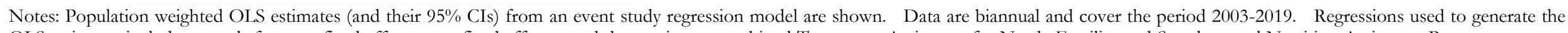

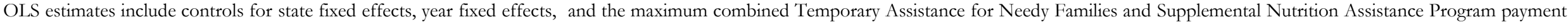

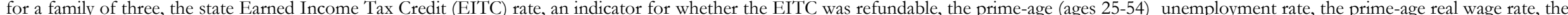

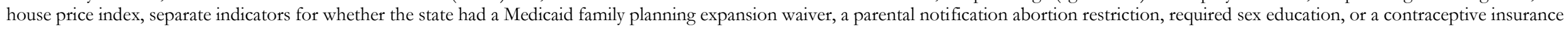
coverage mandate, and individual-level preferred controls, each of which are listed in Appendix Table 2.. 
Appendix Figure 5. Prominent Minimum Wage Increase and Teenage Sexual Behaviors: Using Callaway-Sant'Anna Estimates

Panel A. Ever Sex Active

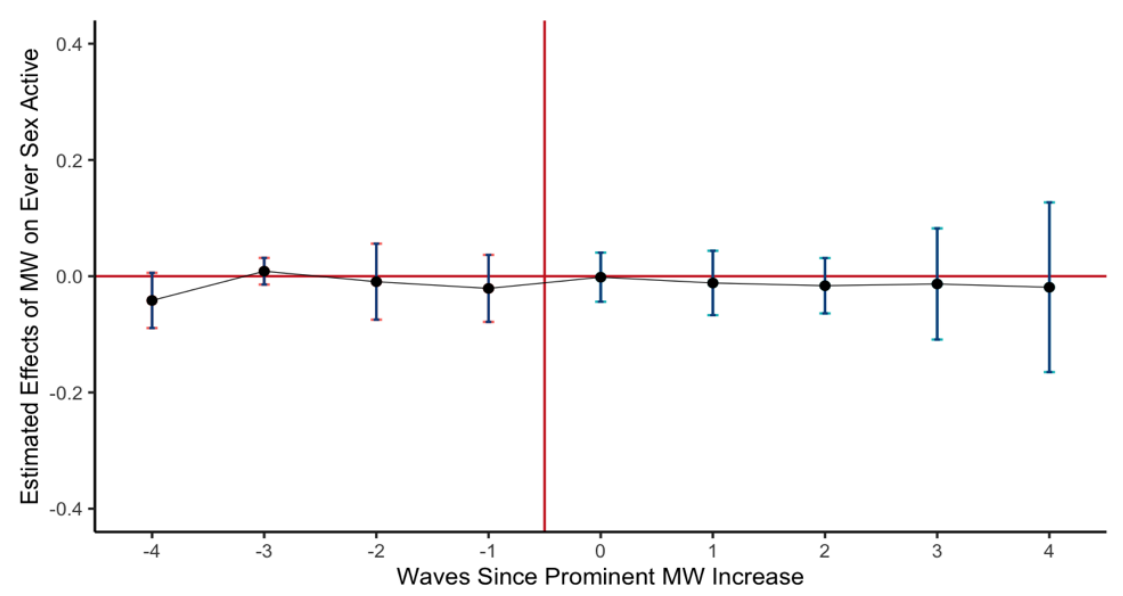

Panel C. Number of Sex Partners | Sex

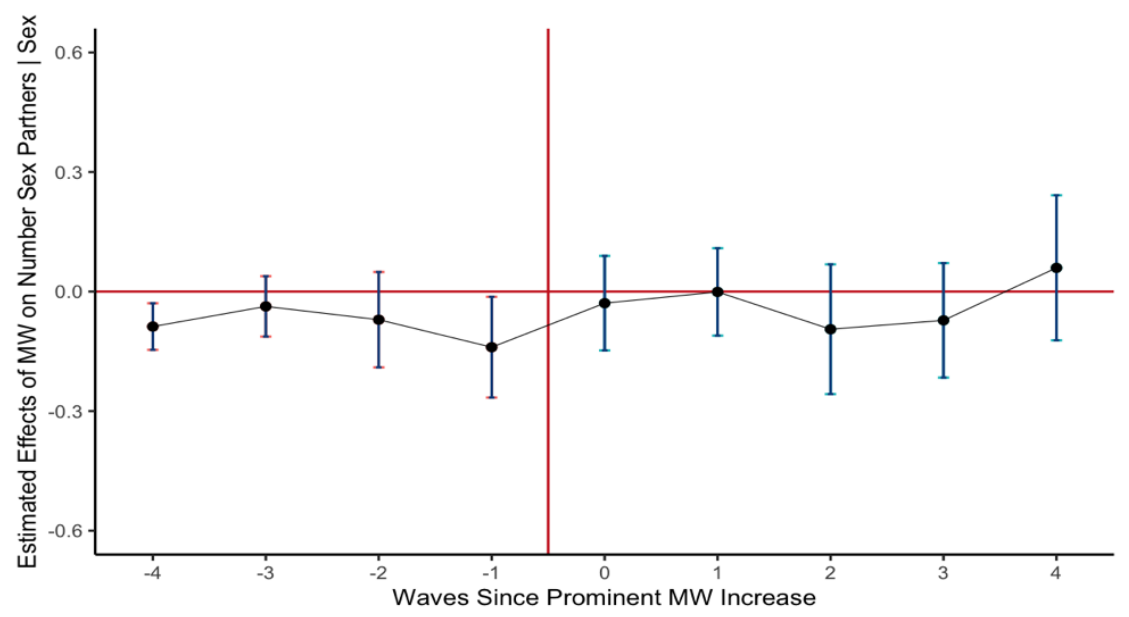

Panel B. Current Sex Active

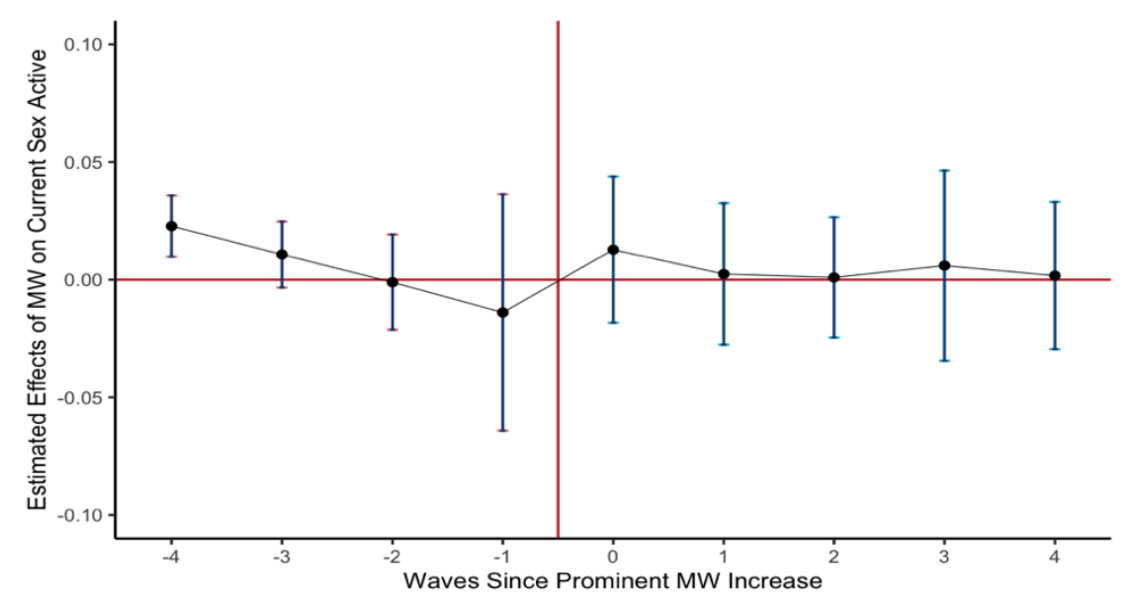

Panel D. Current Unprotected Sex

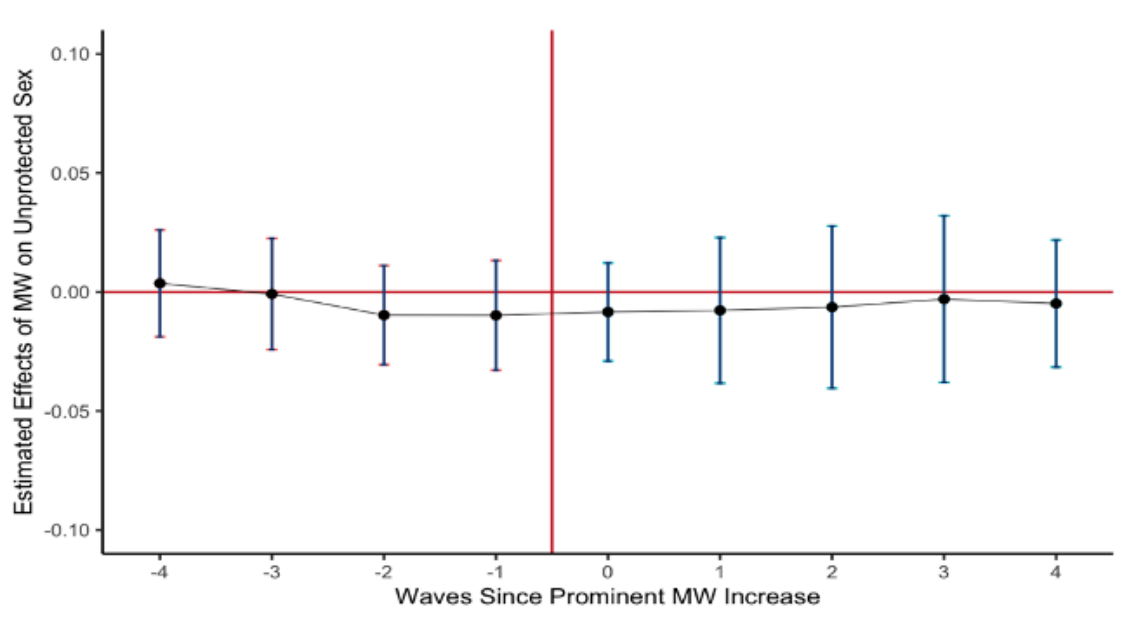


Panel E. Birth Control | Current Sex

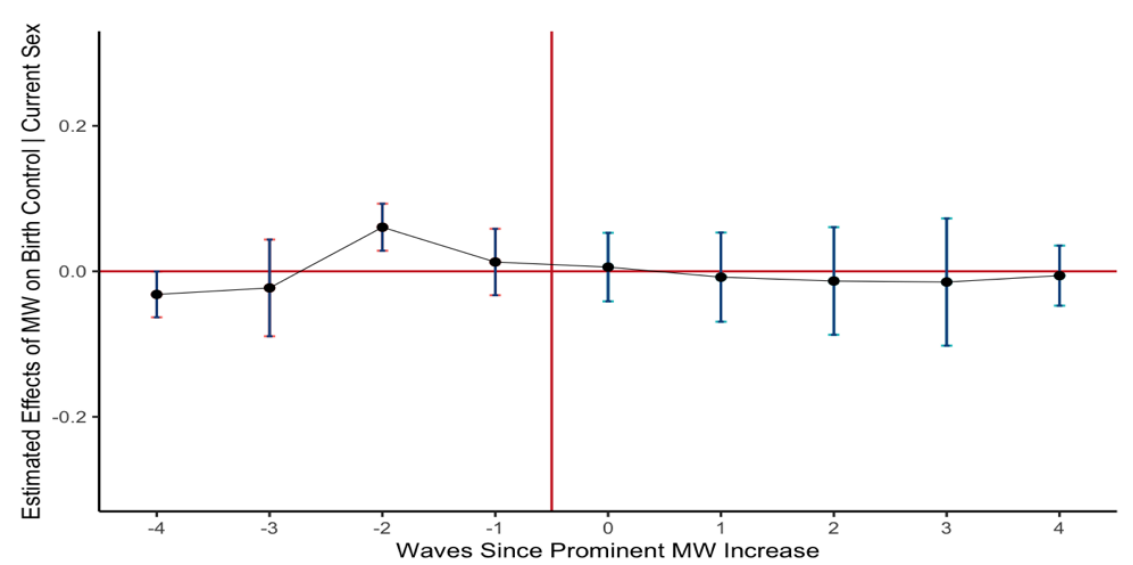

Panel G. Pill | Current Sex

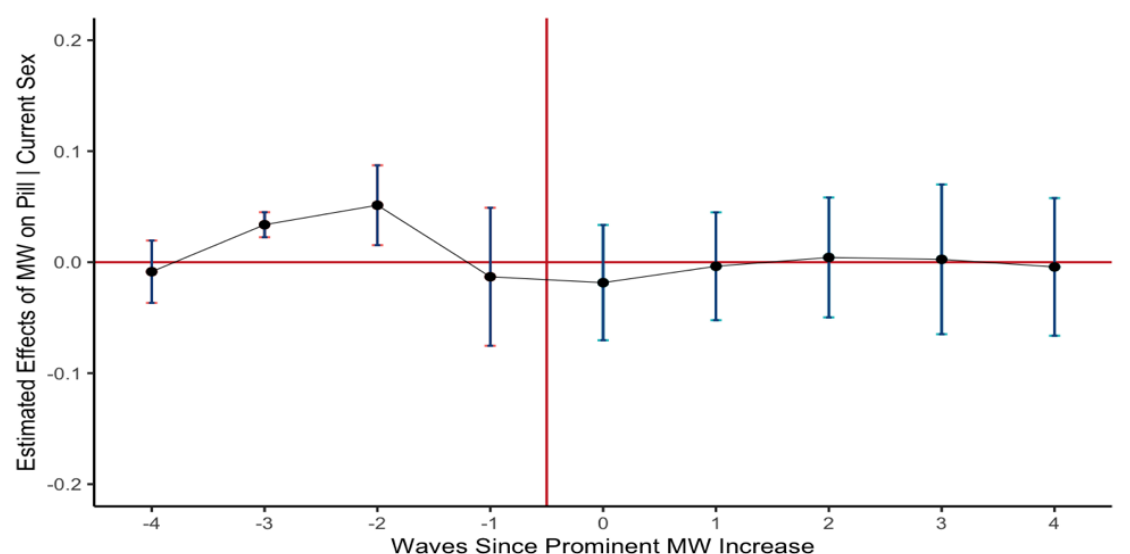

Panel F. Condom | Current Sex

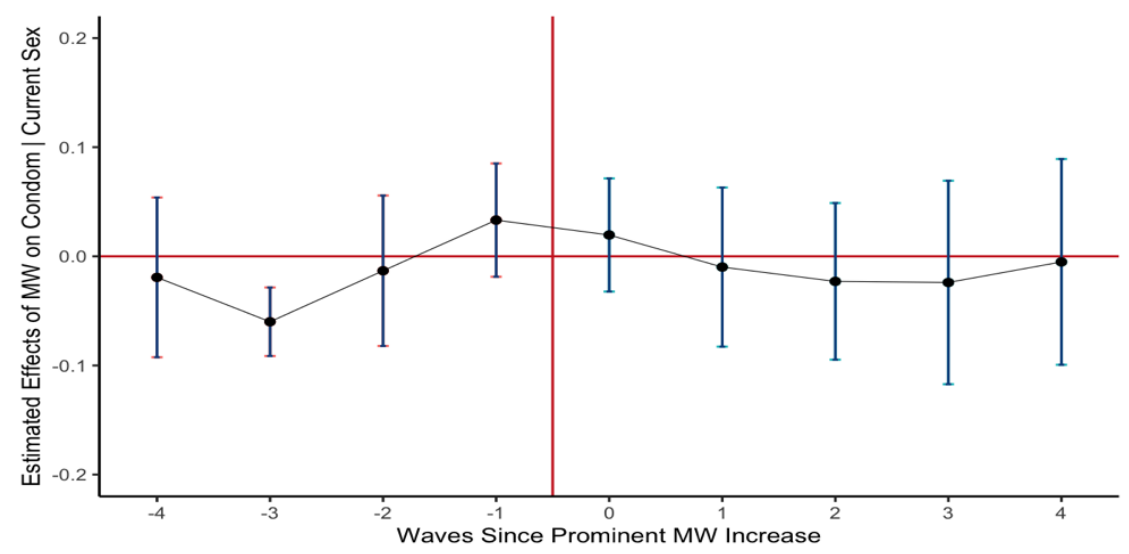

Notes: Callaway-Sant'Anna (2021) estimates (and their 95\% CIs) are shown above. A prominent minimum wage increase occurs when the state minimum wage rises by at least \$1 (in 2014\$s) over any calendar year. Data are at the biannual level and cover the period 2003-2019. The counterfactuals used for the Callaway-Sant'Anna estimates consist of those states that did not experience a $\$ 1$ minimum wage increase (in 2014\$s) over a calendar year (never adopters). Controls variables used include house price index and the prime-age (ages 25-54) unemployment rate. 
Appendix Figure 6. Prominent Minimum Wage Increases, Teenage Pregnancy Rates, and Teenage Abortion Rates: Using Callaway-Sant'Anna Estimates Controlling for Small Minimum Wage Increases

Panel A: Pregnancy Rates, Guttmacher Institute, 2005-2017

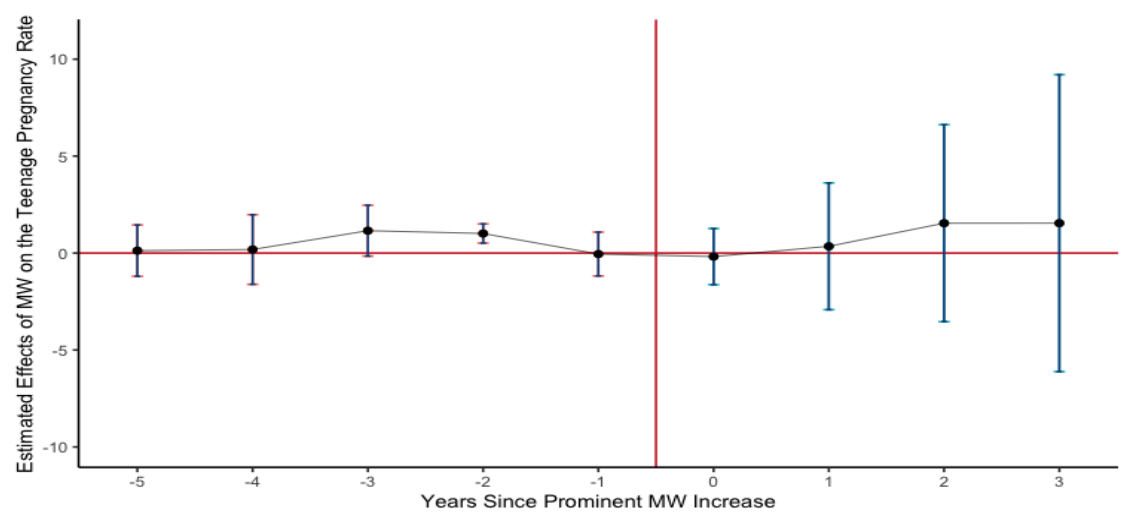

Panel B: Abortion Rates, Guttmacher Institute, 2005-2017

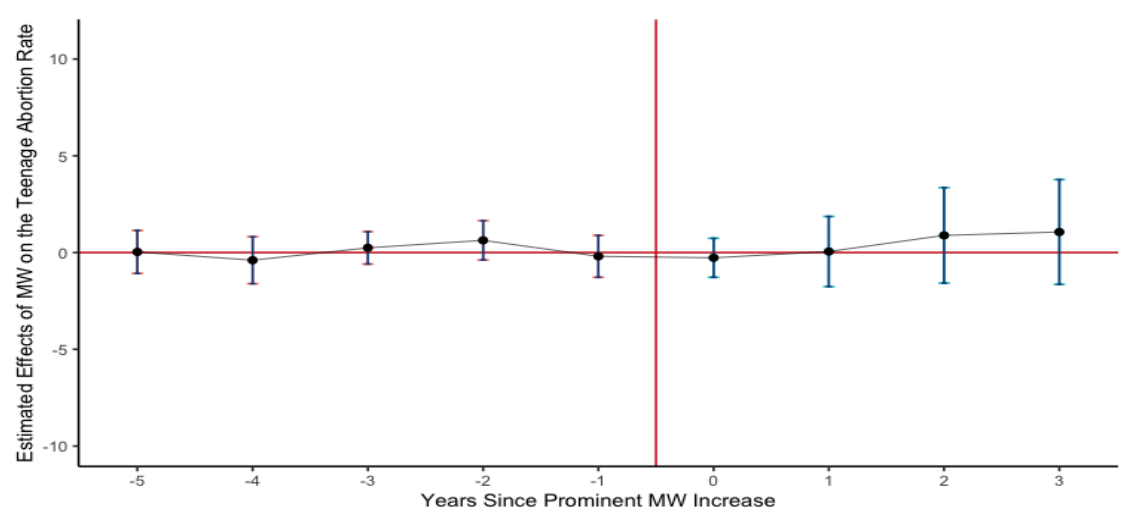

Panel C: Abortion Rates, CDC, 2003-2018

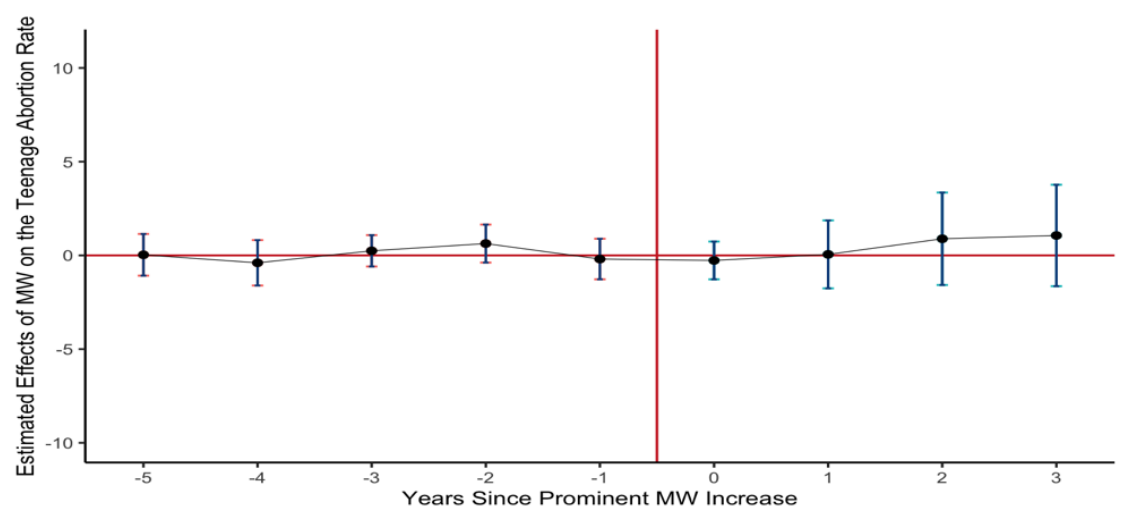

Notes: Callaway-Sant'Anna (2021) estimates (and their 95\% CIs) are shown above. A prominent minimum wage increase occurs when the state minimum wage rises by at least $\$ 1$ (in $2014 \$$ s) over any calendar year. Data are at the annual level and cover the period 2003 2019. The counterfactuals used for the Callaway-Sant'Anna estimates consist of those states that did not experience a $\$ 1$ minimum wage increase (in $2014 \$$ s) over a calendar year (never adopters). All models include a control for a small minimum wage increase, defined as when the state minimum wage rises by at least $\$ 0.50$, but under $\$ 0.99$ (in $2014 \$ \mathrm{~s}$ ) over any calendar year. 


\section{Appendix Table 1. Descriptive Statistics}

$$
\text { 2003-2014 2003-2019 Source }
$$

\section{Panel A. Dependent Variables}

\begin{tabular}{|c|c|c|c|}
\hline Teenage Fertility Rate (TFR) & $\begin{array}{c}8.967 \\
(2.973)\end{array}$ & $\begin{array}{c}7.539 \\
(3.252)\end{array}$ & Vital Stats \\
\hline Non-Hispanic White TFR & $\begin{array}{c}6.029 \\
(2.528)\end{array}$ & $\begin{array}{c}5.176 \\
(2.582)\end{array}$ & Vital Stats \\
\hline Non-Hispanic Black TFR & $\begin{array}{l}13.461 \\
(3.661)\end{array}$ & $\begin{array}{l}11.329 \\
(4.390)\end{array}$ & Vital Stats \\
\hline Hispanic TFR & $\begin{array}{l}15.373 \\
(5.195) \\
\end{array}$ & $\begin{array}{l}12.309 \\
(5.757)\end{array}$ & Vital Stats \\
\hline Marital Teen Fertility Rate & $\begin{array}{l}1.262 \\
(.813)\end{array}$ & $\begin{array}{c}1.019 \\
(0.768) \\
\end{array}$ & Vital Stats \\
\hline Non-Marital Teen Fertility Rate & $\begin{array}{c}7.767 \\
(2.323)\end{array}$ & $\begin{array}{c}6.677 \\
(2.589)\end{array}$ & Vital Stats \\
\hline Adult Fertility Rate & $\begin{array}{c}7.369 \\
(1.219)\end{array}$ & $\begin{array}{c}7.63 \\
(1.26)\end{array}$ & Vital Stats \\
\hline Ever Sexually Active & $\begin{array}{c}0.553^{\mathrm{a}} \\
(0.497)\end{array}$ & $\begin{array}{c}0.539 \\
(0.498)\end{array}$ & State YRBSS \\
\hline Sexually Active in Last 3 Months & $\begin{array}{l}0.362 \\
(.481)\end{array}$ & $\begin{array}{c}0.344 \\
(0.475)\end{array}$ & State YRBSS \\
\hline No. of Partners | Sexually Active & $\begin{array}{c}2.523 \\
(1.714) \\
\end{array}$ & $\begin{array}{c}2.459 \\
(1.691)\end{array}$ & State YRBSS \\
\hline Unprotected Sex & $\begin{array}{c}0.091 \\
(0.288)\end{array}$ & $\begin{array}{c}0.087 \\
(0.282) \\
\end{array}$ & State YRBSS \\
\hline Any Birth Control | Sexually Active Last 3 Mo & $\begin{array}{c}0.721 \\
(0.449)\end{array}$ & $\begin{array}{c}0.721 \\
(0.448)\end{array}$ & State YRBSS \\
\hline Condom | Sexually Active Last 3 Months & $\begin{array}{c}0.427 \\
(0.495)\end{array}$ & $\begin{array}{c}0.412 \\
(0.492)\end{array}$ & State YRBSS \\
\hline Pill | Sexually Active Last 3 Months & $\begin{array}{c}0.223 \\
(0.416)\end{array}$ & $\begin{array}{c}0.228 \\
(0.419)\end{array}$ & State YRBSS \\
\hline
\end{tabular}

Panel B. Baseline Control Variables

\begin{tabular}{|c|c|c|c|}
\hline Proportion of Non-Hispanic White Adolescents & $\begin{array}{l}0.594 \\
(.178)\end{array}$ & $\begin{array}{l}.580 \\
(.178)\end{array}$ & $\begin{array}{c}\text { Current Population Survey } \\
(2003-2019)\end{array}$ \\
\hline Proportion of Non-Hispanic Black Adolescents & $\begin{array}{l}0.139 \\
(.100)\end{array}$ & $\begin{array}{l}0.134 \\
(.098)\end{array}$ & $\begin{array}{l}\text { Current Population Survey } \\
(2003-2019)\end{array}$ \\
\hline Proportion of Hispanic Adolescents & $\begin{array}{l}0.195 \\
(.168)\end{array}$ & $\begin{array}{l}0.207 \\
(.171)\end{array}$ & $\begin{array}{c}\text { Current Population Survey } \\
(2003-2019)\end{array}$ \\
\hline Proportion of Adolescents (Aged 16-19) age 17 & $\begin{array}{l}0.263 \\
(.027)\end{array}$ & $\begin{array}{l}0.264 \\
(.029)\end{array}$ & $\begin{array}{c}\text { Current Population Survey } \\
(2003-2019)\end{array}$ \\
\hline Proportion of Adolescents (Aged 16-19) age 18 & $\begin{array}{l}0.242 \\
(.029)\end{array}$ & $\begin{array}{l}0.242 \\
(.029)\end{array}$ & $\begin{array}{c}\text { Current Population Survey } \\
(2003-2019)\end{array}$ \\
\hline Proportion of Adolescents (Aged 16-19) age 19 & $\begin{array}{l}0.229 \\
(.028)\end{array}$ & $\begin{array}{l}0.228 \\
(.030)\end{array}$ & $\begin{array}{c}\text { Current Population Survey } \\
(2003-2019)\end{array}$ \\
\hline
\end{tabular}




\section{Appendix Table 1, Continued}

\begin{tabular}{|c|c|c|c|}
\hline & $2003-2014$ & 2003-2019 & Source \\
\hline Proportion of Adolescents that are married & $\begin{array}{l}0.021 \\
(.013)\end{array}$ & $\begin{array}{l}0.018 \\
(.012)\end{array}$ & $\begin{array}{c}\text { Current Population Survey } \\
(2003-2019)\end{array}$ \\
\hline Proportion of Adolescents that are cohabitating & $\begin{array}{l}.010 \\
(.008)\end{array}$ & $\begin{array}{l}.009 \\
(.008)\end{array}$ & $\begin{array}{c}\text { Current Population Survey } \\
(2003-2019)\end{array}$ \\
\hline Medicaid Family Planning Expansion Waiver & $\begin{array}{l}0.644 \\
(.479)\end{array}$ & $\begin{array}{l}0.684 \\
(.465)\end{array}$ & $\begin{array}{l}\text { Wherry (2013); } \\
\text { Kearney \& Levine (2009): } \\
\text { Authors' own law searches }\end{array}$ \\
\hline Parental Notification Abortion Restriction & $\begin{array}{l}0.667 \\
(.472)\end{array}$ & $\begin{array}{l}0.686 \\
(.464)\end{array}$ & $\begin{array}{c}\text { Myers \& Ladd (2017); } \\
\text { Guttmacher Institute (2020) }\end{array}$ \\
\hline Contraceptive Insurance Coverage Mandate & $\begin{array}{l}0.641 \\
(.480)\end{array}$ & $\begin{array}{l}0.664 \\
(.472)\end{array}$ & $\begin{array}{l}\text { Raissan and Lopoo (2015); } \\
\text { Guttmacher Institute (2020) }\end{array}$ \\
\hline Whether EITC Refundable & $\begin{array}{l}0.332 \\
(.471)\end{array}$ & $\begin{array}{l}0.369 \\
(.483)\end{array}$ & $\begin{array}{c}\text { University of Kentucky } \\
\text { Poverty Research Center } \\
(2021)\end{array}$ \\
\hline EITC Rate & $\begin{array}{c}0.0579 \\
(.099)\end{array}$ & $\begin{array}{l}0.684 \\
(.465)\end{array}$ & $\begin{array}{l}\text { University of Kentucky } \\
\text { Poverty Research Center } \\
\text { (2021) }\end{array}$ \\
\hline TANF/SNAP Maximum Benefit Level for Family of 3 & $\begin{array}{c}983.690 \\
(186.130)\end{array}$ & $\begin{array}{c}966.114 \\
(187.132)\end{array}$ & $\begin{array}{l}\text { University of Kentucky } \\
\text { Poverty Research Center } \\
(2021)\end{array}$ \\
\hline Unemployment Rate & $\begin{array}{l}0.069 \\
(.022)\end{array}$ & $\begin{array}{l}0.061 \\
(.022)\end{array}$ & $\begin{array}{c}\text { Current Population Survey } \\
(2003-2019)\end{array}$ \\
\hline
\end{tabular}

\section{Panel C. Preferred Control Variables}

\begin{tabular}{|c|c|c|c|}
\hline tate-Level Preferred Control Variables & & & \\
\hline Medicaid Family Planning Expansion Waiver & $\begin{array}{l}0.644 \\
(479)\end{array}$ & $\begin{array}{l}0.684 \\
(.465)\end{array}$ & $\begin{array}{l}\text { Wherry (2013); } \\
\text { Kearney \& Levine (2009): } \\
\text { Authors' own law searches }\end{array}$ \\
\hline Parental Notification Abortion Restriction & $\begin{array}{l}0.667 \\
(.472)\end{array}$ & $\begin{array}{l}0.686 \\
(.464)\end{array}$ & $\begin{array}{c}\text { Myers \& Ladd (2017); } \\
\text { Guttmacher Institute (2020) }\end{array}$ \\
\hline Contraceptive Insurance Coverage Mandate & $\begin{array}{l}0.641 \\
(.480)\end{array}$ & $\begin{array}{l}0.664 \\
(.472)\end{array}$ & $\begin{array}{l}\text { Raissan and Lopoo (2015); } \\
\text { Guttmacher Institute (2020) }\end{array}$ \\
\hline Sex Education Requirement & $\begin{array}{l}0.279 \\
(.449)\end{array}$ & $\begin{array}{l}0.310 \\
(.463)\end{array}$ & $\begin{array}{l}\text { Guttmacher Institute (2021); } \\
\text { Authors' own Lexis searches }\end{array}$ \\
\hline Whether EITC Refundable & $\begin{array}{l}0.332 \\
(.471)\end{array}$ & $\begin{array}{l}0.369 \\
(.483)\end{array}$ & $\begin{array}{c}\text { University of Kentucky } \\
\text { Poverty Research Center } \\
\text { (2021) }\end{array}$ \\
\hline EITC Rate & $\begin{array}{l}0.0579 \\
(.099)\end{array}$ & $\begin{array}{l}0.684 \\
(.465)\end{array}$ & $\begin{array}{l}\text { University of Kentucky } \\
\text { Poverty Research Center } \\
\text { (2021) }\end{array}$ \\
\hline
\end{tabular}




\section{Appendix Table 1, Continued}

\begin{tabular}{|c|c|c|c|}
\hline & $2003-2014$ & 2003-2019 & Source \\
\hline TANF/SNAP Maximum Benefit Level for Family of 3 & $\begin{array}{l}983.690 \\
(186.130)\end{array}$ & $\begin{array}{c}966.114 \\
(187.132)\end{array}$ & $\begin{array}{c}\text { University of Kentucky } \\
\text { Poverty Research Center } \\
(2021)\end{array}$ \\
\hline Prime-Age Unemployment Rate & $\begin{array}{l}0.060 \\
(.022)\end{array}$ & $\begin{array}{l}0.053 \\
(.022)\end{array}$ & $\begin{array}{c}\text { Current Population Survey } \\
(2003-2019)\end{array}$ \\
\hline Proportion of Non-Hispanic White Adolescents & $\begin{array}{l}0.594 \\
(.178)\end{array}$ & $\begin{array}{l}.580 \\
(.178)\end{array}$ & $\begin{array}{c}\text { Current Population Survey } \\
(2003-2019)\end{array}$ \\
\hline Proportion of Non-Hispanic Black Adolescents & $\begin{array}{l}0.139 \\
(.100)\end{array}$ & $\begin{array}{l}0.134 \\
(.098)\end{array}$ & $\begin{array}{l}\text { Current Population Survey } \\
(2003-2019)\end{array}$ \\
\hline Proportion of Hispanic Adolescents & $\begin{array}{l}0.195 \\
(.168)\end{array}$ & $\begin{array}{l}0.207 \\
(.171)\end{array}$ & $\begin{array}{c}\text { Current Population Survey } \\
(2003-2019)\end{array}$ \\
\hline Proportion of Adolescents (Aged 16-19) age 17 & $\begin{array}{l}0.263 \\
(.027)\end{array}$ & $\begin{array}{l}0.264 \\
(.029)\end{array}$ & $\begin{array}{c}\text { Current Population Survey } \\
(2003-2019)\end{array}$ \\
\hline Proportion of Adolescents (Aged 16-19) age 18 & $\begin{array}{l}0.242 \\
(.029)\end{array}$ & $\begin{array}{l}0.242 \\
(.029)\end{array}$ & $\begin{array}{c}\text { Current Population Survey } \\
(2003-2019)\end{array}$ \\
\hline Proportion of Adolescents (Aged 16-19) age 19 & $\begin{array}{l}0.229 \\
(.028)\end{array}$ & $\begin{array}{l}0.228 \\
(.030)\end{array}$ & $\begin{array}{c}\text { Current Population Survey } \\
(2003-2019)\end{array}$ \\
\hline Proportion of Adolescents that live in an MSA & $\begin{array}{l}0.829 \\
(.142)\end{array}$ & $\begin{array}{l}0.839 \\
(.139)\end{array}$ & $\begin{array}{c}\text { Current Population Survey } \\
(2003-2019)\end{array}$ \\
\hline Prime-Age Hourly Wage Rate (in 2014\$s) & $\begin{array}{l}22.765 \\
(2.311)\end{array}$ & $\begin{array}{l}22.543 \\
(2.305)\end{array}$ & $\begin{array}{c}\text { Current Population Survey } \\
(2003-2019)\end{array}$ \\
\hline House Price Index & $\begin{array}{c}358.046 \\
(123.173)\end{array}$ & $\begin{array}{c}376.10 \\
(129.121)\end{array}$ & $\begin{array}{l}\text { Federal Housing Finance } \\
\text { Agency (2003-2019) }\end{array}$ \\
\hline
\end{tabular}

Note: All means are weighted using population estimates from the National Vital Statistics System from 2003-2014 and 2003-2019 respectively. Standard deviations are shown in parentheses. 


\section{Appendix Table 2. Means of Dependent and Independent Variables for the National YRBS}

\begin{tabular}{|c|c|c|c|}
\hline & $2003-2015$ & $2003-2019$ & Source \\
\hline \multicolumn{4}{|l|}{ Dependent Variables } \\
\hline Ever Sexually Active & $\begin{array}{l}0.517^{a} \\
(0.500)\end{array}$ & $\begin{array}{c}0.504 \\
(0.500)\end{array}$ & National YRBSS \\
\hline Sexually Active in Last 3 Months & $\begin{array}{l}0.371 \\
(.483)\end{array}$ & $\begin{array}{c}0.369 \\
(0.480)\end{array}$ & National YRBSS \\
\hline No. of Partners | Sexually Active & $\begin{array}{c}2.567 \\
(1.737)\end{array}$ & $\begin{array}{c}2.515 \\
(1.717)\end{array}$ & National YRBSS \\
\hline Unprotected Sex & $\begin{array}{c}0.107 \\
(0.309)\end{array}$ & $\begin{array}{c}0.101 \\
(0.302)\end{array}$ & National YRBSS \\
\hline Any Birth Control | Sexually Active Last 3 Mo & $\begin{array}{c}0.716 \\
(0.453)\end{array}$ & $\begin{array}{c}0.716 \\
(0.451)\end{array}$ & National YRBSS \\
\hline Condom | Sexually Active Last 3 Months & $\begin{array}{c}0.429 \\
(0.495)\end{array}$ & $\begin{array}{c}0.420 \\
(0.494)\end{array}$ & National YRBSS \\
\hline Pill | Sexually Active Last 3 Months & $\begin{array}{c}0.220 \\
(0.414)\end{array}$ & $\begin{array}{c}0.225 \\
(0.417)\end{array}$ & National YRBSS \\
\hline \multicolumn{4}{|l|}{ Individual-Level Control V ariables } \\
\hline White & $\begin{array}{c}0.591 \\
(0.492)\end{array}$ & $\begin{array}{c}0.578 \\
(0.494)\end{array}$ & National YRBSS \\
\hline Black & $\begin{array}{c}0.146 \\
(0.353)\end{array}$ & $\begin{array}{c}0.142 \\
(0.349)\end{array}$ & National YRBSS \\
\hline Hispanic & $\begin{array}{c}0.187 \\
(0.390)\end{array}$ & $\begin{array}{c}0.198 \\
(0.398)\end{array}$ & National YRBSS \\
\hline Other Race & $\begin{array}{c}0.076 \\
(0.265)\end{array}$ & $\begin{array}{c}0.083 \\
(0.276)\end{array}$ & National YRBSS \\
\hline Grade & $\begin{array}{l}10.607 \\
(1.053)\end{array}$ & $\begin{array}{l}10.618 \\
(1.051)\end{array}$ & National YRBSS \\
\hline Age & $\begin{array}{l}16.274 \\
(1.033)\end{array}$ & $\begin{array}{l}16.277 \\
(1.033)\end{array}$ & National YRBSS \\
\hline
\end{tabular}

Note: Weighted means are generated using data from the 2003-2015 and 2003-2019 National Youth Risk Behavior surveys. Standard deviations are shown in parentheses. 


\section{Appendix Table 3. Sensitivity of Estimates of Teen Birth Effects to the Inclusion of State- Specific Linear and Quadratic Time Trends, 2003Q4-2019Q4}

\author{
(1)
}

Overall
(2)

Blacks
(3)

Hispanics
(4)

Non-Hispanic Whites

\begin{tabular}{cc}
\hline Minimum Wage (2014\$s) & $-0.248^{* * *}$ \\
$(0.05)$
\end{tabular}

Panel A. Overall Minimum Wage Effect

$\begin{array}{ccc}-0.354^{* * *} & -0.358^{* *} & -0.115^{* * *} \\ (0.099) & (0.138) & (0.031)\end{array}$

Panel B: Lead and Lagged Effects

\begin{tabular}{|c|c|c|c|c|}
\hline 4+ Years Lead Minimum Wage & $\begin{array}{c}0.814^{* *} \\
(0.356)\end{array}$ & $\begin{array}{c}0.955 \\
(0.667)\end{array}$ & $\begin{array}{c}2.36^{* *} \\
(1.15)\end{array}$ & $\begin{array}{c}0.109 \\
(0.281)\end{array}$ \\
\hline 3 Year Lead Minimum Wage & $\begin{array}{c}0.718^{* * *} \\
(0.249)\end{array}$ & $\begin{array}{l}0.905^{*} \\
(0.534)\end{array}$ & $\begin{array}{c}1.143 \\
(0.508)\end{array}$ & $\begin{array}{c}0.224 \\
(0.196)\end{array}$ \\
\hline 2 Years Lead Minimum Wage & $\begin{array}{c}0.444 * * * \\
(0.141)\end{array}$ & $\begin{array}{l}0.80 * * * \\
(0.298)\end{array}$ & $\begin{array}{c}0.47 \\
(0.508)\end{array}$ & $\begin{array}{l}0.207 * \\
(0.119)\end{array}$ \\
\hline 1 Year Lead Minimum Wage & - & - & - & - \\
\hline Year of Minimum Wage Increase & $\begin{array}{c}-0.662 * * * \\
(0.175)\end{array}$ & $\begin{array}{c}-0.974 * * \\
(0.411)\end{array}$ & $\begin{array}{c}-1.359 * * * \\
(0.455)\end{array}$ & $\begin{array}{l}-0.219 \\
(0.146)\end{array}$ \\
\hline 1 Year Lag Minimum Wage & $\begin{array}{c}-1.201 * * * \\
(0.241)\end{array}$ & $\begin{array}{c}-1.237^{* *} \\
(0.521) \\
\end{array}$ & $\begin{array}{c}-2.805^{* * *} \\
(0.599) \\
\end{array}$ & $\begin{array}{l}-0.404^{*} \\
(0.202) \\
\end{array}$ \\
\hline 2 Years Lag Minimum Wage & $\begin{array}{c}-1.558^{* * *} \\
(0.349)\end{array}$ & $\begin{array}{l}-1.324 \\
(0.874)\end{array}$ & $\begin{array}{c}-3.758^{* * *} \\
(0.824)\end{array}$ & $\begin{array}{l}-0.61 * * \\
(0.238)\end{array}$ \\
\hline 3+ Years Lag Minimum Wage & $\begin{array}{c}-1.73 * * * \\
(0.447)\end{array}$ & $\begin{array}{c}-1.699 * \\
(0.951)\end{array}$ & $\begin{array}{l}-3.958^{* * *} \\
(1.124)\end{array}$ & $\begin{array}{l}-0.583^{*} \\
(0.303)\end{array}$ \\
\hline State and year-by-quarter FE & Yes & Yes & Yes & Yes \\
\hline Preferred Controls & Yes & Yes & Yes & Yes \\
\hline $\begin{array}{l}\text { State-Specific Linear and Quadratic } \\
\text { Time Trends }\end{array}$ & Yes & Yes & Yes & Yes \\
\hline Mean of dependent variable & 7.539 & 11.329 & 12.309 & 5.176 \\
\hline $\mathrm{N}$ & 3,315 & 3,135 & 3,135 & 3,135 \\
\hline
\end{tabular}

$* * *$ Statistically significant at the $1 \%$ level; **at the $5 \%$ level; *at the $10 \%$ level.

Notes: Population weighted OLS estimates of the association between minimum wages and the fertility of female 15- through 19-year-olds are reported. The data are at the state-quarter level and cover the period 2003Q4-2019Q4. Standard errors, reported in parentheses, are corrected for clustering at the state level. Our preferred controls include the proportion of adolescents (ages 16-19) who were non-Hispanic White, nonHispanic Black, and Hispanic, the proportion who were 17 years of age, 18 years of age, and 19 years of age, and the proportion living in a metropolitan area. Other preferred controls are the maximum combined Temporary Assistance for Needy Families and Supplemental Nutrition Assistance Program payment for a family of three, the state Earned Income Tax Credit (EITC) rate, an indicator for whether the EITC rate was refundable, the prime-age (ages 25-54) unemployment rate, the prime-age wage rate (2014\$s), the house price index, and separate indicators for whether the state had a Medicaid family planning expansion waiver, a parental notification abortion restriction, a contraceptive insurance coverage mandate, and if a state had required comprehensive sex education. 


\section{Appendix Table 4. Estimated Effects of Minimum Wages on the Birth Rates and Marriage Rates of Female 30- through 54-Year-Olds, 2003-2019}

(1)

Adult

(2)

(3)

(4)

Birth Rate

\author{
Adult Marital \\ Birth Rate
}

Adult

Non-Marital

Birth Rate
Adult Marriage
Rate

\begin{tabular}{lcccc}
\hline Minimum Wage (2014\$s) & 0.022 & 0.044 & -0.018 & 1.31 \\
& $(0.055)$ & $(0.041)$ & $(0.016)$ & $(1.89)$ \\
\hline State and year-by-quarter FE & & & & Yes \\
\hline Preferred Controls & Yes & Yes & Yes & Yes \\
\hline Mean of dependent variable & Yes & Yes & 1.58 & 641.206 \\
\hline $\mathrm{N}$ & 7.643 & 6.063 & 3,302 & 867 \\
\hline
\end{tabular}

***Significant at $1 \%$ level **at $5 \%$ level $*$ at $10 \%$ level

Notes: Standard errors are clustered at the state level. All regressions are weighted using state population weights. Our preferred controls include the proportion of adolescents (ages 16-19) who were non-Hispanic White, non-Hispanic Black, and Hispanic, the proportion who were 17 years of age, 18 years of age, and 19 years of age, and the proportion living in a metropolitan area. Other preferred controls are the maximum combined Temporary Assistance for Needy Families and Supplemental Nutrition Assistance Program payment for a family of three, the state Earned Income Tax Credit (EITC) rate, an indicator for whether the EITC rate was refundable, the prime-age (ages 25-54) unemployment rate, the prime-age wage rate $(2014 \$ s)$ the house price index, and separate indicators for whether the state had a Medicaid family planning expansion waiver, a parental notification abortion restriction, a contraceptive insurance coverage mandate, and if a state had required comprehensive sex education. 
Appendix Table 5. Sensitivity of Sexual Behavior Estimates to Inclusion of Controls for State-Specific Linear Time Trends, $2003-2019$

\begin{tabular}{|c|c|c|c|c|c|c|c|}
\hline & Ever Sex Active & $\begin{array}{c}\text { (2) } \\
\text { Current Sex } \\
\text { Active }\end{array}$ & $\begin{array}{c}\text { (3) } \\
\text { Number of } \\
\text { Partners | Sex }\end{array}$ & $\begin{array}{c}\text { (4) } \\
\text { Unprotected Sex }\end{array}$ & $\begin{array}{c}\text { (5) } \\
\text { Birth Control } \\
\text { Current Sex }\end{array}$ & $\begin{array}{c}\text { (6) } \\
\text { Condom | } \\
\text { Current Sex }\end{array}$ & $\begin{array}{c}\text { (7) } \\
\text { Pill } \mid \text { Current } \\
\text { Sex }\end{array}$ \\
\hline & \multicolumn{7}{|c|}{ Panel A. State YRBS } \\
\hline Minimum Wage (2014\$s) & $\begin{array}{c}0.003 \\
(0.008)\end{array}$ & $\begin{array}{c}0.001 \\
(0.002)\end{array}$ & $\begin{array}{l}-0.021 \\
(0.021)\end{array}$ & $\begin{array}{c}0.002 \\
(0.003)\end{array}$ & $\begin{array}{l}-0.000 \\
(0.006)\end{array}$ & $\begin{array}{l}-0.002 \\
(0.006)\end{array}$ & $\begin{array}{l}0.0003 \\
(0.005)\end{array}$ \\
\hline Mean of dependent variable & 0.539 & 0.344 & 2.459 & 0.088 & 0.721 & 0.412 & 0.228 \\
\hline \multirow[t]{2}{*}{$\mathrm{N}$} & 524,168 & 446,399 & 186,892 & 441,559 & 142,284 & 145,100 & 138,914 \\
\hline & \multicolumn{7}{|c|}{ Panel B. National YRBS } \\
\hline Minimum Wage (2014\$s) & $\begin{array}{l}-0.015 \\
(0.014) \\
\end{array}$ & $\begin{array}{l}-0.007 \\
(0.011) \\
\end{array}$ & $\begin{array}{l}-0.013 \\
(0.046) \\
\end{array}$ & $\begin{array}{l}-0.003 \\
(0.005)\end{array}$ & $\begin{array}{c}0.006 \\
(0.011)\end{array}$ & $\begin{array}{c}0.006 \\
(0.018)\end{array}$ & $\begin{array}{l}-0.004 \\
(0.017)\end{array}$ \\
\hline Mean of dependent variable & 0.504 & 0.359 & 2.515 & 0.101 & 0.716 & 0.420 & 0.225 \\
\hline $\mathrm{N}$ & 57,177 & 52,682 & 25,450 & 52,005 & 19,258 & 19,366 & 18,953 \\
\hline
\end{tabular}

$* * *$ Significant at $1 \%$ level **at $5 \%$ level *at $10 \%$ level

Notes: Population weighted OLS estimates of the association between minimum wages and sexual behaviors of females 15 - through $18+$-year-olds are reported. The data are biannual and are obtained from the State Youth Risk Behavior Surveys from 2003-2019. Standard errors, reported in parentheses, are corrected for clustering at the state level. Ever Sex Active is an indicator for whether the respondent has ever engaged in sexual intercourse, Current Sex Active is an indicator for whether the respondent has engaged in sexual intercourse in the last three months, Number of Partners | Sex measures the lifetime number of sexual partners for sexually active respondents, Unprotected Sex is an indicator for whether the respondent has engaged in sexual intercourse in the last three months and did not use any form of contraception, defined as birth control pills, condoms, IUDs, implants, shots, or rings, during the last time they engaged in sexual intercourse, Birth Control | Current Sex is an indicator for if a respondent used any aforementioned contraception method during the last time they engaged in sexual intercourse, conditionally on being sexually active, Condom I Current Sex is an indicator for whether the respondent condoms during the last time they engaged in sexual intercourse, conditional on being sexually active, Pill $\mid$ Current Sex is an indicator for whether the used birth control pills during the last time they engaged in sexual intercourse, conditional on being sexually active. All models include controls for state fixed effects, wave fixed effects, and individual indicators for race/ethnicity, gender, grade, and age. All models also include our preferred state-specific time-varying policy controls, including the maximum combined Temporary Assistance for Needy Families and Supplemental Nutrition Assistance Program payment for a family of three, the state Earned Income Tax Credit (EITC) rate, an indicator for whether the EITC was refundable, the prime-age unemployment rate, the prime-age real wage rate, the house price index, and separate indicators for whether the state had a Medicaid family planning expansion waiver, a parental notification abortion restriction, required sex education, or a contraceptive insurance coverage mandate. 
Appendix Table 6. Sensitivity of Race/Ethnicity-Specific Estimates for Female Adolescents to Controlling for State-Specific Linear Time Trends, State YRBS, 2003-2019

(1)

Ever Sex Active
(2)

Current Sex Active
(3)

Number of

Partners | Sex
(4)

Unprotected Sex
(5)

Birth Control

Current Sex
(6)

Condom

Current Sex
(7)

Pill | Current

Panel A. Black Students

\begin{tabular}{|c|c|c|c|c|c|c|c|}
\hline Minimum Wage (2014\$s) & $\begin{array}{c}0.002 \\
(0.016)\end{array}$ & $\begin{array}{l}-0.006 \\
(0.006)\end{array}$ & $\begin{array}{c}0.001 \\
(0.032)\end{array}$ & $\begin{array}{l}-0.005 \\
(0.010)\end{array}$ & $\begin{array}{c}0.004 \\
(0.021)\end{array}$ & $\begin{array}{c}0.033^{*} \\
(0.018)\end{array}$ & $\begin{array}{l}-0.028 \\
(0.019)\end{array}$ \\
\hline Mean of dependent variable & 0.650 & 0.378 & 2.692 & 0.105 & 0.681 & 0.467 & 0.111 \\
\hline $\mathrm{N}$ & 71,951 & 54,721 & 25,319 & 53,814 & 17,481 & 17,897 & 17,006 \\
\hline
\end{tabular}

Panel B. Hispanic Students

\begin{tabular}{|c|c|c|c|c|c|c|c|}
\hline \multirow[t]{2}{*}{ Minimum Wage (2014\$s) } & -0.002 & 0.007 & -0.033 & $0.005^{*}$ & -0.0001 & -0.019 & $0.023 * *$ \\
\hline & $(0.009)$ & $(0.005)$ & $(0.037)$ & $(0.003)$ & $(0.013)$ & $(0.015)$ & $(0.009)$ \\
\hline Mean of dependent variable & 0.520 & 0.328 & 2.222 & 0.111 & 0.625 & 0.417 & 0.131 \\
\hline $\mathrm{N}$ & 79,562 & 66,903 & 29,695 & 65,929 & 21,481 & 21,937 & 21,109 \\
\hline
\end{tabular}

Panel C. Non-Hispanic White Students

\begin{tabular}{|c|c|c|c|c|c|c|c|}
\hline Minimum Wage (2014\$s) & -0.0004 & -0.003 & -0.030 & 0.002 & -0.006 & -0.008 & -0.001 \\
\hline & $(0.009)$ & $(0.004)$ & $(0.029)$ & $(0.003)$ & $(0.008)$ & $(0.009)$ & $(0.007)$ \\
\hline Mean of dependent variable & 0.520 & 0.348 & 2.455 & 0.074 & 0.771 & 0.399 & 0.297 \\
\hline $\mathrm{N}$ & 291,128 & 260,271 & 106,975 & 257,896 & 85,392 & 87,019 & 83,306 \\
\hline
\end{tabular}

***Significant at $1 \%$ level $* *$ at $5 \%$ level *at $10 \%$ level

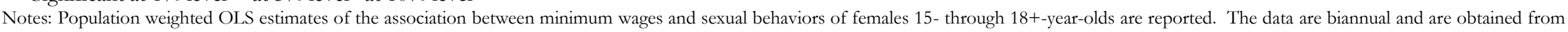

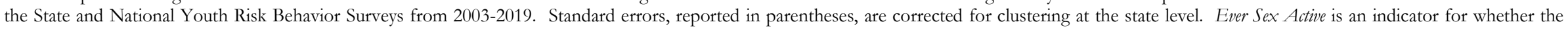

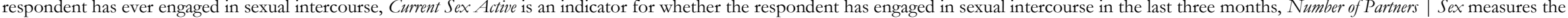

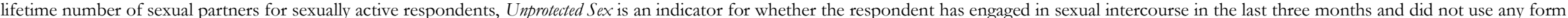

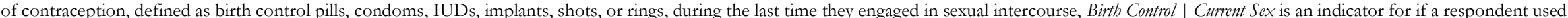

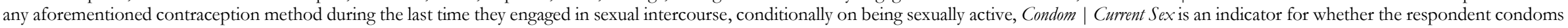

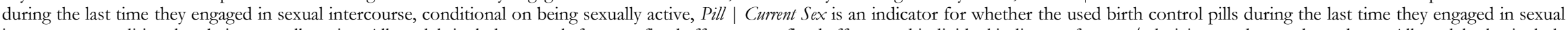

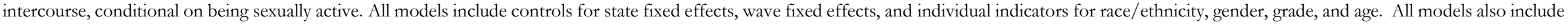
our preferred state-specific time-varying policy controls, included in the notes to Appendix Table 5. 
Appendix Table 7. Estimates of Relationship Between Minimum Wages and Adolescent Male Sexual Behavior, $2003-2019$

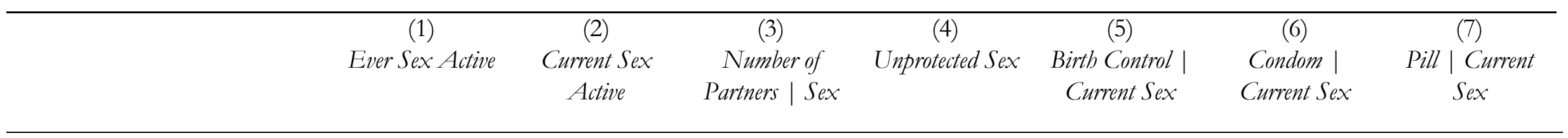

Panel A. State YRBS

\begin{tabular}{|c|c|c|c|c|c|c|c|}
\hline Minimum Wage (2014\$s) & $\begin{array}{c}0.001 \\
(0.008) \\
\end{array}$ & $\begin{array}{l}-0.006 \\
(0.006) \\
\end{array}$ & $\begin{array}{l}-0.018 \\
(0.025) \\
\end{array}$ & $\begin{array}{c}0.002 \\
(0.002) \\
\end{array}$ & $\begin{array}{l}-0.007 \\
(0.006) \\
\end{array}$ & $\begin{array}{l}-0.005 \\
(0.008) \\
\end{array}$ & $\begin{array}{l}0.0020 \\
(0.006) \\
\end{array}$ \\
\hline Mean of dependent variable & 0.539 & 0.344 & 2.459 & 0.087 & 0.721 & 0.412 & 0.228 \\
\hline $\mathrm{N}$ & 512,946 & 412,593 & 182,011 & 406,763 & 123,058 & 125,251 & 119,088 \\
\hline & \multicolumn{7}{|c|}{ Panel B. National YRBS } \\
\hline Minimum Wage (2014\$s) & $\begin{array}{c}-0.020^{*} \\
(0.012)\end{array}$ & $\begin{array}{c}0.002 \\
(0.011)\end{array}$ & $\begin{array}{l}-0.006 \\
(0.038)\end{array}$ & $\begin{array}{c}-0.001 \\
(0.0074)\end{array}$ & $\begin{array}{c}0.010 \\
(0.018)\end{array}$ & $\begin{array}{l}-0.012 \\
(0.016) \\
\end{array}$ & $\begin{array}{c}0.007 \\
(0.011)\end{array}$ \\
\hline Mean of dependent variable & 0.504 & 0.359 & 2.515 & 0.101 & 0.716 & 0.420 & 0.225 \\
\hline $\mathrm{N}$ & 56,947 & 50,801 & 26,749 & 49,847 & 18,316 & 18,458 & 17,903 \\
\hline
\end{tabular}

*** Significant at $1 \%$ level **at $5 \%$ level *at $10 \%$ level

Notes: Population weighted OLS estimates of the association between minimum wages and sexual behaviors of males 15-through 18+-year-olds are reported with the inclusion of state-specific linear time trends. The data are biannual and are obtained from the State and National Youth Risk Behavior Surveys from $2003-2019$. Standard errors, reported in parentheses, are corrected for clustering at the state level. Ever Sex Active is an indicator for whether the respondent has ever engaged in sexual intercourse, Current Sex Active is an indicator for whether the respondent has engaged in sexual intercourse in the last three months, Number of Partners $\mid$ Sex measures the lifetime number of sexual partners for sexually active respondents, Unprotected Sex is an indicator for whether the respondent has engaged in sexual intercourse in the last three months and did not use any form of contraception, defined as birth control pills, condoms, IUDs, implants, shots, or rings, during the last time they engaged in sexual intercourse, Birth Control | Current Sex is an indicator for if a respondent used any aforementioned contraception method during the last time they engaged in sexual intercourse, conditionally on being sexually active, Condom | Current Sex is an indicator for whether the respondent condoms during the last time they engaged in sexual intercourse, conditional on being sexually active, Pill $\mid$ Current Sex is an indicator for whether the used birth control pills during the last time they engaged in sexual intercourse, conditional on being sexually active. All models include controls for state fixed effects, wave fixed effects, and individual indicators for race/ethnicity, gender, grade, and age. All models also include our preferred time-varying state-level policy controls, including the maximum combined Temporary Assistance for Needy Families and Supplemental Nutrition Assistance Program payment for a family of three, the state Earned Income Tax Credit (EITC) rate, an indicator for whether the EITC was refundable, the prime-age (ages 25-54) unemployment rate, the prime-age real wage rate, the house price index, and separate indicators for whether the state had a Medicaid family planning expansion waiver, a parental notification abortion restriction, required sex education, or a contraceptive insurance coverage mandate. 